\title{
INTEGRATION OF REAL-TIME DATA INTO BUILDING AUTOMATION SYSTEMS
}

\section{Final Report}

\section{January 2003}

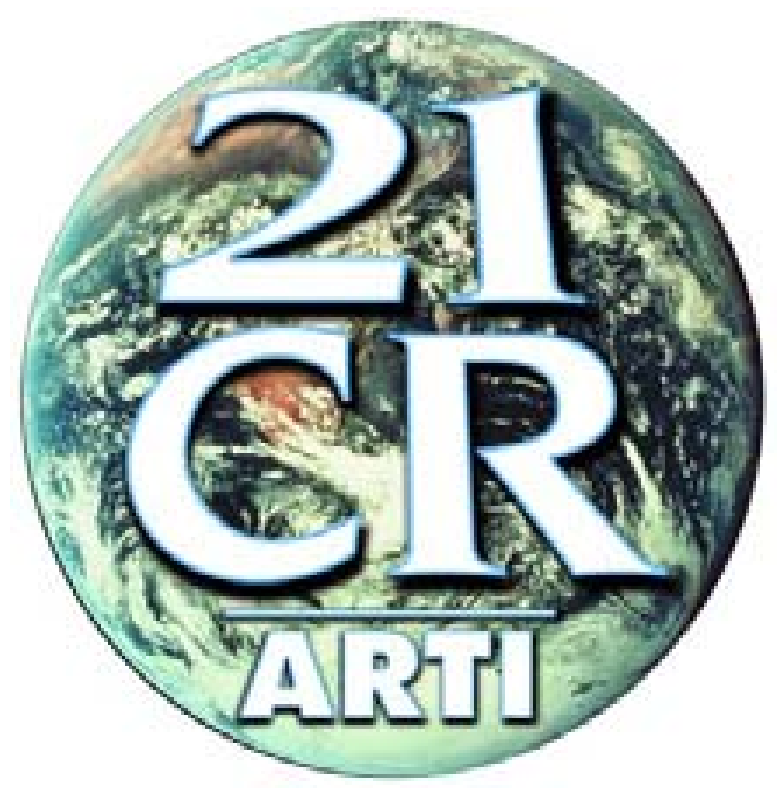

Authors: Mark J. Stunder, Perry Sebastian, Brenda A. Chube, Michael D. Koontz GEOMET TECHNOLOGIES, INC. 20251 Century Blvd., Suite 300 Germantown, MD 20874-1192

Prepared for the AIR-CONDITIONING AND REFRIGERATION TECHNOLOGY INSTITUTE 4100 N. Fairfax Drive, Suite 200, Arlington, Virginia 22203

Distribution A - Approved for public release; further dissemination unlimited. 


\section{DISCLAIMER}

This report was prepared as an account of work sponsored by the Air-Conditioning and Refrigeration Technology Institute (ARTI) under its "HVAC\&R Research for the $21{ }^{\text {st }}$ Century" (21-CR) program. Neither ARTI, the financial supporters of the 21-CR program, or any agency thereof, nor any of their employees, contractors, subcontractors or employees thereof - makes any warranty, expressed or implied; assumes any legal liability or responsibility for the accuracy, completeness, any third party's use of, or the results of such use of any information, apparatus, product, or process disclosed in this report; or represents that its use would not infringe privately owned rights. Reference herein to any specific commercial product, process, or service by trade name, trademark, manufacturer, or otherwise, does not necessarily constitute nor imply its endorsement, recommendation, or favoring by ARTI, its sponsors, or any agency thereof or their contractors or subcontractors. The views and opinions of authors expressed herein do not necessarily state or reflect those of ARTI, the 21-CR program sponsors, or any agency thereof.

Funding for the 21-CR program provided by (listed in order of support magnitude):

- U.S. Department of Energy (DOE Cooperative Agreement No. DE-FC05-99OR22674)

- Air-Conditioning \& Refrigeration Institute (ARI)

- Copper Development Association (CDA)

- New York State Energy Research and Development Authority (NYSERDA)

- California Energy Commission (CEC)

- Refrigeration Service Engineers Society (RSES)

- Heating, Refrigeration Air-Conditioning Institute of Canada (HRAI)

Available to the public from

U.S. Department of Commerce

National Technical Information Service

5285 Port Royal Road

Springfield, VA 22161

(703) 487-4650

Available to U.S. Department of Energy and its contractors in paper from

U.S. Department of Energy

Office of Scientific and Technical Information

P.O. Box 62

Oak Ridge, TN 37831

(423) 576-8401 


\section{INTEGRATION OF REAL-TIME DATA INTO BUILDING AUTOMATION SYSTEMS}

Final Report

\section{January 2003}

Authors:

Mark J. Stunder

Perry Sebastian

Brenda A. Chube

Michael D. Koontz

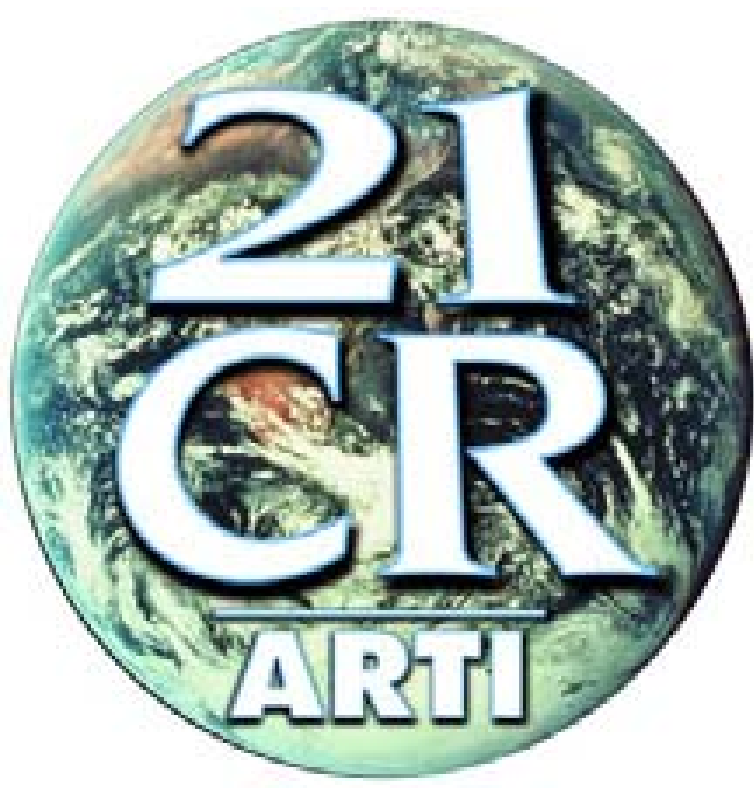

Prepared for the

AIR-CONDITIONING AND REFRIGERATION TECHNOLOGY INSTITUTE Under ARTI 21-CR Program Contract Number 611-30050 
INTEGRATION OF REAL-TIME DATA INTO BUILDING AUTOMATION SYSTEMS FINAL REPORT

ARTI-21 CR Program Contract Number 611-30050

TABLE OF CONTENTS

$\underline{\text { Section }}$

$\underline{\text { Page }}$

EXECUTIVE SUMMARY ES-1

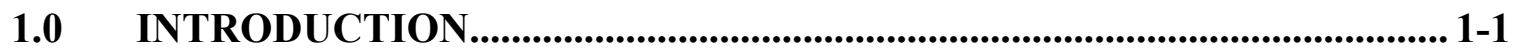

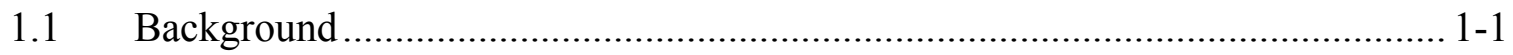

$1.2 \quad$ Project Scope and Objectives............................................................... 1-3

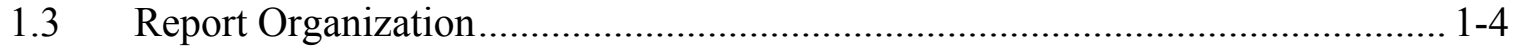

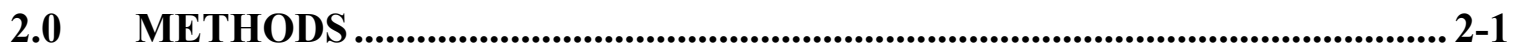

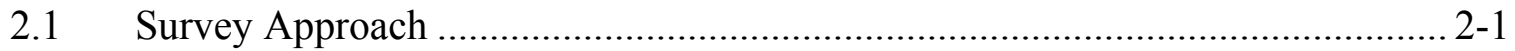

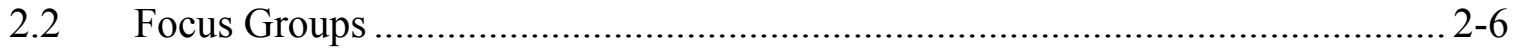

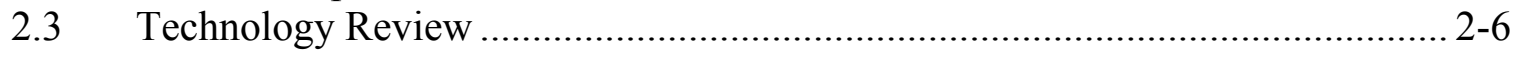

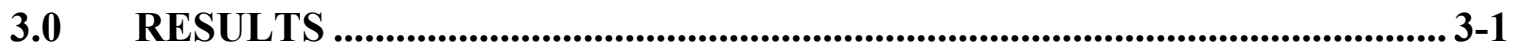

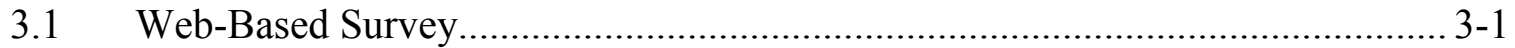

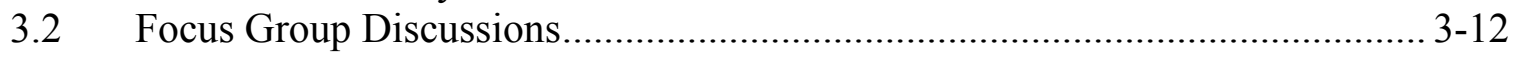

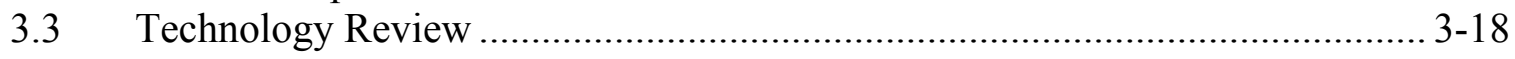

3.4 Accreditation of Real-Time Information/Sites/Providers ............................... 3-41

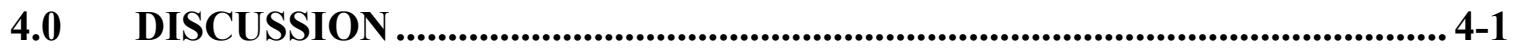

4.1 Considerations for Integrating Real-Time Data........................................... 4-1

4.2 Parameters for Development of Real-Time Information .............................. 4-11

4.3 Issues and Challenges for Data Management ........................................... 4-32

4.4 Building Manager Perspectives ............................................................ 4-37

5.0 EVOLUTIONARY CONTROL STRATEGIES...................................... 5-1

5.1 Preliminary List of Control Strategies ..................................................... 5-1

5.2 Grouping and Pre-Screening ................................................................ 5-2

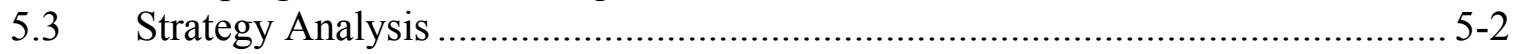

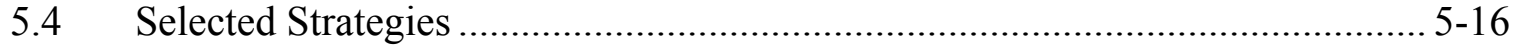

5.5 Preliminary Protocol/Design Specification............................................... 5-17

5.6 Other Potential Strategies: Intelligent Service Provision................................. 5-34

6.0 CONCLUSIONS AND RECOMMENDATIONS.......................................... 6-1

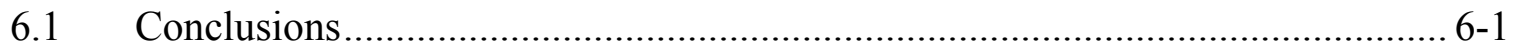

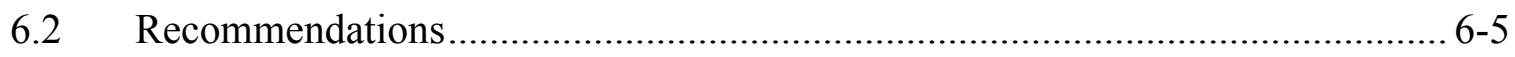

GLOSSARY OF TERMS ..................................................................................... 


\section{LIST OF FIGURES}

Number

Page

Figure 2-1 Technology Review Methodology for Determining Real-Time

Web Services .....

Figure 3-1 Size Distribution of Facilities Covered by the Survey........................... 3-2

Figure 3-2 Selected Building Features for Surveyed Facilities .............................. 3-4

Figure 3-3 Means of Interior Lighting in Surveyed Facilities ................................. 3-5

Figure 3-4 Uses of Exterior Lighting at Surveyed Facilities ................................. 3-5

Figure 3-5 Systems Used in Surveyed Facilities ................................................ 3-6

Figure 3-6 Listing of Some Weather Stations in Virginia .................................... 3-19

Figure 3-7 Virginia Map Showing Representative Weather Stations .................... 3-20

Figure 3-8 Free Weather Data Vendor, University or NWS FTP Services Are

Now Available on the Web............................................................ 3-21

Figure 3-9 Private/Educational Weather Network Sensor Output (Elementary

School in Dade County (Miami), FL) ............................................... 3-22

Figure 3-10 Graphical Model Output from the ETA Model ................................. 3-24

Figure 3-11 Alphanumeric Data from the AVN Model ......................................... 3-25

Figure 3-12 Graphical Output Representation of the Same Alphanumeric Model

Data of Figure 3-11 ......................................................................... 3-26

Figure 3-13 Example of Traffic Data in Alphanumeric Format............................... 3-28

Figure 3-14 Example of Map/Alphanumeric Traffic Data with Weather ................ 3-29

Figure 3-15 FAA Real-Time Status on Airport Delays...................................... 3-31

Figure 3-16 Specific Airport Information...................................................... 3-32

Figure 3-17 State of Maryland Ozone Site ......................................................... 3-34

Figure 3-18 Pollen Web-Based Systems Provide a Wealth of Free Data................. 3-35

Figure 3-19 The National Lightning Detection Network Sensor and the Network

Configuration ........................................................................... 3-37

Figure 3-20 Typical NLDN Displays (fee-based tiered system) ............................ 3-38

Figure 3-21 Example of Human QC as a Form of Accreditation for NWS

Weather Products .......................................................................... 3-42

Figure 3-22 Example of Website Accreditation in the Health Services Field........... 3-45

Figure 5-1 Decision Rules Flow Chart ................................................................. 5-4

Figure 5-2 Dynamic Effects of Temperature and Occupancy ............................... 5-19

Figure 5-3 Control Strategy Components for Advanced Set Point Control ............ 5-20

Figure 5-4 Control Concept for Building Moisture Management .......................... 5-23

Figure 5-5 Concept for Occupant Interactive Services....................................... 5-27

Figure 5-6 Concept of Real-Time Maintenance Management Services................. 5-31 


\section{LIST OF TABLES}

Number

$\underline{\text { Page }}$

Table 3-1 Building Systems with Habitual Worst Performance in Surveyed Facilities ..................................................................................... 3-8

Table 3-2 Most Critical Reliability/Performance Incidents in Surveyed Facilities . 3-8

Table 3-3 Possible Avoidance of Critical Incidents in Surveyed Facilities .

Table 3-4 Utility of Additional Information in Resolving Incidents in Surveyed Facilities ........................................................................................ 3-9

Table 3-5 Encouragement to Nonmaintenance Staff and Occupants for Energy-Efficient Practices ................................................................ 3-9

Table 3-6 Types of Automation/Functionality to Help Operate Facilities at Maximum Efficiency ......................................................................... 3-11

Table 3-7 Focus Group Responses for Topic 1 - Tenant Temperature Control .... 3-12

Table 3-8 Focus Group Responses for Topic 2 - Operator-Based Control ........... 3-13

Table 3-9 Focus Group Responses for Topic 3 - System Stability........................ 3-14

Table 3-10 Focus Group Responses for Topic 4 - System Maintenance ................ 3-15

Table 3-11 Focus Group Responses for Topic 5 - Useful Information ................... 3-16

Table 3-12 Focus Group Responses for Topic 6-Designing the Perfect Building Control System................................................................... 3-17

Table 3-13 Summary of QC Procedures for Potential Real-Time Web Data Streams........................................................................................... 3-43

Table 4-1 Data Structure-Acquisition Characteristics........................................ 4-6

Table 4-2 Real-Time Parameters and Their Attributes ...................................... 4-12

Table 4-3 Summary of Responses to Selected Web Survey Items ....................... 4-38

Table 4-4 Summary of Responses to Focus group Discussion Topics .................. 4-40

Table 6-1 Parameters of Potential Use as Real-Time Data Elements .................... 6-3 


\section{EXECUTIVE SUMMARY}

\section{BACKGROUND AND OBJECTIVES}

As building owners strive to reduce operating costs while avoiding occupant complaints, they are likely to increasingly utilize Building Automation Systems (BAS) to save energy and to increase occupant comfort. While investment in smart-building technology has been increasing, the science or art of using real-time information in adaptive building management systems is in a relatively immature state. Automated building systems traditionally have utilized either no local sensors or only a limited number of such sensors. As local sensors require routine maintenance, gathering this information by other means (e.g., via the Internet) could result in considerable cost savings and efficiencies.

Internet technology has now progressed to the point where it can be a source of real-time information for predictive purposes in managing buildings. Proactively managing and operating building systems in accordance with actual or anticipated conditions should increase space comfort while reducing operating costs. Although the Internet is becoming a viable source of real-time information, two aspects of the information technology are unclear at present: (1) the types of predictive information available in real time; and (2) which of the available information items can be integrated automatically into building management systems. Ancillary issues of importance include the reliability, integrity, and guaranteed availability of information, along with appropriate methods to accredit the information and the organizations/sites that provide it.

ARTI sponsored this project to provide for a detailed examination of the issues identified above. The fundamental research objective was to investigate the possibility of using predictive, real-time information from the Internet as an input to building management system algorithms. Seven specific objectives were to:

1. Identify the types of information most valuable to commercial (primarily) and residential (secondarily) building owners, managers, and system designers; 
2. Comprehensively investigate and document currently available electronic real-time information suitable for use in building management systems;

3. Verify the reliability of the information and recommend accreditation methods for data and providers;

4. Assess methodologies to automatically retrieve and utilize the information;

5. Characterize equipment required to implement automated integration;

6. Demonstrate the feasibility and benefits of using the information in building management systems; and

7. Identify evolutionary control strategies.

\section{METHODS}

GEOMET staff used a combination of approaches - web-based survey and focus-group discussions involving building owners/managers, along with a review of technology and major considerations for integrating real-time web data streams - in an effort to satisfy the project objectives. In order to determine types of useful information for building owners or managers, GEOMET undertook a survey of selected representatives of this community over the web. The web-based survey included respondents in four cities who operated a variety of building types. GEOMET also held focus groups in Washington, DC, and New Orleans, LA. The topics covered in these discussions included:

- Should tenants have control of the space temperature?

- Can a skilled building operator control a building better than a state-of-the-art BAS?

- Would up-to-the-minute information about events at other regional facilities increase the stability of your control system?

- Would Internet access to OEM equipment data and product updates, or access to remote diagnostic services, improve building system maintenance?

- What kind of information would be useful for building operations?

- What do you consider the "perfect" BAS? 
The technology review of possible real-time web data streams included: (1) web searches of real-time web services; and (2) consideration of the needs of building or technology types within the building system. GEOMET identified broad categories of real-time web data from the search strategy according to the following characteristics: parameter(s) of interest; data source and latency issues; method of data acquisition; sponsorship (private versus government); data collection methods for energy applications; fee structures if any; quality of the data; and other significant attributes of the web data stream.

An examination of building types and technology provided a check against the web searches. GEOMET developed a master checklist at this stage to examine how real-time web data could benefit different building technologies of the present and future. In compiling the list, we used more commonly known systems/technologies and input from the web-based survey and focus-group discussions. A review of considerations for integrating real-time web data streams addressed the remote client/server interaction and real-time data management, with the latter having four main steps of (1) data acquisition, (2) validation, (3) channeling and (4) utilization. In exploring accreditation of real-time websites, we included a search for existing strategies or approaches that might apply here.

GEOMET examined evolutionary control strategies by developing an initial list based on available data streams and associated parameters. After prescreening the list, we analyzed the control strategies along four dimensions: (1) cost and savings; (2) reliability of the real-time data; (3) feasibility of the technology; and (4) validity of the proposed approach.

\section{FINDINGS AND CONCLUSIONS}

Responses to the web-based survey and focus-group discussions were disappointing. Although there were survey respondents from four cities, the total number of respondents was only 19. Focus-group discussions were limited to two areas - Washington, DC, and New Orleans, LA. Candidate participants who ultimately declined cited time constraints and the requirement to commute from homes outside the city for evening/weekend sessions as reasons for not participating in the focus groups. 
Despite the small sample size, certain recurring themes, issues or concerns were apparent from the survey and focus groups:

- Critical incidents in building management can be avoided by (1) detailed inspection and maintenance at regular intervals (including system "self analysis"), and (2) predictive diagnostics (to detect potential problems before they occur or become severe).

- Buildings could be operated at maximum efficiency with state-of-the-art equipment, variable frequency drivers, occupancy-based ventilation/lighting, automatic paging, access to building controls via the Internet, weather stations, automatic blinds, solar generation, and software for energy efficiency.

- Current information about events at regional facilities (e.g., weather-related phenomena such as rain and snow or tracking of frontal system) would be useful in increasing the stability of control systems. However, such information would be of use only for fairly small regions, as there can be too much variability within larger regions.

- One critical aspect of building maintenance - validation against plans, both in terms of adherence to schedule and covering all prescribed activities - could be completely or at least partially Internet-based.

- Internet-based weather information can be useful for building operations, particularly in relation to schedules for major regional/local events. The web could play a role in scheduling meeting or conference rooms and in tying that information into the BAS. Links to security systems and to real-time information on traffic, catastrophic events, fuel pricing, and energy consumption also may be useful.

Building managers concurred that an ideal system would be self-calibrating with diagnosis capabilities. It would be user-friendly and not overly complex. It would also have remote access and would need to be checked routinely by humans. Ideally, the system should be able to implement some adjustments before "calling" an engineer and should be capable of providing a $\log$ of key events and preparing routine or special reports. Potential barriers to success in implementing such a system include security concerns for Internet-based operations, occupant privacy, cost issues, and training requirements. 
The technology review of possible web data streams revealed the most available type to be real-time weather data. There are, however, other types of useful data elements available, including air quality, energy pricing, local traffic, and geophysical/astrophysical parameters. Candidate parameters or groups of parameters from the review of real-time data web streams are listed in Table ES-1, with an indication of how they could be used. Section 3 of this report provides further details on illustrative uses of the parameters in template form for easy reference.

Unfortunately, the technology review indicated that accreditation of real-time websites will be a difficult task. However, many real-time sites have their origin in the U.S. government; in such cases, accreditation may be a moot point, as these sites tend to have some of the best management and quality control around. The healthcare field has done extensive work in the area of accreditation. Adaptation of the healthcare web accreditation model to the subject of this study resulted in identification of eight key areas: (1) mission and purpose of the accreditation process; (2) clear definition of terms; (3) disclosure of services; (4) content and service delivery; (5) linkages; (6) data security; (7) accountability; and (8) policy and procedures.

Real-time data system architecture is constrained by the type of data interface needed. The varied types of data interface were grouped into three categories: (1) broadcast; (2) simple request/response; and (3) Structured Data Services. Different sampling needs for different types of data suggest that it would be beneficial for the BAS to interact with the Internet data server using a Structured Data Services interface. Many steps in the data-retrieval process could be managed on the client or the data server. Control algorithms for novel types of building controls using real-time data could reside entirely off-site, sending only needed control inputs to the BAS.

Important considerations for integrating real-time data include the remote client/server interaction and real-time data management, with the latter having four main steps of data acquisition, validation, channeling and utilization. Three levels of potential benefit from using remote real-time data as BAS inputs are: (1) improvement of environmental conditions in the facility; (2) improvements in the operational efficiency and effectiveness of building systems; and (3) improvements in the building's interaction with the community (e.g., with building occupants through scheduling tools and with the community via alerts and alarms). 
Table ES-1. Parameters of Potential Use as Real-time Data Elements

\begin{tabular}{|c|c|}
\hline Parameter(s) & Potential Use \\
\hline $\begin{array}{l}\text { Local outside temperature (with dew point } \\
\text { or relative humidity) }\end{array}$ & $\begin{array}{l}\text { Determine whether economizer functions are to be } \\
\text { activated or evaporative cooling is to be used, or as } \\
\text { an input to a hygrothermal model for building } \\
\text { moisture management }\end{array}$ \\
\hline $\begin{array}{l}\text { Local outside temperature, dew point, } \\
\text { precipitation, wind and solar radiation }\end{array}$ & $\begin{array}{l}\text { Determine the configuration/setting for operable } \\
\text { windows }\end{array}$ \\
\hline $\begin{array}{l}\text { Local outside temperature (with a } \\
\text { precipitation parameter) }\end{array}$ & $\begin{array}{l}\text { Determine whether walkways or driveways need to } \\
\text { be de-iced via heat or chemical reaction }\end{array}$ \\
\hline $\begin{array}{l}\text { Predicted outdoor temperature (up to } 12-24 \\
\text { hours in advance) }\end{array}$ & $\begin{array}{l}\text { Input to energy model, to suggest pre-heating or } \\
\text { cooling strategies or determine whether to use on- } \\
\text { site thermal storage for greater energy efficiency }\end{array}$ \\
\hline Barometric pressure & $\begin{array}{l}\text { Optimize combustion settings, or as an input to a } \\
\text { model for airflows within or around a building }\end{array}$ \\
\hline Air quality indicator (e.g., ozone) & $\begin{array}{l}\text { Automatically close fresh-air intakes under certain } \\
\text { conditions (i.e., poor outdoor air quality) }\end{array}$ \\
\hline Energy pricing data & $\begin{array}{l}\text { Support the decision to sell excess power from } \\
\text { cogeneration back to the grid (for larger facilities } \\
\text { or complexes) }\end{array}$ \\
\hline Weather warnings/watches/advisories & $\begin{array}{l}\text { Automatically shut down selected building systems } \\
\text { or prompt display of appropriate disaster plan } \\
\text { information }\end{array}$ \\
\hline Solar radiation (including predictive data) & $\begin{array}{l}\text { Determine the most opportune times for strategies } \\
\text { such as solar shading or daylighting }\end{array}$ \\
\hline Local lightning strikes & $\begin{array}{l}\text { Automatically activate selected backup systems or } \\
\text { take actions to protect building assets/personnel }\end{array}$ \\
\hline Space weather (e.g., solar flares) & Prompt actions to protect susceptible systems \\
\hline Chemical/biological sensor systems & Prompt building use for sheltering in place \\
\hline Local precipitation (predicted) & Rain harvesting applications \\
\hline Geophysical parameters (e.g., tides) & Buildings susceptible to water table fluctuations \\
\hline Astrophysical parameters (e.g., moonlight) & Potential effects on security systems \\
\hline Local traffic data & Potential effects on parking facilities \\
\hline Intelligent tags & $\begin{array}{l}\text { Track movement of cars into/out of parking areas, } \\
\text { as a preliminary predictor of building occupancy }\end{array}$ \\
\hline Aircraft/rail arrival times & $\begin{array}{l}\text { Determine potential delays in guest arrival (e.g., } \\
\text { for hotels) }\end{array}$ \\
\hline
\end{tabular}


Based on the considerations of cost and savings, reliability of the data, feasibility of the technology, and validity of the proposed approach, the following control strategies appear to be viable for use within a real-time data system:

- Advanced set point control based on forecast conditions external/internal to the building

- Moisture management based on predicted dew point and rate of precipitation

- Occupant interface for services such as comfort improvement, transportation links, traffic updates, express food delivery assistance, and security assistance with deliveries/visitors

- Alarms and notifications to on-call and remote technicians for system maintenance.

Smart buildings of the future may be able to handle tasks such as parking, office scheduling, food services, digital recreation services, and waste services. Greater granularity in the delivery of HVAC services to building users, with smart control devices, will significantly increase a building's capability to respond to interior and exterior airborne contaminants. This increased capability also would improve the ability of the BAS to deliver thermal and lighting services with greater specificity, improving the energy efficiency of the building.

\section{RECOMMENDATIONS}

This report has identified some evolutionary control strategies and associated real-time data parameters that appear to hold the promise of benefits to building owners, managers, and occupants. However, proof of concept and feasibility of implementation must be demonstrated for such strategies and parameters. There are additional strategies, beyond those highlighted in Section 5 of this report, that warrant further investigation and development of specifications.

Potential benefits of using predictive, real-time information need to be assessed in comparison with more traditional approaches involving use of local sensor information for HVAC-related control strategies. In parallel with this exercise, potential methodologies for implementation need to be proposed to address issues such as data latency, proactive versus reactive actions, feedback, and alternate controls when real-time information is unavailable. 
It also is important to demonstrate representative hardware, software, and tools that can automatically retrieve reliable, predictive, real-time information from the Internet and make it available to a building management system. As part of the demonstration, the building management system would need to use the information in a traditional or evolutionary control strategy to increase space comfort while reducing operating costs. Ultimately, formal pilot or demonstration projects will be required to address the full realm of cost and logistical issues for selected approaches that are deemed the most promising. 


\subsection{INTRODUCTION}

\subsection{Background}

The Internet is rapidly becoming the world's preeminent source of real-time electronic information. The Internet is pervasive, expanding into virtually every aspect of life. Moreover, real-time information that is available though the Internet has become increasingly reliable and more readily accessible. From the standpoint of management and operation of building systems, this relative proliferation of data implies greater access to relevant information such as weather conditions, environmental trends, population movement, utility rates, astronomical/astrophysical conditions, economic influences, and energy consumption.

As building owners strive to reduce operating costs while avoiding occupant complaints, they are likely to increasingly utilize automated building systems to save energy, to increase occupant comfort, or to accomplish both of these goals. During the past several years, most automated building system manufacturers have gone with either BACnet or Lon protocols, which allow flexibility in the development and deployment of automated building systems. Client/server architecture also allows automated building system manufacturers to link into the Internet or to use the Internet to monitor individual building systems.

A survey recently conducted by the STAMATS Building Group (BOMA, 2001) found that 50 percent of participating facility executives had invested in smart-building technologies and that 75 percent had related projects planned for the short term. Among the reasons cited by survey participants for integrating building systems (e.g., lighting, HVAC, and security) were reduced operating costs, lower maintenance and repair costs, better tracking and management of systems, improved user comfort, and the ability to avoid major systems failure through event management.

While investment in smart-building technology generally has been increasing, the science $r$ art of using real-time information in adaptive building management systems is in a relatively immature state. Automated building systems traditionally either have utilized no local sensors 
(i.e., those inside the building or in the outside vicinity) or have used only a limited number of such sensors (e.g., to measure commonly used parameters such as temperature and humidity). Because local sensors require routine maintenance at the cost of labor and materials, gathering this information by other means (e.g., via the Internet) could result in considerable cost savings and efficiencies.

Various world-wide-web pages, file servers and other URLs, along with non-Internet sources of electronic data, indicate that predictive real-time information relevant to the overall management and operation of building systems is now available from data sources that can be made accessible to building operators or managers. Moreover, programming experts suggest that methods currently are available to automatically collect data from such sources. Thus, Internet technology has now progressed to the point where it can be a source of real-time information that can be used for predictive purposes in managing buildings.

When equipped with predictive, real-time inputs, building management systems could proactively modify the operating characteristics of various building systems to cope with actual or anticipated conditions in the following ways, for example:

- Preemptive temperature conditioning based on approaching weather systems

- Modification of ventilation strategies based on smog indices

- Load shedding based on real-time fluctuations in utility prices.

Proactively managing and operating building systems in accordance with actual or anticipated conditions should increase space (occupant) comfort while reducing operating costs (energy consumption).

Although technology has progressed to the point that the Internet is becoming a viable source of real-time information, two aspects of the information technology are unclear at present: (1) the types of predictive information available in real time via the Internet; and (2) which of the available information items can be integrated automatically into building management systems to improve space comfort and reduce operating costs. Ancillary issues of importance include the 
reliability, integrity, and guaranteed availability of information, along with appropriate methods to accredit not only the information itself but also the organizations or sites that provide it. In addition, from an implementation standpoint it is important to identify the equipment (hardware, software, and tools) required to obtain and use real-time Internet information in building management systems that employ existing or evolutionary building control strategies.

In summary, there are two compelling reasons to assess whether and how real-time information systems can be automatically integrated into building management systems: (1) the Internet is in place and gaining acceptance within the building-system market; and (2) economic drivers are creating the demand for greater efficiency in building management that translates to an improved bottom line.

\subsection{Project Scope and Objectives}

The overall goal of this project was to investigate the possibility of using predictive, realtime information from the Internet as an input to building management system algorithms. The following were specific objectives of the project:

- Identify the types of information that are most valuable to commercial (primarily) and residential (secondarily) building owners, managers, and system designers

- Comprehensively investigate and document currently available electronic real-time information suitable for use in building management systems

- Verify the reliability of the information and recommend methods to accredit it and its providers

- Assess the existing technological methodologies to automatically retrieve and utilize the information

- Characterize the equipment required to implement automated integration

- Demonstrate the feasibility and benefits of using the information in building management systems

- Identify evolutionary building control strategies 
- Assess how the use of predictive real-time information could increase space comfort and reduce operating costs for both evolutionary and traditional building control strategies.

\subsection{Report Organization}

Section 2 describes three methods by which GEOMET staff sought to meet the project objectives: (1) a web-based survey; (2) focus-group discussions; and (3) a technology review. Section 3 summarizes the results of these efforts, and Section 4 provides a discussion of the results and their implications. Section 5 contains further discussion specifically addressing the possibilities for evolutionary control strategies. Section 6 presents the major conclusions and recommendations stemming from the project.

\section{REFERENCES}

BOMA, 2001: Integrated Systems: Increasing Building and Workplace Performance. A professional paper by the Building Owners and Managers Association. Found in:

www.boma.org/download/research/whitepages.pdf [accessed 3/2002]. 


\subsection{METHODS}

GEOMET developed a survey instrument to investigate the possibility of using predictive real-time information from the Internet as input to building management system algorithms, to be administered via:

- A written response either on the Internet, through email, or by regular post and,

- An on-site, focus-group setting.

All participants would first take the web survey and then a certain number of these respondents would participate in focus groups. In addition, a technology review was performed to identify potential data sources available through the worldwide web, along with associated technology.

Subsections 2.1 through 2.3 present the approach used to identify and survey study participants and to locate viable web-based information resources.

\section{$2.1 \quad$ Survey Approach}

\subsubsection{The Targeted Cities}

The goal was to collect at least 50 complete survey responses from a minimum of five areas that would be representative of the continental U.S. in terms of extremes in weather, topography, heavily trafficked cities, and well-documented, prevalent energy and environmental issues. The areas selected were:

- New Orleans: hot, wet, and sticky for most of the year and subject to intense hurricanes coming from the Gulf of Mexico;

- Washington, DC: extremes in rain and snowfall (from drought-like conditions to floods and blizzards) and warm to hot and humid in the summer; 
- New York City: weather extremes in summer and winter; aggressive approach to energy conservation;

- Denver, Colorado: high and dry with a long winter season and snow and avalanche hazards; and

- Los Angeles: consistently warm weather throughout the winter months, but smog problems in the summer; vulnerable to natural disasters such as mudslides, brush fires, and earthquakes; arguably the most proactive city in the United States in terms of air pollution control and energy conservation;

Unfortunately, it was difficult to find people willing to participate. Most of the reasons given were related to prioritization of time related issues. For example, New York was dropped as a venue for focus groups since potential participants felt that the focus group meetings would take too much time from their primary duties, and they were unwilling to commute from their homes outside the city to participate in evening or weekend sessions. Ultimately GEOMET received responses to the online surveys from four of the regions (all but Los Angeles) and held the focus group meetings in New Orleans and Washington, DC.

\subsubsection{The Web-Based Survey}

In designing the survey, GEOMET attempted to maximize the ability to collect data results (e.g., equipment types, fuel choices, indoor air quality, operating schedules etc.). We formulated a list of the kinds of buildings to survey, the roles of the building representatives, and the basic factors that would affect all of them, no matter where they were located or how they functioned. HVAC systems obviously topped the list, followed by system reliability. The latter factor was particularly appropriate because the objective was to facilitate more effective system performance. Environmental issues were another critical factor; if building occupants were uncomfortable because of poor ventilation or indoor air quality, the building manager would hear about it. These factors, along with other considerations-lighting, security, noise, the age of the installed technology, building management practices, and weather-formed the foundation of the information baseline. 
Building on GEOMET's background (a convergence of energy-related studies; environmental monitoring and compliance, including ambient and indoor air quality; weatherrelated analyses; statistical sampling and analysis; and information technology/web development), we designed and developed a six-part survey in which respondents were asked to provide information about the following areas:

- Respondent's role and responsibilities, her or his facility (name, location, type of building, etc.);

- General building operations (e.g., operating hours, maintenance, energy costs, lighting);

- Energy systems and control strategies used in the building (e.g., heating/cooling systems, heating fuels used, ventilation);

- Building systems from a performance and reliability perspective (e.g., system monitoring, positive or negative affective factors);

- Peripheral energy issues (e.g., occupant complaints, energy audits, indoor air quality assessments); and

- Respondent's ideas on possible technologies or practices that could improve efficiency.

Because most residential properties do not have the kinds of sophisticated control systems used in commercial buildings, all the buildings surveyed were non-residential facilities. Therefore, their hours and daily operating schedules were fairly consistent along their functional venues. For example, a hospital of necessity operates on a 24/7 schedule with no time allocated for building shutdowns and, therefore, no reduction of system operations. Hotels also generally fall into this category with some exceptions (e.g., all but primary entrance doors, restaurants, bars, meeting rooms, etc., shut down after a certain hour). On the other hand, most office buildings, banks, universities, etc., have firmly established hours or periods of operation, including weekends and holidays. Other facilities, like auditoriums and convention centers, are subject to greater fluctuations in hours of operation because of the special events that are held there. 
The target facilities used a wide range of HVAC equipment and other systems that required sophisticated building controls. Many involved multi-use services/areas, including kitchens, laundries, laboratories, climate-controlled rooms, administrative offices, data centers, indoor pools, walk-in freezers, libraries, gymnasiums/spas, and bank/security vaults. System performance and reliability were extremely important in all of the facilities but especially in facilities like hospitals that must function 24/7 with no weekend or holiday shutdown periods. The list included:

- Large urban, full-service hospitals

- Commercial, privately owned buildings

- Government buildings (e.g., GSA facilities)

- Research facilities (e.g., laboratories)

- Large data or information processing centers

- Large residential units (high rises)

- Large, indoor shopping malls

- Movie theaters, casinos, auditoriums, and other entertainment venues

- Grocery stores

- Aquariums

- Convention centers

- Hotels

- Airports

- Correctional institutions.

\subsubsection{Survey Participants}

GEOMET was clearly able to identify building types (e.g. hospitals, malls, public buildings), however, finding appropriate building representatives was difficult. This was because of the prioritization of time issue mentioned previously. GEOMET enlisted the aid of various organizations (especially IFMA-International Facility Management Association and Consolidated Engineering Services) to identify facilities/representatives who fit our survey criteria. We provided a copy of the survey to our contacts in each of these organizations, an 
overview of what we hoped to achieve, the formal invitation letter we intended to send to potential participants, and the assurance (which turned out to be a critical factor) that the survey was to be used for study purposes only, with all respondents' names and information held in strictest confidence and not to be used for profit.

GEOMET's target was to identify 25 people in each of five selected locations.

GEOMET limited participants to those with general knowledge of building systems as well as an intimate knowledge of their particular building's functions, heating/cooling and lighting systems, overall operations, and tenant/occupant observations and complaints. Representatives included:

- Facility managers,

- Building engineers,

- Maintenance managers,

- Space planners,

- Building owners, and

- Architects.

GEOMET obtained names, addresses, emails, and phone numbers for more than 300 qualified building representatives in all five regional areas and, in collaboration with IFMA representatives from almost every region, refined those lists down to between 20 to 30 choices in each region. All qualified building representatives were sent formal letter explaining the purpose of the study, the connection with ARTI, and the name of the person referring them for inclusion. In many cases, participants were invited via email or phone calls, and all positive responses were followed up in writing.

\subsubsection{Survey Administration}

A survey was developed for and available over the Internet. GEOMET devised a simple control number system to restrict web access to confirmed survey participants. The unique control numbers allowed participants to access their own information (for updates or revisions) after completion and submission of the survey. They were also able to print out their completed 
responses for their personal records. Once submitted, completed surveys were captured in a database, and email notifications (including the completed survey) were sent to the survey coordinator and the technical analyst. Confirming emails were sent back to respondents, thanking them for their participation.

\subsection{Focus Groups}

The written surveys, as comprehensive as they were in terms of the information solicited, lacked the creative energies generated by focus group settings, especially among building representatives who faced many of the same building-related problems. The dynamics of sharing experiences and problems in a group setting would foster interchanges and yield creative ideas for enhancing system performance and information gathering, as well as methods for sharing resources. Because we knew that a successful focus group would depend on an environment that was conducive to spontaneous reactions and ideas, we decided not to over-structure the meeting by going through the survey on a question-by-question basis. At the same time, we did need some common reference (or starting point) for all focus group participants.

The first step, therefore, was to determine what we wanted to extract from the group, namely, a clear picture of how well or poorly their control systems were working and the extent of their interest in finding real-time resources to help optimize system performance. Next, we established areas of the survey that should be emphasized for group discussion and determined the meeting format, including introductions by each participant and a roundtable seating arrangement to ensure that all would be able to contribute to the discussion, without any one person dominating. A mechanism for immediate feedback of information collected during the meeting provided material for final discussion or enhancement.

\subsection{Technology Review}

A comprehensive technology review was performed to determine possible real-time web data streams and associated technologies. The technology review consisted of two main drivers: 
(1) Web searches of real-time web services and, (2) The needs of the building type or type of technology within the building system.

The discussions with the focus groups provided a secondary driver in terms of real-time data systems that they were willing to consider. These systems were consistent with the two main drivers. Thus, only some new information regarding possible web data streams was obtained from the focus groups, although many other useful pieces of information and data applications were obtained. One recurring theme was the need for web data streams that could facilitate detailed inspection and maintenance at regular intervals via some form of integrated self-diagnostic system to assist facility managers in detecting potential problems before they occur or become severe. Another potential application was some form of on-line training module for maintenance personnel based on their levels of need. Figure 2-1 shows the process for determining the availability of real-time web services. In addition, the figure shows that building technology issues are a key element. It also shows the concept of first executing the comprehensive search strategy and then confirming those newly found real-time web parameters against building systems.

\subsubsection{Web Searches of Real-Time Web Services}

GEOMET also conducted a comprehensive web search of potential real-time web services. Some first starting points (such as weather data) were obvious, as were some categories of data sources (e.g., government versus private sources). Of more importance, however, was capturing categories not normally recognized (e.g., TV/list servers). In order to do this, the term "real-time web" with many variations was entered into common search engines such as Google and Northernlight. We expected that a sophisticated web search strategy coupled with other search engines (including metacrawlers such as Dogpile and invisible web search mechanisms such as Pro-Fusion) would provide a good listing of possible data sources. Indeed, the search strategy worked well, and the results appear in Section 3.3. 


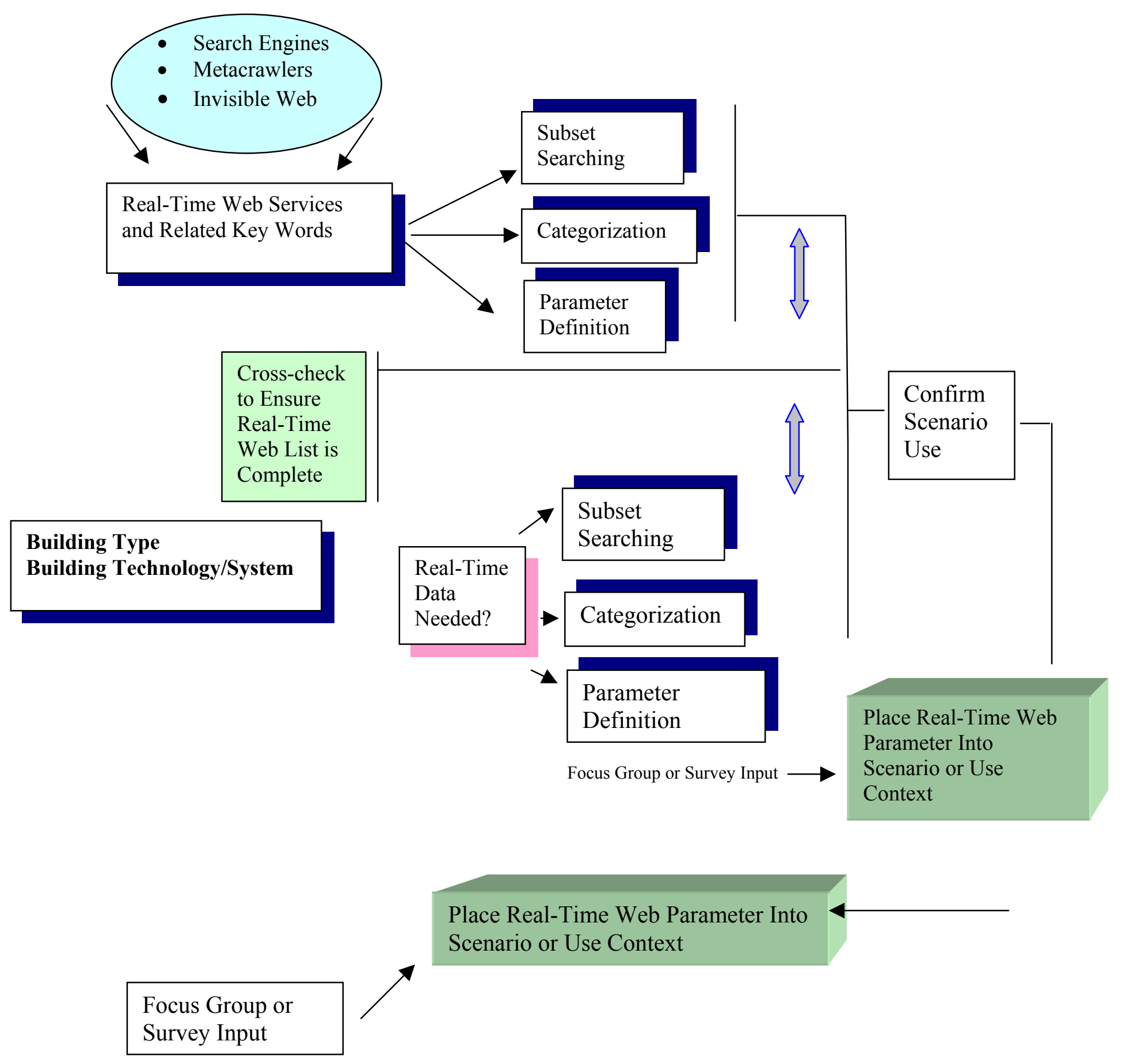

Figure 2-1 Technology Review Methodology for Determining Real-Time Web Services 
The majority of the many potential sites we analyzed were weather-related. Broad categories of real-time web data were determined from the search strategy. Each category was identified according to the following characteristics:

1. Parameter(s) of interest

2. Data source and latency issues

3. Method data was obtained

4. Private sector vs. government

5. How data are collected in many energy applications (although this part of the analysis was limited by the scope of the current project, because of the importance of weather data to most building management systems, we spent some time in determining how National Service data are processed)

6. Fee structures (if any)

7. Quality of the data, including any Quality Control (QC) type procedures, human intervention in the QC process, etc.

8. Other significant attributes of the web data stream.

Parameter(s) of interest was a fairly straightforward subset search whereby important parameters of each data stream were identified. These parameters were often lumped together (temperature and dew point, wind direction and wind speed).

The data source and latency subset search centered on how timely the data are collected. None of the data sources appeared to have latency problems. The data appeared in a timely manner with adequate backup capability.

The method data was obtained subset search focused on the mechanism by which the data can be transferred from the Internet. Many real-time web data streams utilized FTP transfer mechanisms for easy and efficient transfers of data. There were some streams that utilized images or graphics, which may prove to be more difficult to transfer. 
The private sector versus government ownership was a straight subset search (either private or government!). However, in one case a data stream that appeared to be government (lightning) was in reality a private vendor who had been in this business since the 1980s. This was the only case that we could find where critical weather information such as lightning was not collected by a U.S. government entity, but was used in almost every U.S. government agency dealing with natural resources, operations, defense, or environment.

The how data are collected subset search involved determining the process by which data are collected and compiled by the sensor. For example, considerable time was spent describing how weather data were collected since those data are critical to many aspects of this project. This category also laid the foundation for examining how the QC process works within the various data streams.

The fee structure subset search examined what, if any, fees were charged by commercial vendors. Detail was not provided here because private fee structures had too many variables or considerations to list. For example, the lightning fee structure had at least ten different components and many variations of those components based on amount of data, resolution/map background, etc.

The quality of data subset search was important because it led to the analysis of accreditation and whether accreditation was even possible. QC mechanisms were determined from the best means possible for each data stream, with the understanding that in the private sector, QC procedures could vary widely within the same data stream. Many times GEOMET contacted private vendors to ask questions about QC procedures. It is interesting to note that some government sites utilize human intervention after machine-QC mechanisms have been completed.

\subsubsection{Needs of the Building Type or Technology/System}

As a check against the web-related search strategy, GEOMET also performed an examination of building type and technology. This examination yielded two results: 
1. The generation of any new web data streams or the supplementing of information regarding existing web data streams

2. The development of scenarios and parameters when coupled with the focus group discussion and data.

A master checklist was developed at this stage to enable different building technologies of the present and the future to be examined from the perspective of how real-time web data could benefit them. This checklist basically followed the thinking of the Advanced Buildings effort sponsored by various Canadian agencies. GEOMET believed that this list captured both the current and future thinking regarding building systems technology. When compiling the list, we also used more commonly known systems/technologies and input from the focus groups and the surveys.

The list consisted of the following areas (not all shown):

- Building structure issues

- Finishes and furnishings

- Heating and cooling

- Plumbing and water heating

- Lighting and daylighting

- Load management

- Electricity production

- Ventilation and air quality

- Site services

- Motors and equipment.

This list and its subsets were analyzed against the already developed real-time web data parameters to ensure that nothing was missed. It was here, for example, that solar radiation/sun angle became a factor for any of the solar-related subcategories under lighting/daylighting, heating/cooling, etc. Sections 4 and 5 of this report include further discussion of these data. 


\subsection{RESULTS}

GEOMET used focus groups as one means of developing ideas for tying real-time information from the Internet to building automation systems for predictive and management purposes. Prior to the focus-group meetings, potential participants completed a web-based survey. Results from that survey are presented below. Section 3.2 summarizes comments and ideas generated during the focus-group discussions.

\subsection{Web-Based Survey}

Nineteen individuals responsible for building management completed the survey. While the sample size was small, the results, as described later, do point to some recurring themes. Seven participants were located in the Washington, DC, metropolitan area; seven in New Orleans, Louisiana; three in Denver, Colorado; and two in New York City. Most of the buildings managed by the respondents were used for office space. One person was responsible for the management of 48 buildings associated with a school system, another managed a casino complex, and a third managed a building used for assembly purposes.

The facilities varied considerably in age and size. The distribution by age was fairly even, ranging from five facilities built within the last 10 years to three aged 30 years or more, with six buildings 10 to 19 years, and five 20 to 29 years. The buildings ranged in size from just under 100,000 square feet to more than a million square feet. (For purposes of the tabulations in Figure 3-1, the average building size was used for the set of 48 schools managed by one of the respondents.)

Survey respondents indicated that they used the following energy management features: a dedicated energy manager (eight cases), energy records (seven), and maintenance logs (seven). Consistent with the varying facility size, annual electric consumption ranged from 1 million to 100 million $\mathrm{kWh}$ for electricity and from 5,000 to 100,000 therms for natural gas. Two-thirds of the respondents who answered this question indicated that the highest demand month was July or August (10 responses), with the remainder indicating December, January, or February (5 
responses. The average or preferred building temperature, from the viewpoint of building managers, was 72 ( 10 responses) or $73 \mathrm{EF}$ ( 5 responses) in most cases, but $74-75^{\circ} \mathrm{F}$ in two cases and 78-79EF for respondents in New Orleans.

Facility Size (square feet)

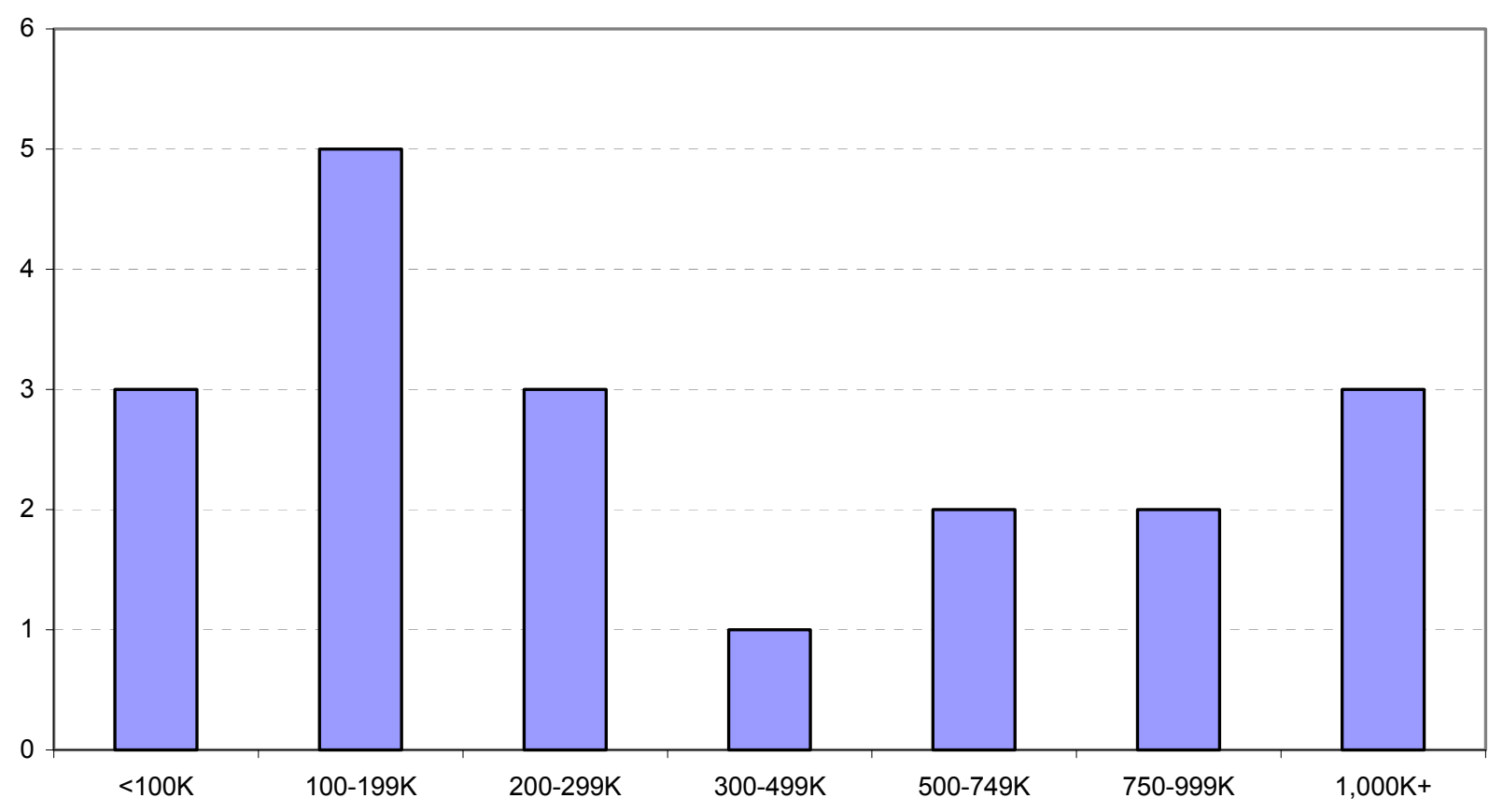

Figure 3-1 Size Distribution of Facilities Covered by the Survey

Figures 3-2 through 3-4 show participants' responses to questions concerning building features, means of interior lighting, and uses of exterior lighting. The most common building features were loading docks, kitchens, and information-processing centers. Auditoriums or theaters and indoor parking were also mentioned by about half of the respondents. The most common types of interior lighting were high-efficiency fluorescent bulbs and incandescent types. Nearly half of the respondents also mentioned metal halide, high-pressure sodium lighting, and halogen standard fluorescent. Exterior lighting was used primarily to serve outdoor parking areas and perimeter security as well as landscaping. 
The primary type of weather-related factors mentioned by nearly half the respondents was sunlight, which was controlled by window shading. Other weather-related factors, in decreasing frequency of mention, included heavy rain and flooding (two responses); high winds (two responses); and heavy rain or snow, moonlight, and tides (one response each)

While central cooling/heating plants were the most common systems in these buildings, decentralized systems were not uncommon (Figure 3-5). Both central and decentralized systems were used in some facilities. Ten respondents used simultaneous heating/cooling systems, and eight used electric submetering. Twelve different control strategies were used in the facilities:

- Space temperature (15 responses)

- Operator, clock-based, and comprehensive building system (12 responses each)

- Central plant (11 responses)

- Occupancy temperature (10 responses)

- Occupancy lighting (8 responses)

- Temperature reset (7 responses)

- Demand/limiting (4 responses)

- Campus/multi-building system (3 responses)

- Demand controlled ventilation (2 responses)

- Water usage (1 response).

Half of those responding to this question (nine) indicated that they used electricity as the primary heating fuel, and a third (six) used natural gas. Two used a hybrid of sources, and one used fuel oil. The most common means of temperature regulation was thermostat input to control systems (13 cases), followed by manually operated thermostats (10); seven facilities used a time clock thermostat. Forced-air was the most common type of heating system (13 responses). Respondents also indicated that they used a hydronic system or high-temperature hot water (four each), heat pump (three), steam (two), and heat recovery (one). Automatic start/stop of the system was the predominant method (13 responses), with hybrid systems, combining manual with automatic controls, indicated in five cases. 
Respondents used six types of cooling systems, but the most common type was a central electric chiller (15 responses). Other systems were:

- Roof-top unit (seven);

- Unitary package unit, split system, or heat pump (four each)

- Refrigeration (two).

As with the heating systems in these buildings, automatic cooling system start/stop was used in the majority of cases (12 responses), with manual/automatic hybrids used in the remainder (6 responses). The most common features of ventilation systems in buildings covered by the survey were variable-volume (14 responses) and constant-volume supply systems (11 responses). Three participants reported using unit fans; one respondent reported using an exhaust system with less than 50 percent supply air; and one reported using natural ventilation.

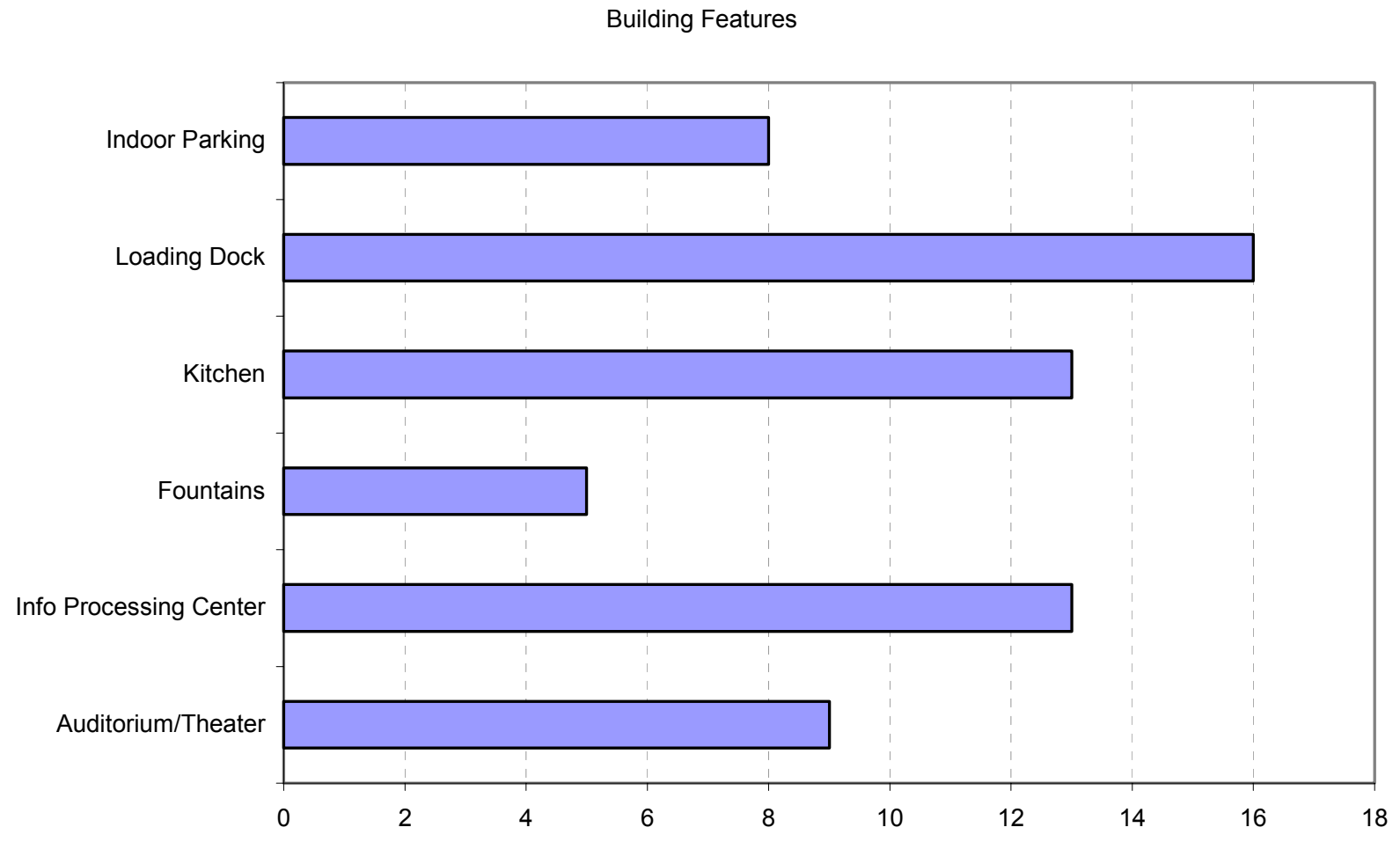

Figure 3-2 Selected Building Features for Surveyed Facilities 


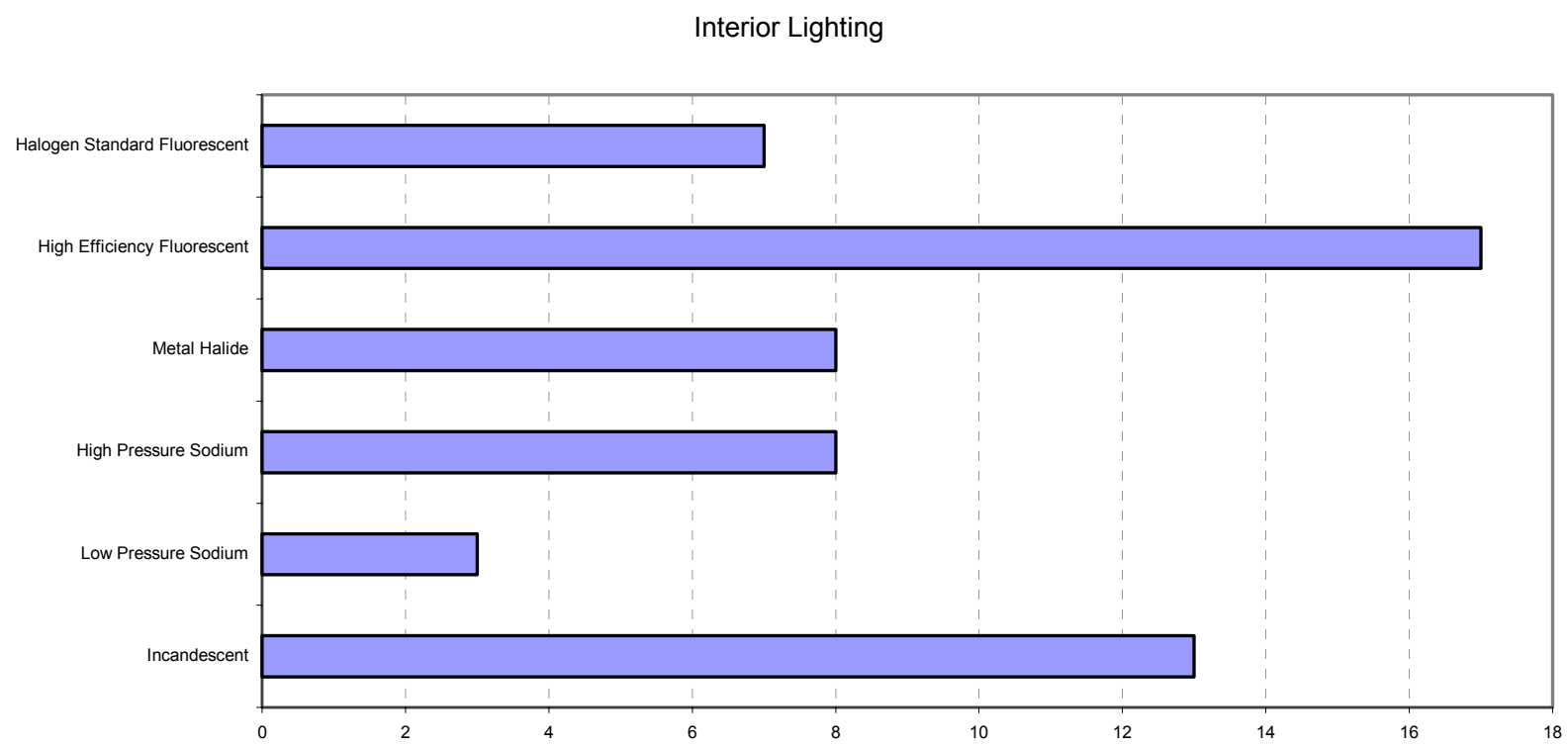

Figure 3-3 Means of Interior Lighting in Surveyed Facilities

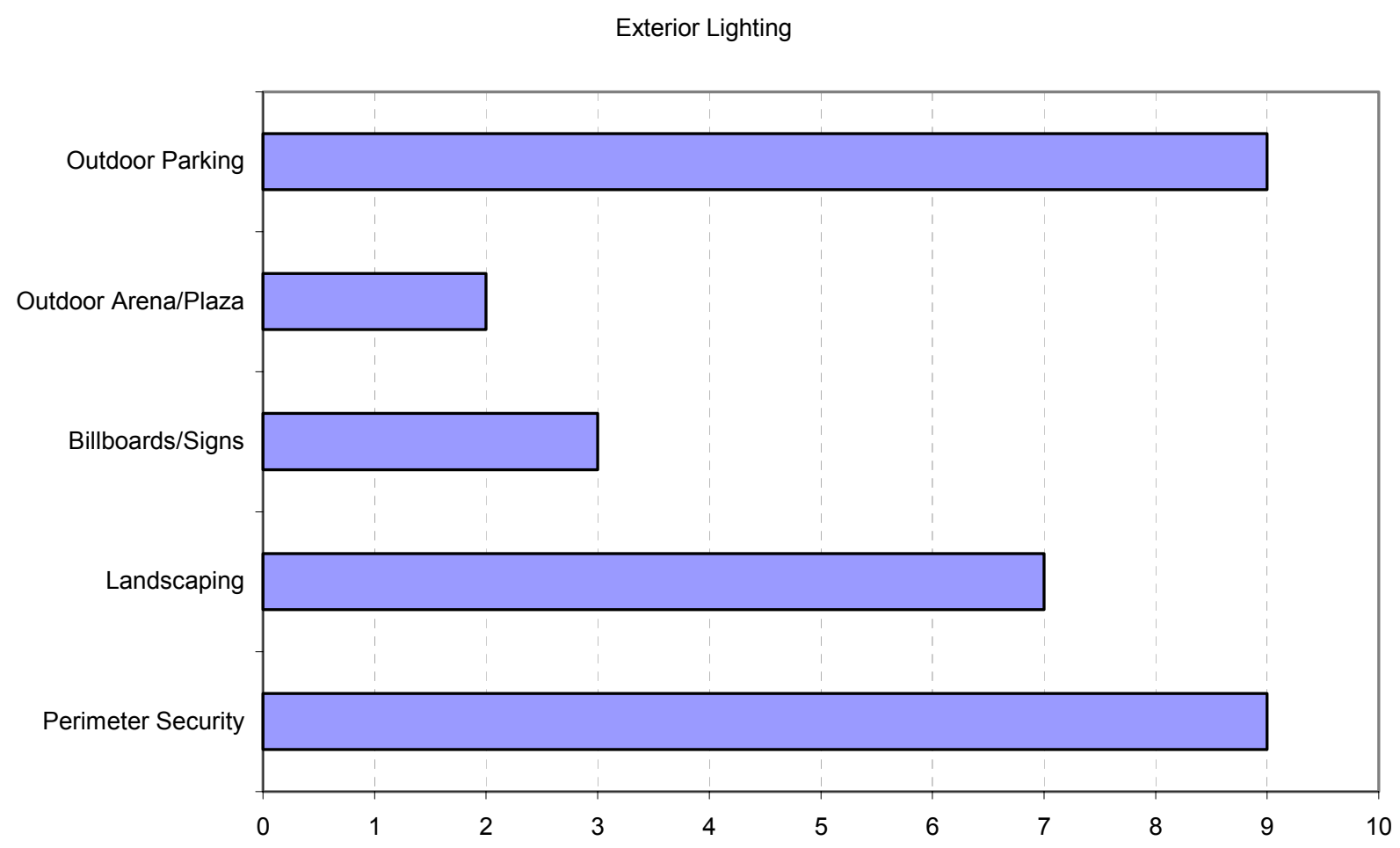

Figure 3-4 Uses of Exterior Lighting at Surveyed Facilities 


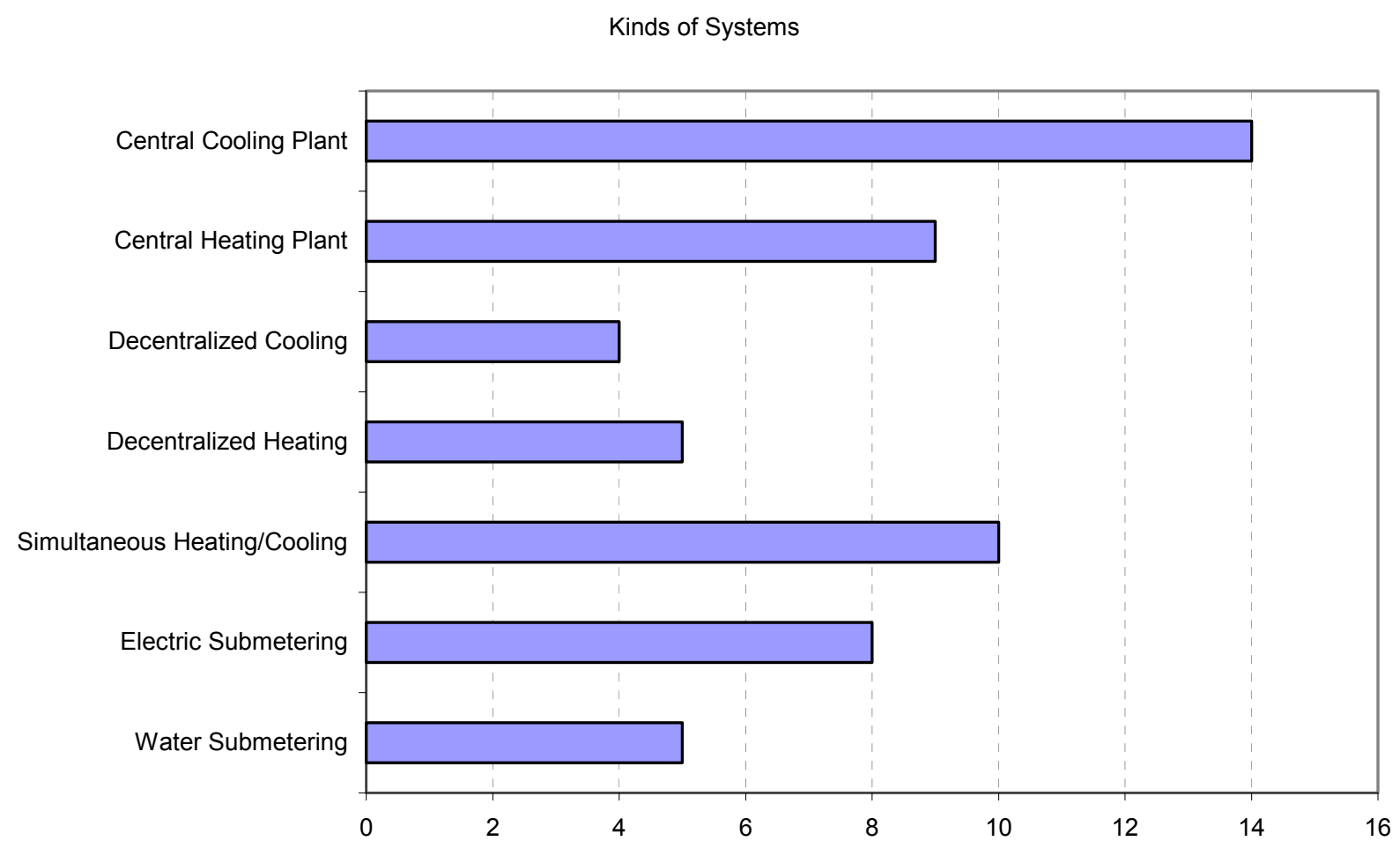

Figure 3-5 Systems Used in Surveyed Facilities

The most common methods of monitoring building system performance were:

- Scheduled maintenance (12 responses)

- Automatic monitoring/notification systems and responses to occupant complaints (10 each)

- Written logged reports (9 responses)

- Hybrid of all methods (7 responses)

- Predictive maintenance (6 responses).

When queried in regard to building systems or components that habitually performed the best, respondents cited chillers most frequently (five cases). Responses regarding components with habitual poor performance were quite varied (Table 3-1), but perimeter or stand-alone units were mentioned by three respondents, and problems with static pressure were cited by two. The factor cited most frequently as a contributor to poor performance was an aging system (six 
responses), followed by inadequate knowledge or poor planning (four). Other factors mentioned by three respondents each were weather, system users, staffing, and unforeseen demands. Two people cited immature technology, and one mentioned vendors.

Despite the fact that chillers were often mentioned as a component with habitual good performance, they were also mentioned most frequently in connection with critical incidents relating to reliability or performance (Table 3-2). In a number of cases, respondents believed that the problem could have been avoided through closer inspection or routine maintenance (Table 3-3). In only a few cases did respondents feel that additional information would have helped in resolving the problem (Table 3-4); one respondent mentioned predictive diagnostics as being potentially useful.

The most frequent complaint respondents received from occupants was about lack of heat or air conditioning (17 responses). In several cases, the managers also indicated that occupants were dissatisfied because they had no control over thermostats (four responses) or because of temperature fluctuations (three responses). Other complaints cited by two managers concerned ventilation, lighting, and false alarms. Frequent power failures, excessive humidity, and lack of hot water were each mentioned by one respondent.

About half of the respondents indicated that some type of effort was made to encourage nonmaintenance staff and occupants to follow energy-efficient practices (Table 3-5). Occupant activities included shutting off lights or use of light sensors, and shutting off certain types of equipment (e.g., computers, copiers) when not in use. Nearly three-quarters (13 responses) of the facilities covered by this survey have had some type of environmental assessment, and about half (10) have an energy/resource consumption audit. Eight have formal policies to maximize efficiency. 


\section{Table 3-1 Building Systems with Habitual Worst Performance in Surveyed Facilities}

\begin{tabular}{|l|}
\hline Static pressure controller. A pneumatic controller with several leaks. \\
\hline Free cooling economizer mode, or integrated mechanical/ economizer. \\
\hline Energy Management - usually failure of a controller or system module. \\
\hline $\begin{array}{l}\text { Perimeter induction unit heating/cooling control. Poor performance due to single source of power to } \\
\text { each unit for controlling the secondary chilled water valve and electric heat, allowing an individual } \\
\text { occupant to simultaneously heat and cool, over heat or over cool any given perimeter space. }\end{array}$ \\
\hline One compressor per floor. \\
\hline $\begin{array}{l}\text { Heating - due to freeze-control settings the system sometimes cannot maintain building static } \\
\text { pressure. }\end{array}$ \\
\hline Kitchen Equipment. \\
\hline Air handling units - lack of maintenance. \\
\hline Stand-alone units. \\
\hline Cooling - lots of demand. \\
\hline VAV Boxes. \\
\hline Steam heating system - most people don't know how to operate system. \\
\hline Heat Pumps. \\
\hline Heating - perimeter heating is always an issue. \\
\hline
\end{tabular}

\section{Table 3-2 Most Critical Reliability/Performance Incidents in Surveyed Facilities}

Commercial cooling tower - broken make-up water float.

Chiller lost two years ago in the middle of heating season.

Energy management losing programming or communication with terminal units.

Compressor went out on a hot day, catastrophic failure with no previous indication.

Electrical short (beyond the UPS system) caused loss of power.

Chiller failure during heat wave.

Chilled water pumps failing.

Two of the main chillers went out.

Chilled water valve failure that could not be isolated in a 5,000-ton system. Required shutdown and draining of entire system to replace a single 12-inch butterfly valve.

Chiller failure during a rain and lightning storm - power spikes caused chillers to fail. 


\section{Table 3-3 Possible Avoidance of Critical Incidents in Surveyed Facilities}

Yes, by closer inspection of the system.

Yes, by not using the Mac-Adapts computer program.

Nothing other than to replace components before failure.

If we had had a competent electrician on site.

Yes, if adequate maintenance.

Yes, the electrical terminal strip feeding power to the chiller became loose, and predictive diagnostics could have identified the problem.

Yes, routine maintenance.

The problem could have been avoided by the installation of two valves during initial construction to isolate the central plant from the remainder of the system.

Yes, but safety parameters must be sidestepped to restart machines.

\section{Table 3-4 Utility of Additional Information in Resolving Incidents in Surveyed Facilities}

\begin{tabular}{|l|}
\hline Yes, by seeing the make-up water consumption. \\
\hline Possibly, one can look for potential problems or issues, but no guarantee of finding everything. \\
\hline No, there wasn't enough time. \\
\hline $\begin{array}{l}\text { No, this was a financial issue. The director, in an effort to cut cost, severely cut the maintenance } \\
\text { budget. }\end{array}$ \\
\hline Yes, predictive diagnostics could have identified the problem before failure. \\
\hline $\begin{array}{l}\text { Yes, if the work orders had been given to the manager, indicating that the oil in the chillers had not } \\
\text { been changed as it was supposed to be. }\end{array}$ \\
\hline Additional valves could have been installed in the original design. \\
\hline
\end{tabular}

Table 3-5 Encouragement to Nonmaintenance Staff and Occupants for Energy-Efficient Practices

\begin{tabular}{l}
$\begin{array}{l}\text { Yes, by attending several company-provided awareness seminars for reduction in consumption and peak } \\
\text { load shaving. }\end{array}$ \\
\hline Yes and no, we try to shave and save as much as possible but when client speaks we answer the call. \\
\hline Only to the point of having PCs with automatic power saver features. \\
\hline Yes, we have a system wide energy program whereby all staff are encouraged to participate in energy \\
conservation. \\
\hline $\begin{array}{l}\text { This issue is coming full circle. Due to past changes in market emphasis we moved from energy usage } \\
\text { first to tenant comfort first achieving both in the most economical manner. We are now moving rapidly } \\
\text { toward energy concerns governing operations, preparing an initiative with nonmechanical personnel re- } \\
\text { instituting proven methods of electrical demand and consumption reduction. }\end{array}$ \\
\hline $\begin{array}{l}\text { Yes, instructions to shut off lights when space is not occupied. } \\
\text { Blinds closed, avoid excessive settings on t-stats. }\end{array}$ \\
\hline Yes, such as shutting off computers and copiers at night. \\
\hline Sensors for lighting, reminders in newsletter about conservation and shutting down equipment \\
\hline Yes, turn off lights and other equipment when not in use (e.g., escalators). \\
\hline Not really - no active energy management plan is in place. \\
\hline
\end{tabular}


About two-thirds of the study facilities (12) have had a major effort concerning replacement/retrofit of lighting or HVAC systems, and a third (6) have had some type of efficiency study. Very few facilities have participated in the EPA Energy Star program, a utility incentive program, or another type of energy savings performance program (one in each category). Various automation procedures or equipment components to facility energy are in place including (in descending order of frequency); heating and cooling systems (all respondents); back-up power sources (15 responses); security systems (13); ventilation (11); interior or exterior lighting (10 each); domestic hot water systems (10); fresh-air ventilation (10); automatic operator paging or alerts (7); day-lighting systems or occupancy-based lighting (4 each); window shading, occupancy-based ventilation, fuel switching, or seasonal changeovers (3 each).

Types of functionality related to building automation systems are in place at the surveyed facilities. In descending order of frequency, this equipment includes; operator workstations/ pneumatic controls (15 cases each); DDC controls (13); central plant controllers/field panels (12 each); data logging (8); trending analysis (7); terminal unit controllers (6); alerts via email or pagers (5); panel-mounted LCD interface (3); and self-learning algorithms (2). Some facilities have more advanced equipment or procedures in place. Four respondents indicated that they had built-in weather stations, TCP/IP gateways, or file servers. Three indicated Internet access to the system.

The final survey question solicited suggestions concerning the types of automation or functionality that would help in operating buildings at maximum efficiency. Recommendations shared by multiple respondents included state-of-the-art equipment, variable frequency drivers, occupancy-based ventilation and lighting, and automatic paging. Other ideas, mentioned by individual respondents, included access to building controls via the Internet, weather stations, automatic blinds, solar generation, and software for energy-efficient operations. Table 3-6 displays respondents' suggestions. 


\section{Table 3-6 Types of Automation/Functionality to Help Operate Facilities}

\section{at Maximum Efficiency}

Solar generation for hot water and electric with automatic changeover.

Occupancy-based ventilation.

Lighting - exterior.

Private office, conference room, and restroom lighting occupancy sensors.

Frequency drives on all chillers.

Take the temperature controls away from our tenant

Ability to communicate with all buildings at once — right now we must dial up each building individually.

Trouble alerts to pagers - we have three different systems with different front ends and programming for each, resulting in a long learning curve for EMS operators and technicians.

Complete DDC retrofit.

Replace aging equipment.

Put motion sensors in space for ventilation and lighting use.

Automatic blinds, upgrade window film, convert cooling towers to thermal wells.

Automatic paging.

Internet access.

Trending analysis.

I would change the DDC controls to pneumatic control for reliability and long-term cost savings.

Computer systems always on line with graphics capability.

Zone temperature alarms.

Occupancy sensors for rooftop control.

Load shedding.

Updating the current system with state-of-the-art equipment and personnel to use it.

Centralized system for all stand-alone units that could be monitored together and adjusted accordingly.

A real energy-efficient operations software package.

Getting the operating engineers to operate the software properly.

Improved control of central plant.

Access to building controls via the Internet.

Weather station.

VFD on pumps and cooling tower fans. 


\subsection{Focus Group Discussions}

Six different topics were covered at the focus-group sessions. The first, on the subject of tenant temperature control, was used as an icebreaker. While respondents admitted that it is desirable for occupants to have some control over their local environments, there was consensus that ultimate control needs to reside with building managers. One example of this philosophy would be for the building manager to set a temperature range within which tenants would have latitude. Further details on individual responses are provided in Table 3-7 below.

\section{Table 3-7 Focus Group Responses for Topic 1 - Tenant Temperature Control (Should tenants have control of the space temperature?)}

\begin{tabular}{|c|c|}
\hline Washington, DC Responses & New Orleans, LA Responses \\
\hline $\begin{array}{l}\text { - To a certain extent-building manager sets } \\
\text { range, then tenants (occupants) should have } \\
\text { the opportunity to operate within that range. } \\
\text { - Nonpassive thermostats allow tenants full } \\
\text { control, but would prefer that they didn't } \\
\text { have that control; range is } 68-74 \mathrm{EF} \text {. } \\
\text { - Some tenants take control, even if they don't } \\
\text { have it, with a little screwdriver. } \\
\text { - Tenants need to be educated on the controls } \\
\text { in their building, especially induction type or } \\
\text { perimeter systems. } \\
\text { - Manager isn't allowed to set parameters- } \\
\text { tenants can set controls anywhere from } 55 \text { to } \\
\text { 90EF. Because of political environment, } \\
\text { tenants have to be placated; they should at } \\
\text { least have some semblance of control, but } \\
\text { building manager should have ultimate } \\
\text { control. } \\
\text { - Need to have some control for comfort of } \\
\text { each individual. }\end{array}$ & $\begin{array}{l}\text { - No, zones are too big (people vary). } \\
\text { - Can't get good mix. } \\
\text { - OK for small zones if they can control } \\
\text { without affecting overall efficiency. } \\
\text { - Mandatory for patient comfort (in hospital). } \\
\text { - Yes, but how do you get there? } \\
\text { - Winning versus losing can be a factor for } \\
\text { casino patrons. }\end{array}$ \\
\hline
\end{tabular}


Participants were asked if they believed that a skilled operator was capable of controlling a building better than a state-of-the-art BAS. As indicated in the summary of comments in Table 3-8, there were a number of affirmative replies, but with some caveats - constant attention would be required, the system needs to have a central location combined with pneumatic controls, and there is variability in individual capabilities. On the other hand, it was admitted that a BAS might be able to spot trends, and "tweak" accordingly, better than a human. For adequate control, a BAS would need feedback from many sensors. At the same time, it was noted that excessive reliance should not be placed on monitoring. Perhaps if there was a consensus position, it was that the optimal approach uses a BAS in combination with human skills and experience.

Table 3-8 Focus Group Responses for Topic 2 - Operator-Based Control (Can a skilled building operator control a building better than a state-of-the-art BAS?)

\begin{tabular}{|l|l|}
\hline \multicolumn{1}{|c|}{ Washington, DC Responses } & \multicolumn{1}{c|}{ New Orleans, LA Responses } \\
\hline $\begin{array}{l}\text { - Possible for central location combined with } \\
\text { pneumatic. }\end{array}$ & - No matter how good system is, it still \\
- Controls not programmed to pick up trends. & - Yests, people. \\
- BAS by itself is not enough. & watching all day. \\
- Newer software can "learn" (must have & - Beware of excessive reliance on monitoring. \\
many sensors). & - Trending-BAS can figure trends and "tweak" \\
- Range of temperature difference can be & accordingly, better than a human. \\
significant over fairly short distances. & - Human "skill" is variable, even in the same \\
- Generally higher satisfaction in BAS & person from day-to-day (personal, \\
buildings. & emotional, other issues may be influence). \\
\hline
\end{tabular}

Participants were asked to discuss whether current information about events at other regional facilities would be useful in increasing the stability of their control systems. Most positive responses had to do with weather-related phenomena such as rain and snow or tracking of frontal systems (Table 3-9). At the same time, it was acknowledged that a "region" would have to be fairly small for such information to be of use, as there can be too much weatherrelated variability within a larger region. Traffic patterns also were mentioned, but these generally were felt to be predictable (i.e., largely a function of time of day or major regional/local events). 


\section{Table 3-9 Focus Group Responses for Topic 3 - System Stability (Would up-to-the-minute information about events at other regional facilities increase the stability of your control system?)}

\begin{tabular}{|c|c|}
\hline Washington, DC Responses & New Orleans, LA Responses \\
\hline $\begin{array}{l}\text { - Currently, interface from real-time weather } \\
\text { data to BAS is human. } \\
\text { - Tracking movement of frontal systems. } \\
\text { - Snow day notifications are manual } \\
\text { processes. Snow day decisions are made } \\
\text { around 5:30 a.m. but operators don't come } \\
\text { on until 7:30. } \\
\text { - Need interface for snow day mode at } \\
\text { schools. }\end{array}$ & $\begin{array}{l}\text { - Start of rain, building skin temperatures. } \\
\text { - In New Orleans, there can be rain on one side } \\
\text { of street but not the other; just too variable } \\
\text { ("region" would have to be small). } \\
\text { - May be OK elsewhere (e.g., Chicago). } \\
\text { - Wintertime is the most predictable here. } \\
\text { - Monitor Saints game; big influx of people into } \\
\text { casino based on whether team wins or loses. } \\
\text { - Traffic predictable: pretty much time of day } \\
\text { and big events. } \\
\text { Nonspecific Responses } \\
\text { - Peak water use } \rightarrow \text { pressure drops (e.g., water } \\
\text { pressure drops during heat waves when folks } \\
\text { water their lawns (affects hospital). } \\
\text { - Cell phone dropout at peak commuting time. } \\
\text { - River level and salinity } \rightarrow \text { chemical plant } \\
\text { controls. } \\
\text { - From bank compliance point of view, exterior } \\
\text { light control based on moonlight. }\end{array}$ \\
\hline
\end{tabular}

The fourth discussion topic concerned system maintenance, that is, whether Internet access to OEM equipment data and product updates, or access to remote diagnostic services, might help to improve building system maintenance. This topic was addressed only in the second focus-group discussion in New Orleans. Most of the responses (Table 3-10) did not tackle the issue directly. In at least one case, some aspects of maintenance already are Internetbased, but the process is not tied into the BAS. A key issue, mentioned by several participants, was validation that maintenance activities had been performed as planned, both in terms of schedule and in covering all prescribed maintenance activities. 
Table 3-10 Focus Group Responses for Topic 4-System Maintenance

(Would Internet access to OEM equipment data and product updates, or access to remote diagnostic services, improve building system maintenance?)

\begin{tabular}{|c|c|}
\hline Washington, DC Responses & New Orleans, LA Responses \\
\hline (Question not posed at this focus group) & $\begin{array}{l}\text { - Data processing center } \rightarrow \text { work order } \& \\
\text { maintenance already Internet-based, but not tied } \\
\text { into BAS. Reverse might be easier } \rightarrow \text { system } \\
\text { tells operator when it has a problem. } \\
\text { - Lot of time spent making sure something has } \\
\text { been done, usually limited to spot checks. } \\
\text { - Trend toward full-time maintenance service } \\
\text { when you buy HVAC. } \\
\text { - Even if you get maintenance function validated } \\
\text { to point where you know guy is right there at } \\
\text { system. } \\
\text { - In short, need ways for validation of } \\
\text { maintenance. } \\
\text { - Vibration sensor - call mechanic when specs } \\
\text { are exceeded. } \\
\text { - Kw/ft comparisons. } \\
\text { - No way to get into system from home - only } \\
\text { one system hooked into Internet. }\end{array}$ \\
\hline
\end{tabular}

The fifth topic (Table 3-11) concerned the types of additional information that might be useful for building operations. Weather-related information was mentioned by several participants, particularly as it relates to schedules for major regional/local events (e.g., the Riverwalk in New Orleans). One interesting concept was using the web for scheduling use of meeting/conference rooms in a building and then tying that information into the BAS. Other types of information or approaches thought to be of potential use included BAS links to security systems and real-time information on traffic, catastrophic events, fuel pricing, and energy consumption. 
Table 3-11 Focus Group Responses for Topic 5 - Useful Information (What kind of information would be useful for building operations?)

\begin{tabular}{|l|l|}
\hline \multicolumn{1}{|c|}{ Washington, DC Responses } & \multicolumn{1}{c|}{ New Orleans, LA Responses } \\
\hline - BAS link to security system, number of & - What it costs to operate a building. \\
people, individual office shutdown. & - Energy/ft ${ }^{2}$. \\
- Get real-time fuel pricing for dual-fuel plants & - Employees on web $\rightarrow$ schedule use of \\
or full switching to cogeneration. & meeting rooms/conf. facilities $\rightarrow$ BAS. \\
- Temperature, relative humidity, solar, wind. & - More cost-effective for very large places like \\
- Example for wind direction near airport. & auditoriums. \\
- Traffic (delays affect people coming in or & - Shopping mall applications? \\
leaving. & - New Orleans rain $\rightarrow$ Riverwalk. \\
- Catastrophic events (e.g., advanced warning & - Advance notice for big rain events. \\
on smoke events), Hazmat release, water & - Schedule information, e.g., Riverwalk wants \\
problems. & to know when Convention Center events let \\
- Utility info, brownouts/blackouts, generation & out. \\
capacity. & - Load shedding as trade for advance warning \\
& of grid failure. \\
& - Secure facilities remotely based on certain \\
& events.
\end{tabular}

The final discussion topic (Table 3-12) concerned the notion of a "perfect" building control system. One key ingredient, mentioned at the Washington, DC, session, is knowledge of where both the occupants and operators are at all times. The system needs to be self-calibrating with self-analysis and diagnosis capabilities. At the same time it must not be overly complex; it must be user-friendly with remote access; and it needs to be checked routinely by humans. Certain aspects of automation were considered highly desirable. For example, ideally the system would be able to automate some adjustments before "calling" an engineer. Similarly, the system should be capable of providing a log of key events (e.g., adjustments) and preparing routine or special reports. Potential barriers to success included security concerns for Internet-based operations and occupant privacy concerns (e.g., various occupancy-based sensors may lead to a feeling of being watched). Cost issues and training needs also were cited as possible barriers. 


\section{Table 3-12 Focus Group Responses for Topic 6 - Designing the Perfect}

Building Control System

\begin{tabular}{|c|c|}
\hline Washington, DC Responses & New Orleans, LA Responses \\
\hline $\begin{array}{l}\text { Functions and Features } \\
\text { - Lighting, elevators, emergency power } \\
\text { systems, backup power systems, how many } \\
\text { people and where they are, floor-by-floor } \\
\text { zone control. } \\
\text { - Knowing where the operators are. } \\
\text { - Doesn't take a master's degree to operate. } \\
\text { - Should be self-calibrating, but must be } \\
\text { checked routinely. } \\
\text { - Real-time information on what it's costing to } \\
\text { operate the building at any given moment. } \\
\text { - Self-diagnostics (e.g., control logic on- } \\
\text { screen). } \\
\text { Barriers and Bridges } \\
\text { - Resistance to being "followed" (privacy } \\
\text { concerns). } \\
\text { - Costs. } \\
\text { - Interoperability (differences between } \\
\text { systems). } \\
\text { - Firewalls. } \\
\text { (temp, RH). }\end{array}$ & $\begin{array}{l}\text { Functions and Features } \\
\text { - More reliable humidity sensor. } \\
\text { - User-friendly (remote user friendly). } \\
\text { - Able to self-analyze. } \\
\text { - Relay zone information back to maintenance } \\
\text { \& complaints. } \\
\text { - Relay data to design specs, has it been } \\
\text { tweaked to its maximum? } \\
\text { - Need before } \rightarrow \text { type of change } \rightarrow \text { after. } \\
\text { - Gauge way system operates versus design } \\
\text { criteria from all sides - are operators as } \\
\text { efficient as possible? } \\
\text { - Nice if system could put in information } \\
\text { itself, a self-contained log. } \\
\text { - Ability to capture data/reports directly from } \\
\text { BAS. } \\
\text { - Automate some adjustments before calling } \\
\text { engineer (include self-checks). } \\
\text { - Web access from a PDA. } \\
\text { Barriers and Bridges } \\
\text { - Need more engineer training; others keep } \\
\text { hand off! } \\
\text { - Tuccess Factors } \\
\text { - Fenants directly tied to web to monitor their } \\
\text { receipt. }\end{array}$ \\
\hline
\end{tabular}




\subsection{Technology Review}

This section describes the currently available predictive/real-time data on the web. The data described could be utilized by a BAS for real-time or predictive reasons. The data are divided into several categories.

\subsubsection{Real-Time Weather Data}

Real-time weather data is by far the most readily available real-time data on the web. The ultimate source of this data is the National Weather Service (NWS), which is part of the National Oceanic and Atmospheric Administration (NOAA). NOAA is the major agency within the U.S. Department of Commerce.

Surface weather observations, which are taken on a mandatory basis in the United States at around 10 minutes before the hour, consist of the following types of data: wind velocity (speed and direction), visibility, weather and obscurations, sky condition, temperature, dew point temperature, and altimeter setting (barometer).

The observations are collected by either NWS human observers or by an NWS automated system. If one of the above parameters changes significantly over a short period of time (e.g., a wind direction change of greater than 30 degrees over 5 minutes), then a "special" observation is taken. Most observations are taken at airports. With the advent of automated systems, these airports can be very small private fields, thus aiding in the density of coverage across a region. Buoy and ship observation types also exist for maritime areas. Figure 3-6 shows a listing of NWS human observer and automated stations for Virginia. Figure 3-7 shows a map representation of weather reporting stations. Maps usually show less dense representation of data than alphanumeric files.

More than 400,000 weather observations are taken daily across the United States. This includes 131,000 surface observations, 2,300 upper air observations, 4,000 ship reports, 5,000 aircraft reports, and observations from 30,000 places. Seven computer models, which are run 
daily, provide 3-hour to 15-day guidance on weather patterns and forecasts; 50,000 meteorological products are produced for forecasters and the meteorological community.

\section{Communication Linkages}

The NWS uses various methods to make data available to its offices, other parts of NOAA, other federal agencies (NRC, FEMA, DOD, NASA, and others), the private sector (Accu-Weather, Inc., other forecast companies), and the public (TV/radio/newspapers).

However, the major connectivity or "hub point" within the NWS communication system is the NWS Telecommunications Gateway (NWSTG). All data flow through this point and are separated into various streams for either rapid dissemination (e.g. warnings/watches, observations) or more analysis. Data requiring more analysis are input into models for use by forecasters.

\begin{tabular}{|c|c|c|c|c|c|c|c|c|c|c|}
\hline \multirow[t]{2}{*}{ ID } & \multirow{2}{*}{$\begin{array}{r}\text { Temp } \\
F\end{array}$} & \multirow{2}{*}{$\begin{array}{r}\text { Dew } \\
F\end{array}$} & \multirow{2}{*}{$\begin{array}{c}\text { Winds } \\
\text { deg }\end{array}$} & \multirow{2}{*}{\multicolumn{2}{|c|}{$k n t$}} & \multirow{2}{*}{$\begin{array}{r}\text { Press } \\
m b\end{array}$} & \multicolumn{2}{|c|}{ Clouds } & \multirow{2}{*}{$\begin{array}{r}\text { Prec } \\
\text { in }\end{array}$} & \multirow[t]{2}{*}{ Weather } \\
\hline & & & & & & & $100 \mathrm{ft}$ & $\mathrm{COV}$ & & \\
\hline KNYG & 38 & 20 & 0 & at & 3 & 1032.2 & --- & CLR & ---- & \\
\hline KAKQ & 38 & 21 & 0 & at & 0 & 1031.0 & --- & CLR & ---- & \\
\hline KAVC & 36 & 19 & 50 & at & 3 & ------ & --- & CLR & ---- & \\
\hline $\mathrm{KBCB}$ & 30 & 18 & 0 & at & 0 & ------ & 120 & $\mathrm{SCT}$ & ---- & \\
\hline $\mathrm{KCHO}$ & 28 & 13 & 0 & at & 0 & 1031.1 & --- & CLR & ---- & \\
\hline KCJR & 30 & 19 & 0 & at & 0 & ------ & --- & CLR & ---- & \\
\hline $\mathrm{KCPK}$ & 45 & 23 & 40 & at & 8 & ------ & --- & CLR & ---- & \\
\hline $\mathrm{KDAA}$ & 30 & 18 & 10 & at & 1 & 1032.2 & --- & CLR & ---- & \\
\hline KDAN & 34 & 14 & 60 & at & 6 & 1030.6 & --- & CLR & ---- & \\
\hline $\mathrm{KDCA}$ & 32 & 14 & 60 & at & 4 & 1032.2 & --- & CLR & ---- & \\
\hline $\mathrm{KEZF}$ & 30 & 16 & 0 & at & 0 & ------ & --- & CLR & ---- & \\
\hline $\mathrm{KFKN}$ & 39 & 21 & 60 & at & 6 & ------ & --- & CLR & ---- & \\
\hline KHEF & 23 & 16 & 0 & at & 0 & ------ & --- & CLR & ---- & \\
\hline KHSP & 25 & 18 & 260 & at & 7 & ------ & --- & CLR & ---- & \\
\hline KIAD & 26 & 17 & 0 & at & 0 & 1032.0 & --- & CLR & ---- & \\
\hline KJYO & 30 & 18 & 0 & at & 0 & ------ & --- & CLR & ---- & \\
\hline KLFI & 39 & 18 & 50 & at & 11 & 1030.9 & 200 & FEW & ---- & \\
\hline KLKU & 34 & 18 & 0 & at & 0 & ------ & --- & CLR & ---- & \\
\hline KLNP & 30 & 19 & 0 & at & 0 & ------ & --- & CLR & ---- & \\
\hline
\end{tabular}

Figure 3-6 Listing of Some Weather Stations in Virginia 


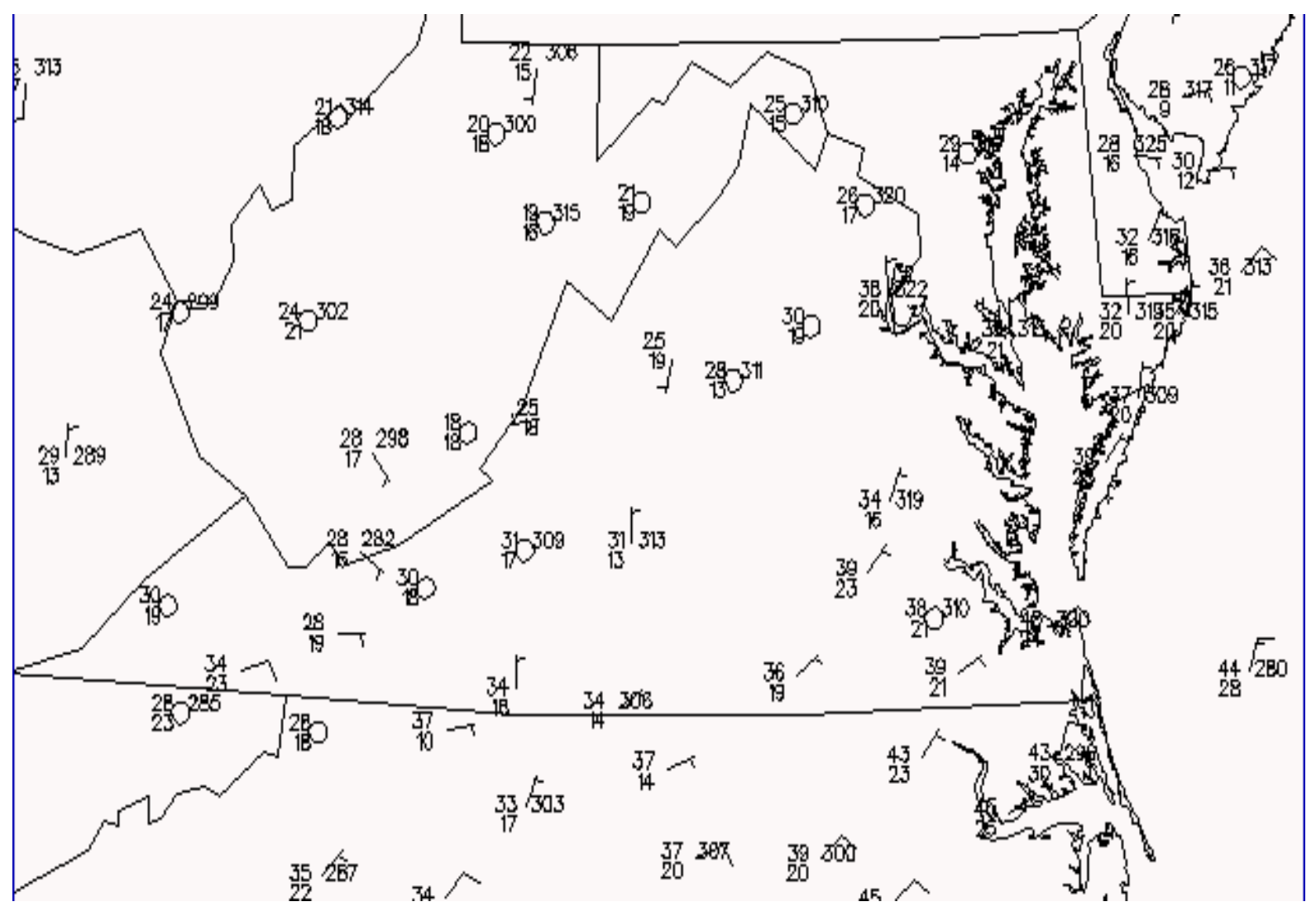

Figure 3-7 Virginia Map Showing Representative Weather Stations

Other data are transformed into map or chart displays (e.g., upper air wind data, surface map data). The model and mapping process is conducted by the National Center for Environmental Prediction (NCEP).

It is important to note that until recently all weather data in the United States had to pass through third-party vendors in order to be utilized by weather consultants, forecast companies, and the public in general (non-TV/radio). This was an interesting case of public data being processed or displayed for a fee by the private sector. Now, however, many universities and other groups offer weather data free over the web. Ohio State University's is shown in Figure 38. There are also FTP services available directly from NWS. Outside the U.S., however, many weather services have begun to charge for weather data obtained over the web.

Weather radar data are also available over the web. This data is provided free by the NWS but with up to one hour delay in transmission. Radar data are provided for a fee by 
vendors such as WeatherTaP, which guarantees six minutes or less delay. (The data still come from NWS weather radar systems nationwide).

\section{$\underline{\text { Non-NWS/Federal Weather Data }}$}

Many TV stations in the U.S. with newscasts provide some sort of weather data on the Internet via their websites. This data usually consist of surface type data, cooperative weather spotter reports, watch/warning information, or weather radar data. It is usually hard to download this type of information.

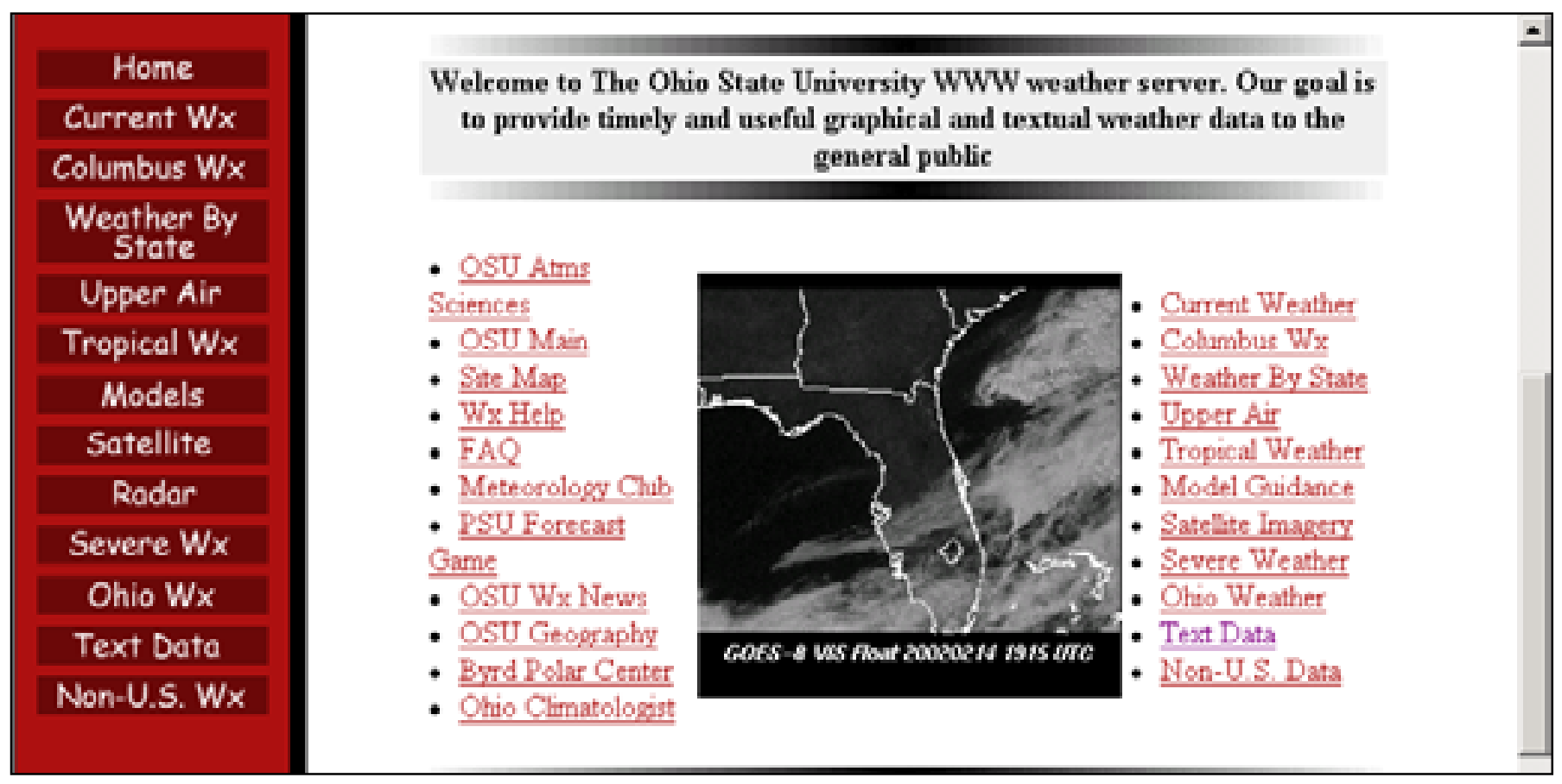

\section{Figure 3-8 Free Weather Data Vendor, University or NWS FTP Services Are Now Available on the Web}

In 1993, a group of individuals formed AWS, Inc. to deal with weather education and weather observing. They began to develop weather stations that could be used at schools and other educational facilities to teach more about weather. These stations were linked to a central database by modem and, later, via the Internet. Today, this network has expanded to more than 100 television markets in the U.S., along with numerous schools. 
The stations record all the basic weather parameters along with solar radiation type parameters and precipitation amounts. Many stations also have limited data retrieval capability. Occasionally the quality of the data is suspect due to maintenance or quality control issues. The information is processed on-site and transmitted to a central location for dissemination to educational institutions and TV stations. Often, when you see local temperatures displayed on a TV weathercast and they are not coming from someone's backyard observation or from an airport, they are coming from a sensor in this educational network.

Figure 3-9 shows output from the network for an elementary school in Dade County (Miami), Florida. The output shows standard meteorological parameters along with a rate of precipitation and minimum/maximum temperatures and pressure. Some stations also provide solar radiation data as well as 72-hour, one-week, monthly, and yearly summaries. The stations are located in key cities across the country and are usually linked to a TV station for data display and dissemination to the public.

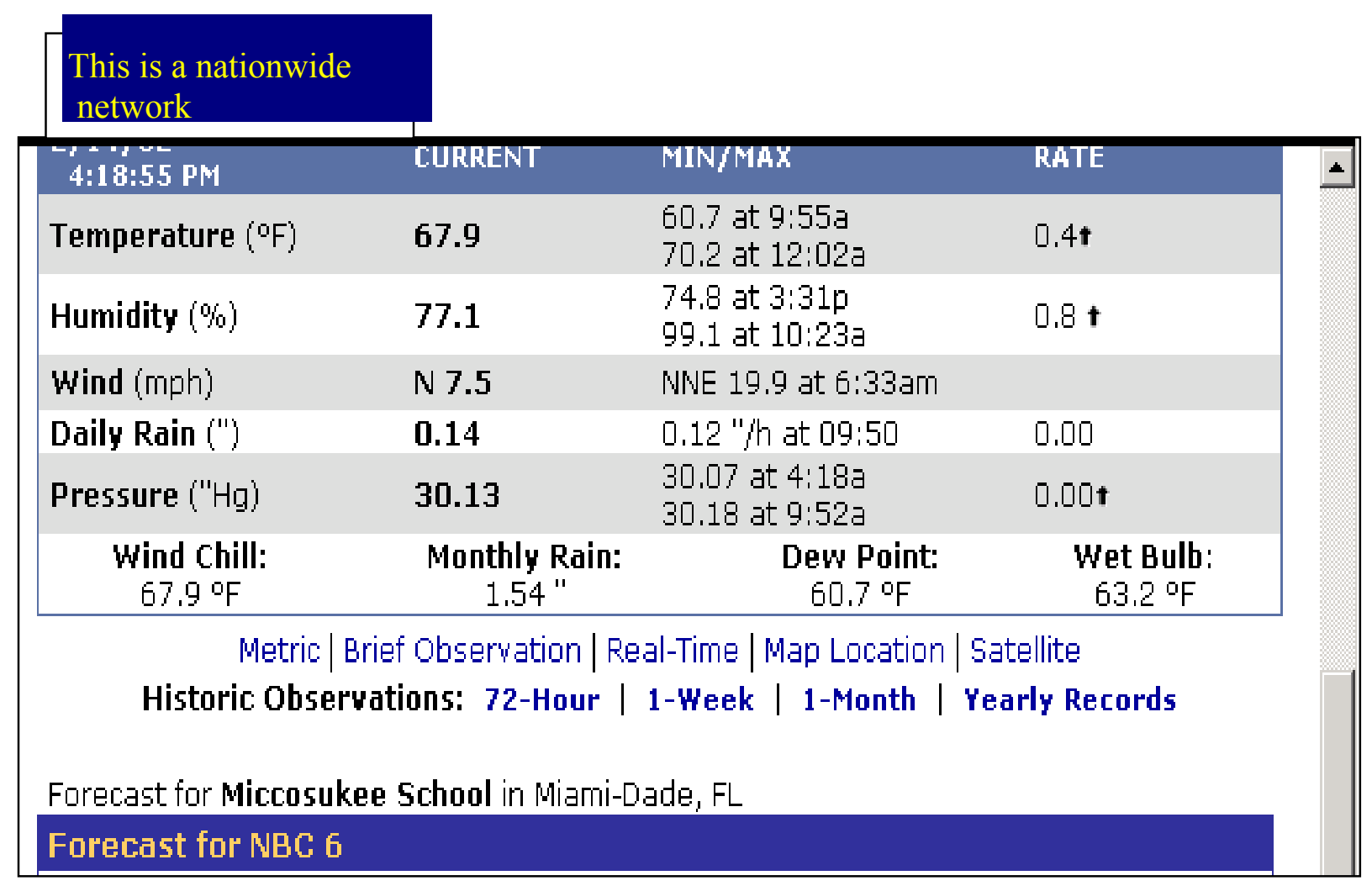

Figure 3-9 Private/Educational Weather Network Sensor Output (Elementary School in Dade County (Miami), FL) 


\section{Model-Related Weather Data}

The NWSTG handles seven U.S. models on a daily basis. These models are run on scales ranging from a few hundred kilometers up to worldwide. The most common scale is North America and surrounding oceans. Models are important to users of weather data because they predict all the different parameters of the atmosphere and provide the basis for a forecast. Thus for the building-owner community, they are key in terms of future events. The models are run on IBM-SP (Super Cray equivalent computers) and consist of the following:

- ETA: A model run out to three days, encompasses North America

- Meso-ETA: Same as ETA, but run on a finer grid scale

- AVN: A model run out to five days, encompasses North America/Oceans

- MRF: A model run out to 15 days, encompasses world

- NGM: A model run out to two days, encompasses North America

- RUC: A model run out to 12 hours, encompasses North America (U.S.)

- MM5: A model run out to 48 hours, encompasses smaller scale features

In addition to the U.S. models, the NWSTG receives models from foreign governments (European, Great Britain-UKMET, Canadian) that have a U.S. output component. The U.S military has an Air Force model and a Navy model, and both are used to support missions. The Navy model, as one would expect, is worldwide and is oriented toward marine forecasting. There are also specialty models for hurricanes (five hurricane models) and for severe weather. Several very localized models exist for different parts of the country. Most models have statistical as well as graphical output. All models forecast in four dimensions, the fourth dimension being time. There are also model ensembles that summarize the results of the models.

Models are typically initialized based on 1200 GMT and 0000 GMT sounding (weather balloon) upper air data and corresponding surface observations. Because the MRF is worldwide, it is run once a day (1200 GMT). The NGM is run every 12 hours. The ETA, meso-ETA, AVN, and MM5 are run every six hours. The RUC is run every three hours. Figures 3-10 through 3-12 show various aspects of model output. 


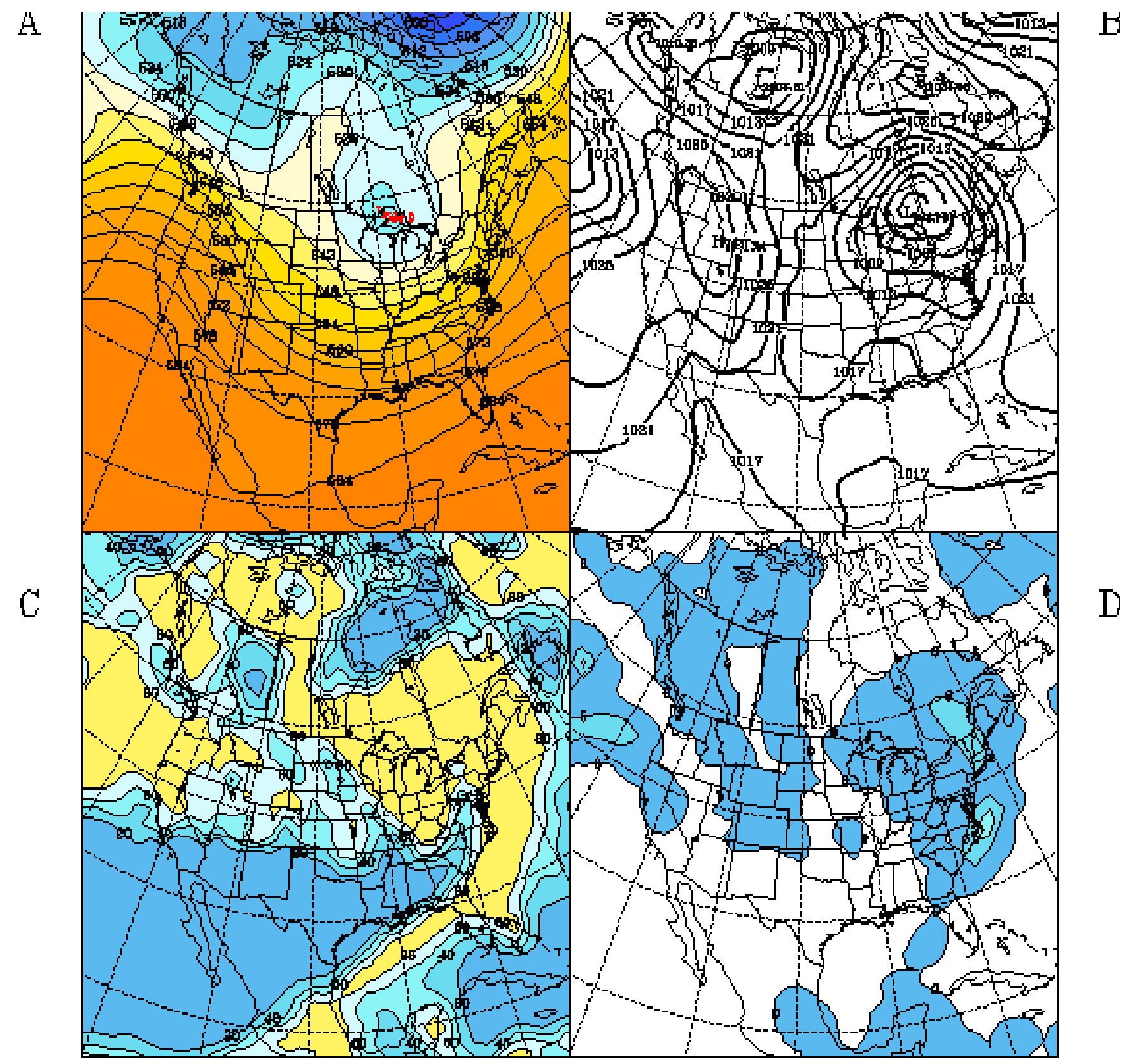

Figure 3-10 Graphical Model Output from the ETA Model 
AVN $191 \mathrm{~km}$

GRID POINT: 48.6547 .03 LAT.: 47.45 LON.:-122.30

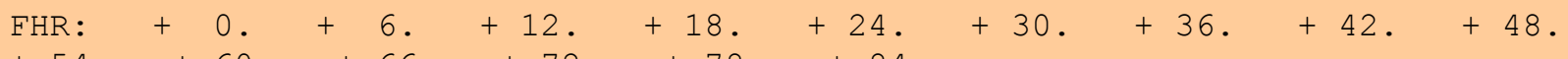

$+54+60+66+72 .+78 .+84$.

MEAN SEA-LEVEL PRESSURE IN UNITS OF HPA

$1011.411012 .70 \quad 1012.18 \quad 1008.951005 .15 \quad 1004.361007 .891011 .551014 .30$

$1017.61 \quad 1023.391026 .351029 .38 \quad 1027.72 \quad 1023.81$

2 M TEMPERATURE

$\begin{array}{cccccccccc} & 1.87 & 1.68 & 2.44 & 4.02 & 3.86 & 3.85 & 3.34 & 3.15 & 1.98\end{array}$

$850 \mathrm{MB}$ TEMPERATURE IN UNITS OF DEGC

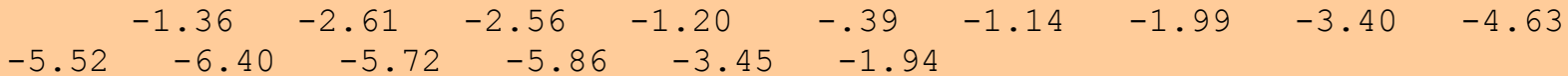

10 M WIND DIRECTION IN UNITS OF DEGREES

$\begin{array}{lllllllll}234.49 & 219.85 & 150.18 & 146.54 & 148.71 & 199.19 & 225.61 & 250.96 & 247.51\end{array}$

$\begin{array}{llllll}263.36 & 255.21 & 255.32 & 233.82 & 106.28 & 118.08\end{array}$

$10 \mathrm{M}$ WIND SPEED IN UNITS OF KNOTS

$\begin{array}{cccccccccc} & 5.52 & 3.46 & 6.22 & 9.26 & 14.70 & 11.98 & 12.90 & 9.27 & 5.08 \\ 6.65 & 6.79 & 7.16 & .41 & 9.14 & 16.09 & & & \end{array}$

6HR PRECIPITATION IN UNITS OF MM

$\begin{array}{lllllllllll}.80 & .40 & .16 & .30 & 3.38 & 4.69 & 2.87 & 1.44 & .49 & .71 & .66\end{array}$

Figure 3-11 Alphanumeric Data from the AVN Model

(While this appears complicated, predictive surface data could be utilized as input into

various BAS. This predictive data is for Seattle, Washington.) 


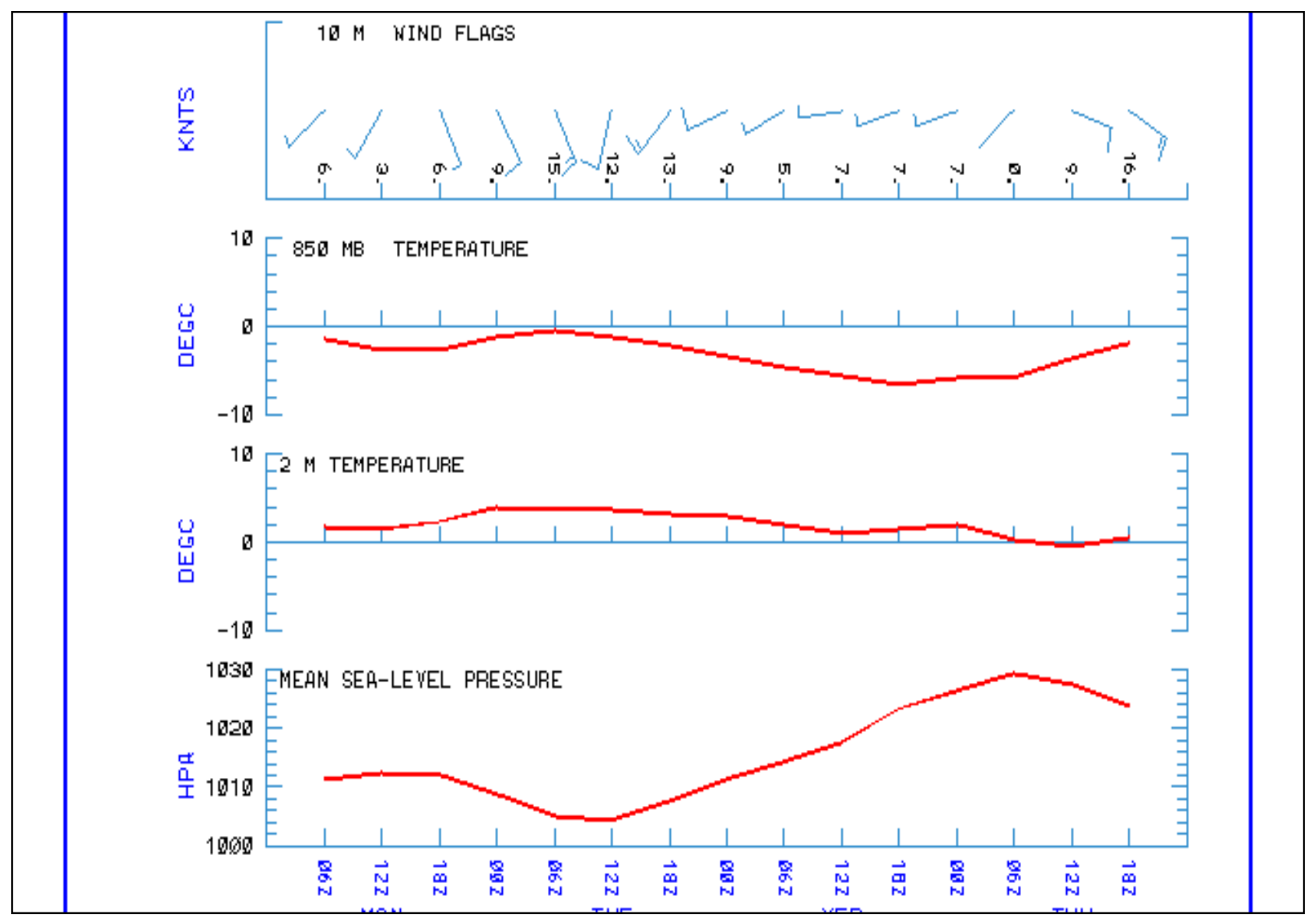

Figure 3-12 Graphical Output Representation of the Same Alphanumeric Model Data of Figure 3-11 


\subsubsection{Real-Time Traffic Data}

The use of real-time traffic data across the web has blossomed over the past few years. Every major city and many small- and medium-sized towns have traffic information that is readily available to users. Upon review of available categories of real-time web data, traffic data placed second. Real-time traffic data rely on road sensors, traffic cameras, and reports from police and fire departments and citizens. Real-time data are obtained from state or Federal Highway Administration road sensors that measure the speed of each vehicle that passes over them. The speed of vehicles crossing the sensor is calculated over a certain averaging time. The results are usually expressed in terms of a color code; green indicates the posted speed, yellow below speed, and red at near stopping speed. Weather data are also sometimes reported with the road data, thus providing another useful source of information.

Traffic data come in many forms. Figure 3-13 illustrates data in alphanumeric form. Data appear in the form of a chart indicating locations and causes of traffic delays. Data can also appear on maps or in a variety of other forms. Figure 3-14 shows alphanumeric data, weather data, and map data for I-270 near Washington, D.C. The alphanumeric data provide speed information for specific locations, and the map shows the whole picture. Weather data are provided as adjunct information for temperature and other hazards.

\subsubsection{Intelligent Tag Systems}

The use of Radio Frequency Identification (RFID) is not new. However the miniaturization of RFID has come a long way. The use of intelligent tag systems such as Intellitag (Transcore Inc.) has provided even more flexibility in this type of technology. Intelligent tag systems can measure as small as 45x80x1mm and operate in the low $900 \mathrm{mhz}$ radio band. These RFID tags have 1024-bit memory storage and can read/write to computer systems that are designed to sense information on the tag. The information can then be displayed on the web for further real or archive analysis. 


\begin{tabular}{|c|c|c|c|}
\hline San Diego & Condition & Route & Detail \\
\hline $\begin{array}{l}\text { Area Iraffic } \\
\text { links }\end{array}$ & & $\begin{array}{l}\text { I-5/San Diego } \\
\text { Fwy. South }\end{array}$ & $\begin{array}{l}\text { Expect delays Poinsettia Ln., Aviara Pkwy. - Carlsbad TO } \\
\text { MANCHESTER AVE. Delays. Expect delays. }\end{array}$ \\
\hline Advertising & & $\begin{array}{l}\text { I-5/San Diego } \\
\text { Fwy. North }\end{array}$ & There are no problems or delays to report at this time. \\
\hline
\end{tabular}

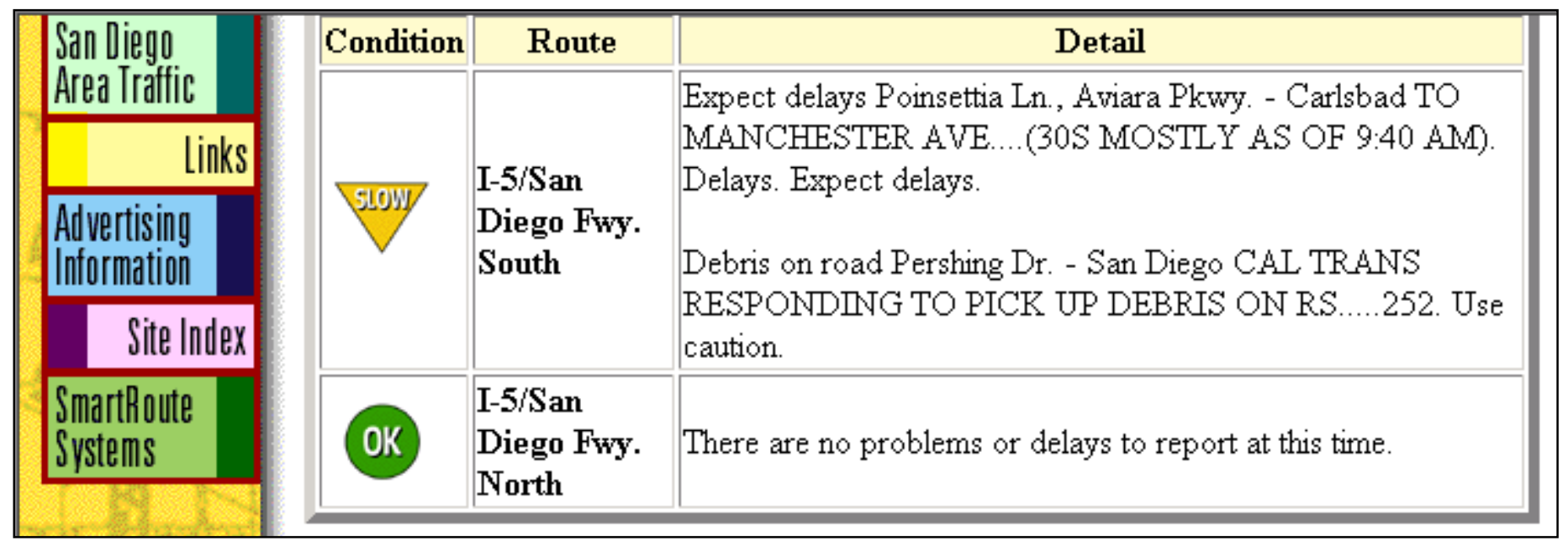

Figure 3-13 Example of Traffic Data in Alphanumeric Format 


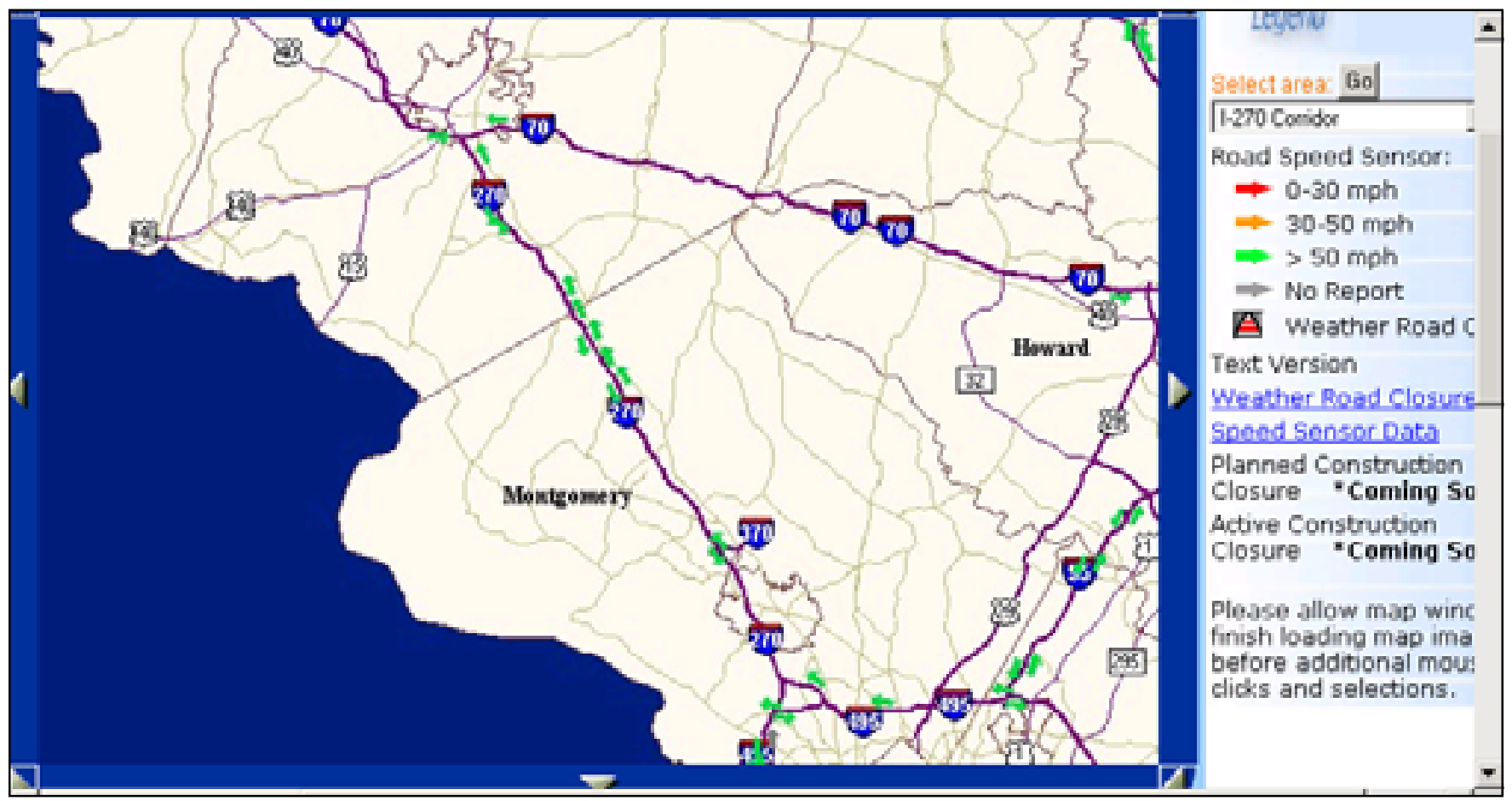

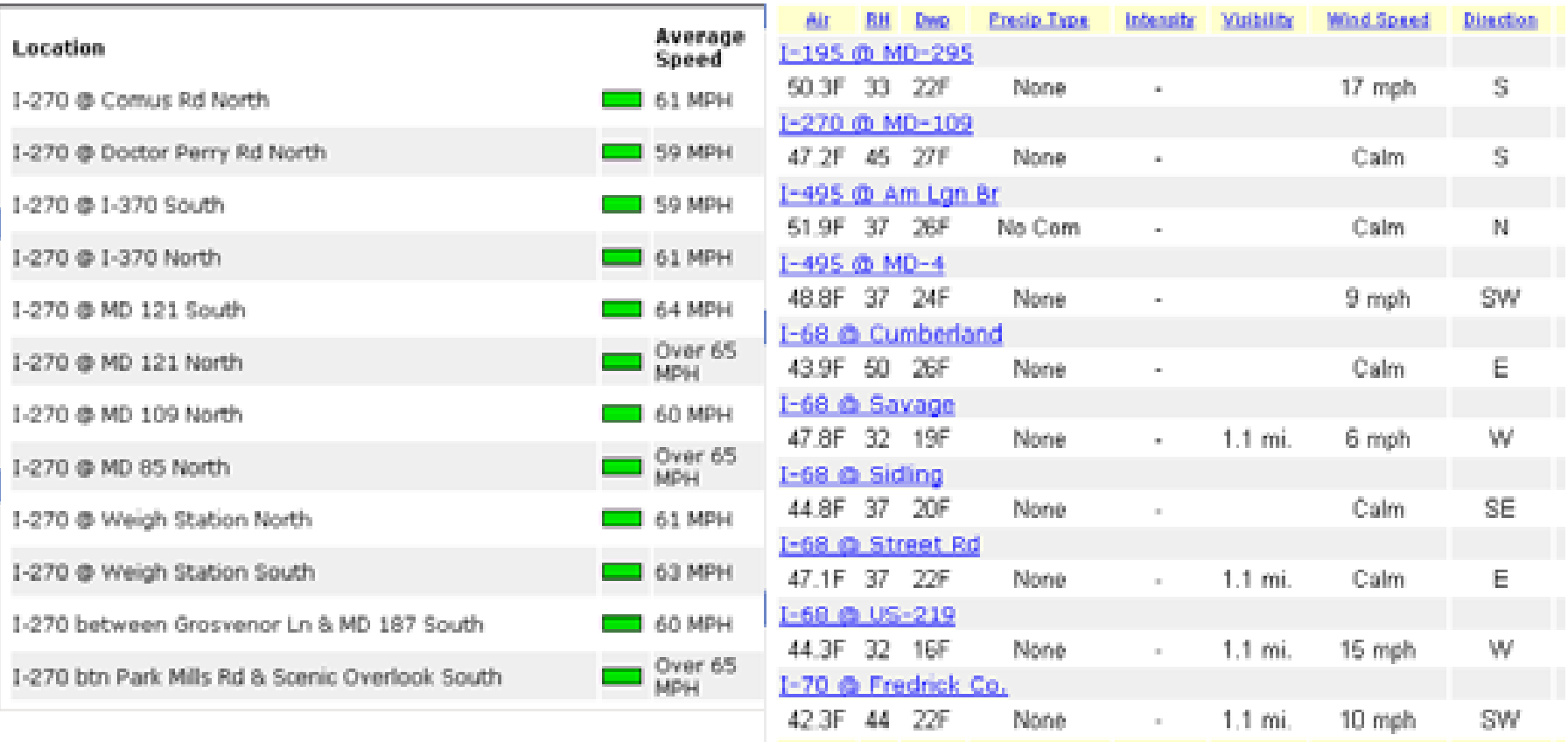

Figure 3-14 Example of Map/Alphanumeric Traffic Data with Weather 
These systems are typically used where fees need to be collected - at toll plazas or in building parking areas. They are also used in parking areas as a means of tracking movement. The advantages of such a system are tremendous, particularly with data now available over the web. They can allow recording of driving patterns, usage, time series analysis, etc. These data can then be interpreted in terms of parking trends, arrival/departure times, etc.

\subsubsection{Air Traffic/Airport Related Systems}

Air traffic related systems that provide real-time information over the Internet basically come down to the "fly FAA" site and various sites that track individual aircraft. Although there are a number of fee-oriented providers of information, the FAA site seems to provide the most comprehensive information in terms of airport delays. While the use of air traffic/airport realtime information for a building may be limited to hotels or other facilities that are linked directly to travel, nonetheless the information can prove to be valuable.

Airport delays including "ground stops" are displayed on the FAA's "fly FAA" website. There are two basic data views available: the map view and the tabular view. The map view in Figure 3-15 shows at a glance the status of airport delays. On this day, both Houston (IAH) and St. Louis are showing delays, with Houston in status red meaning more than a 45-minute delay. Figure 3-16 shows the actual situation at Houston, along with the situation at some other airports. The FAA to implement ground stoppage and hold procedures uses this information, which is updated frequently.

The FAA has recently developed an XML interface that allows users to import FAA data directly to their websites (this could allow for potential connectivity to certain building types such as hotels/reservation systems).

A second system allows individual aircraft to be tracked. Some vendors provide these systems for free, while others charge for more detailed information. GPS location equipment on board aircraft transmits a signal to the ground, where it is transferred to vendors for processing. It can track the characteristics of aircraft, the ETA, location, etc. The data are displayed on a 
map background or in text format. Many characteristics of the aircraft are shown that would not be of interest to a BAS (altitude, heading, aircraft type, etc.). However, ETA is a critical factor that could be utilized by buildings that have time-sensitive operations based on peoples' arrival times (hotels, for example).

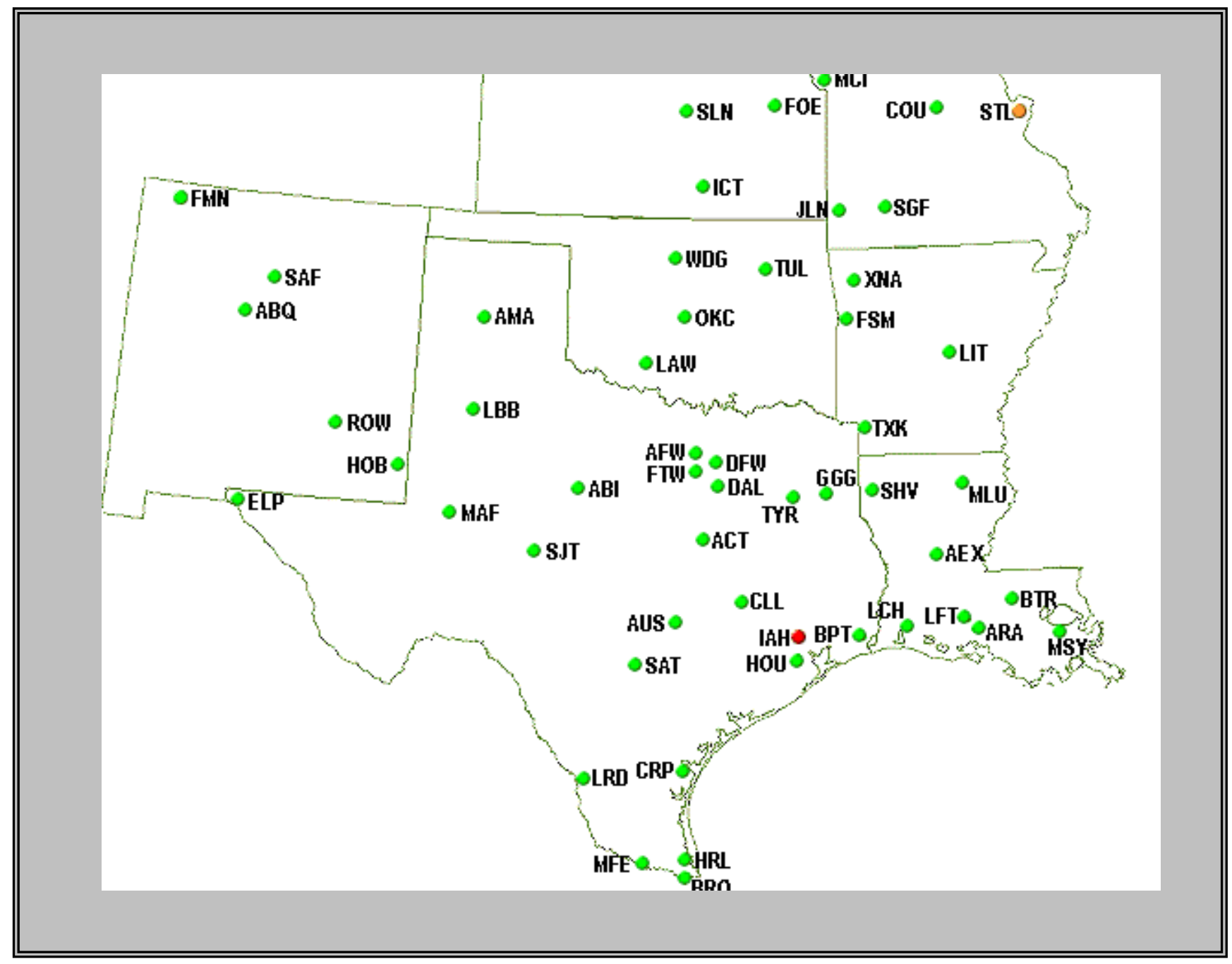

Figure 3-15 FAA Real-Time Status on Airport Delays

(Houston appears red due to delays greater than 45 minutes) 
George Bush Intercontinental/Houston Airport (IAH) Real-time Status

The status information provided on this site indicates general airport conditions; it is not flight-specific. Check with your airline to determine if your flight is affected.

\section{Delays by Destination:}

- Due to WEATHER, LOW CIGS/RAIN/WINDS, departure traffic destined to Chicago OHare International Airport, Chicago, IL (ORD) is currently experiencing delays averaging 1 hour and 14 minutes, with some flights receiving as much as 2 hours and 9 minutes delay.

- Due to WEATHER, LOW CIGS/SE PLAN, departure traffic destined to San Francisco International Airport, San Francisco, CA (SFO) is currently experiencing delays averaging 1 hour and 11 minutes, with some flights receiving as much as 2 hours and 21 minutes delay.

- Due to WEATHER, LOW CIGS, departure traffic destined to Lambert-St Louis International Airport, St Louis, MO (STL) is currently experiencing delays averaging 1 hour and 9 minutes, with some flights receiving as much as 1 hour and 52 minutes delay.

General Departure Delays: Due to TSTMS, traffic is experiencing Gate Hold and Taxi delays between 46 minutes and 1 hour in length and increasing.

General Arrival Delays: Arrival traffic is experiencing airborne delays of 15 minutes or less.

Figure 3-16 Specific Airport Information

(Figure shows status of Houston's Airport as well as other airports.) 


\subsubsection{Air Quality Systems}

The Clean Air Act of 1970, amendments to the Act in 1977, and additional amendments in 1991 have resulted in an improvement in air quality in the United States. The Act requires air quality to be monitored and reported to Congress yearly. This monitoring function is carried out by states under the guidance of the Environmental Protection Agency (EPA). Monitoring sites are located across the country, but in particular are focused on non-attainment areas that have failed to meet an air quality standard.

\section{Ozone-Related Data}

The most common non-attainment standard is that for ozone, a summertime pollutant frequently referred to as smog. EPA encourages states to publish live ozone-related data over the web. Data are collected on an hourly basis as well as an eight-hour averaged basis. EPA operates the AirNow site, which provides animated output of ozone concentrations in various parts of the country. Individual states or local air quality agencies operate their own websites to display air quality information. One such site, operated by the State of Maryland, is shown in Figure 3-17. This site has received more than 35,000 hits in one high ozone day. Data are sent from field monitors around the state to a central point where the data files are processed for web display.

Figure 3-17 shows the overall Maryland site along with the forecasted ozone-level for that day and the following day. These forecasts are prepared by air quality meteorologists and are placed on the site early in the morning. The site has the ability to focus on counties and to pull up specific information from individual monitoring stations. The use of such timely air quality data could be critical to building comfort issues. 


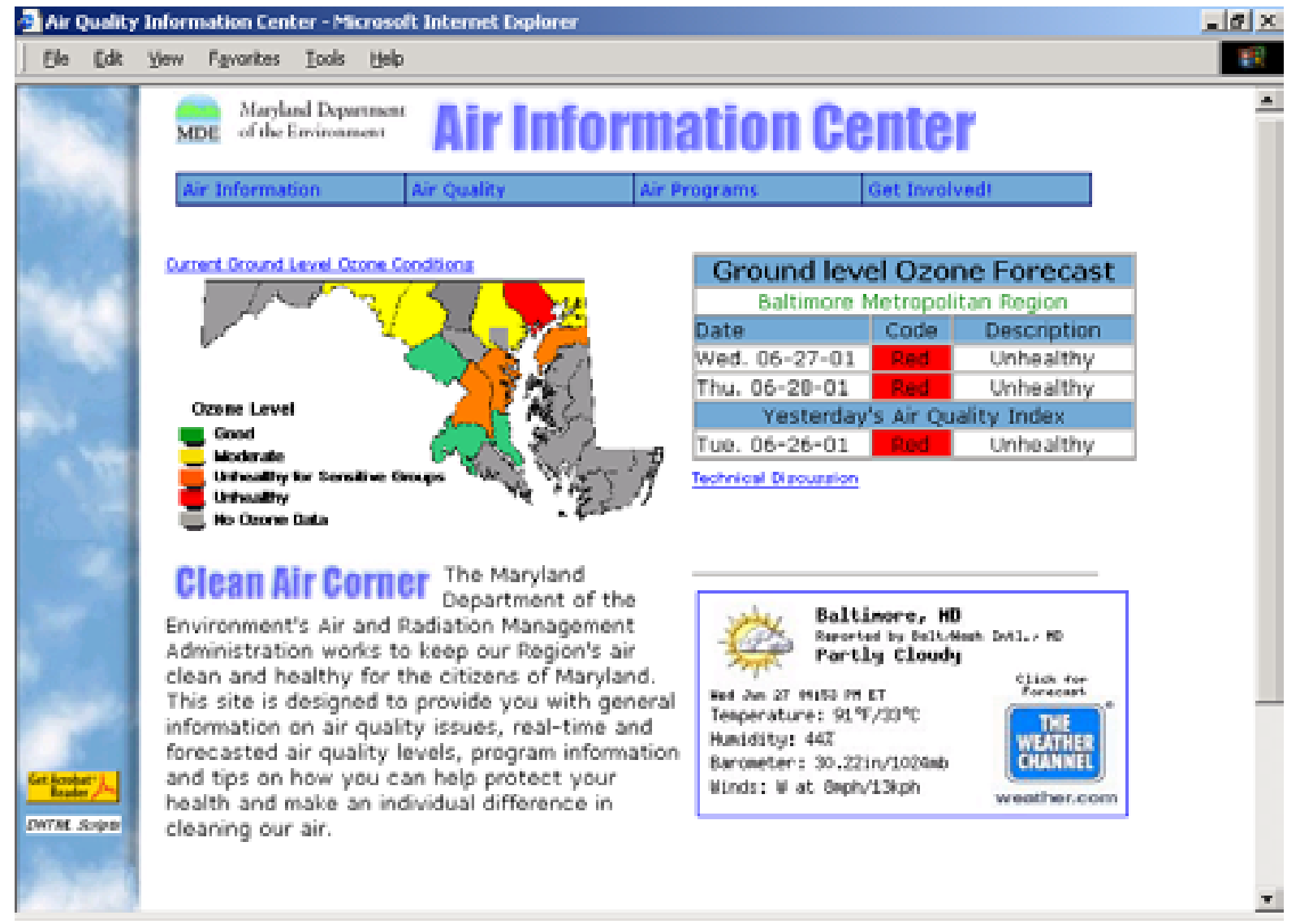

Figure 3-17 State of Maryland Ozone Site

(Website shows data/status of air quality in Maryland. Figure from Summer 2001 season.)

\section{Pollen Systems}

Many pollen forecast and data reporting systems exist across the United States. The most comprehensive system appears to be on pollen.com, which acts as an information portal for the compilation of all pollen data and resources (see Figure 3-18). Although this is a privately run site, it provides information to the public for free. Pollen counts are usually determined once a day in an area. The collection devices record the 24-hour average expressed in units of grains of pollen per cubic meter. There is usually only one or perhaps two pollen collection points in a community because it is assumed that pollen is uniformly distributed across a city or smaller area. 
Pollen forecasting is based on the meteorology and climatology of an area along with natural occurrences. Of prime importance is the contribution of each pollen allergenic to the overall pollen count. This is affected by plant and tree type and by season. Meteorology and historic climatology patterns come into play in terms of transport of the pollen and dispersion patterns. On pollen.com the data appear in forecast form in bar-chart graphics. The pollen index represents all contributing pollen allergenics in the area coupled with the historic and meteorological data. Data can be readily transferred from this site.

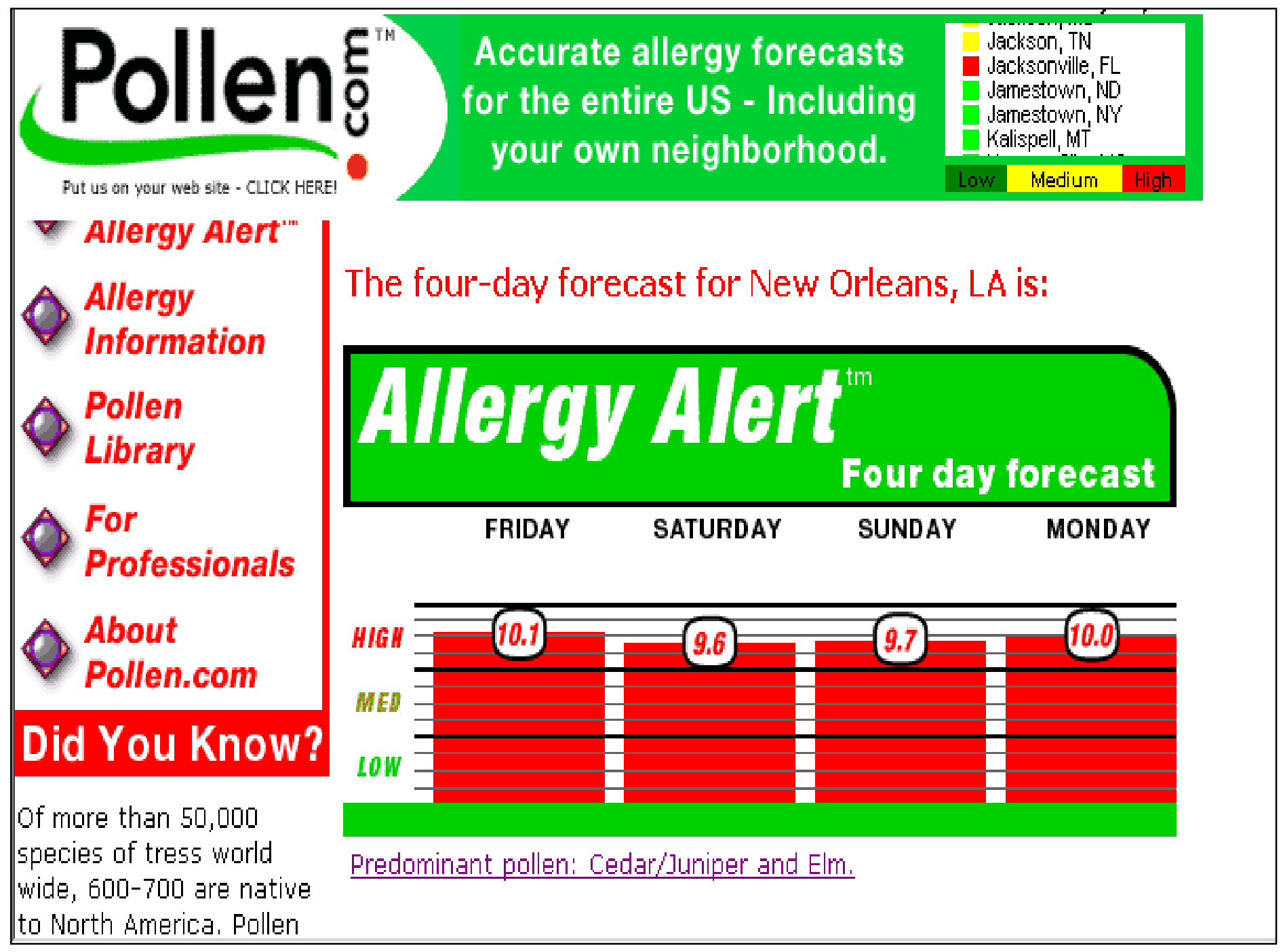

Figure 3-18 Pollen Web-Based Systems Provide a Wealth of Free Data 


\subsubsection{Lightning Detection Systems}

We define lightning detection systems as a separate real-time data category because of their use in the power systems community. Almost every utility in the United States has access to information about lightning and thunderstorms. The National Lightning Detection Network (NLDN) collects most lightning data in the U.S. The NLDN has 107 sensors across the country that measure the electromagnetic signals given off when lightning is discharged from a cloud. A sensor determines that a flash occurred based on five different electromagnetic signal criteria. The sensor compiles and sends the data via satellite to a central facility in Tucson, Arizona, where it is processed. Lightning is typically displayed 10 to 30 seconds after the actual strike.

The NLDN is a fee system. Scientists at the University of Arizona did the preliminary research and then formed a company to develop the network. The NLDN is currently undergoing an upgrade that should be completed by fall 2002. The upgrade will increase the number of sensors to 115 and improve the technology and communication systems. Figure 3-19 shows the typical lightning sensor configuration and how data are transferred to the Internet. The sensor detects the lightning and determines its location, strength, and type (+ or - charge). Those lightning attributes are sent via satellite to the NLDN, which processes the data and sends it back to the satellite for distribution to the user community.

The user community is diverse and includes the NWS, the FAA, and numerous other federal agencies (e.g., BLM, NASA, etc.). Private-sector clients include major sporting events and golf courses, industry, utilities, emergency management services, and the general public. There are various products and means to display lightning data based on different levels of service. Figure 3-20 shows some of the ways lightning data can be displayed and illustrates various map backgrounds for display of the data. Data can also be sent to servers and emailed. In terms of the spatial representation, data can be as fine or as coarse as a user requires. The top part of the figure provides a spatial representation of lightning data in the Chicago area. The software display provides range and bearing information to clusters or to individual strokes. The software also provides "buffering" display capability where users can see the general outline of the lightning part of the thunderstorm (the brownish contoured line). 

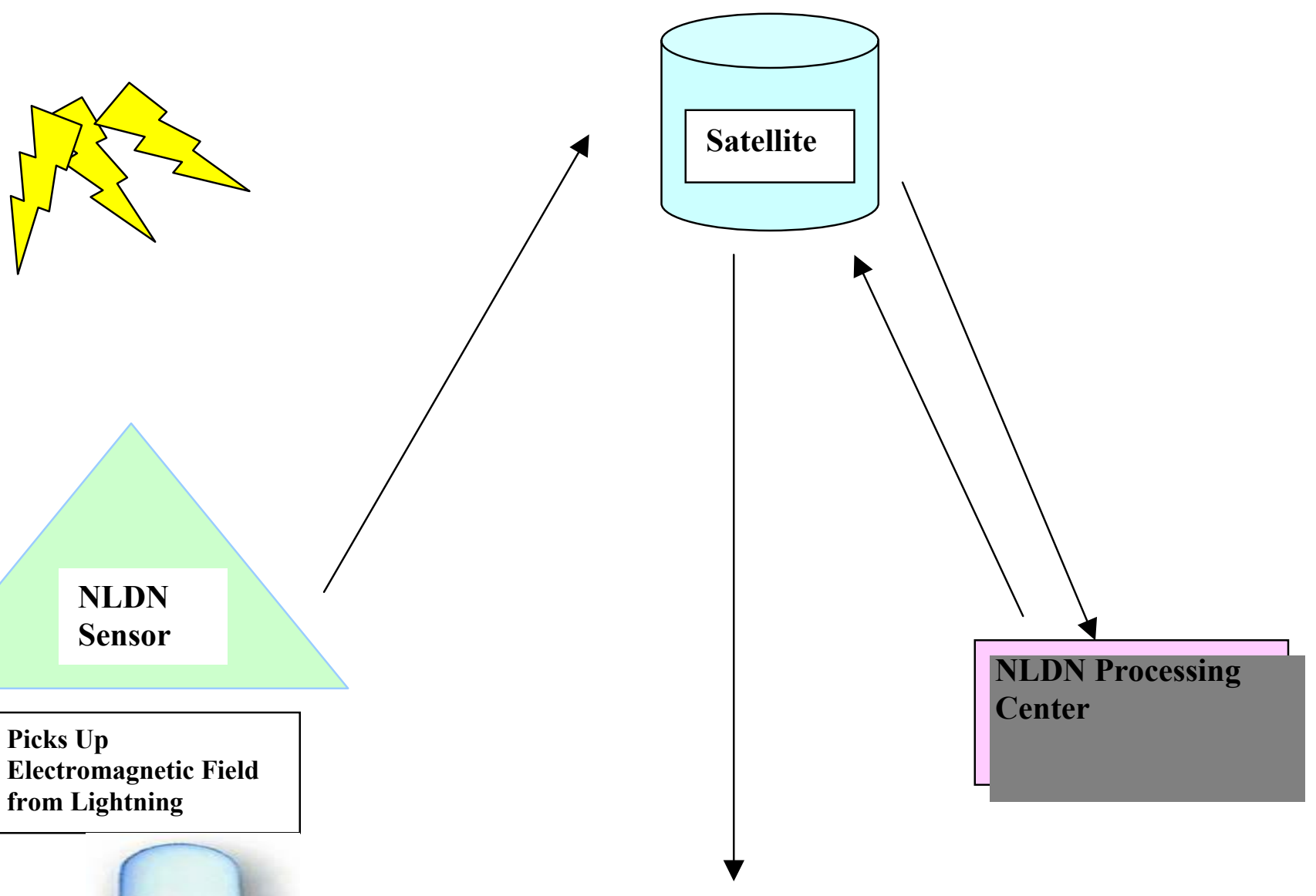

Picks Up
Electromagnetic Field
from Lightning

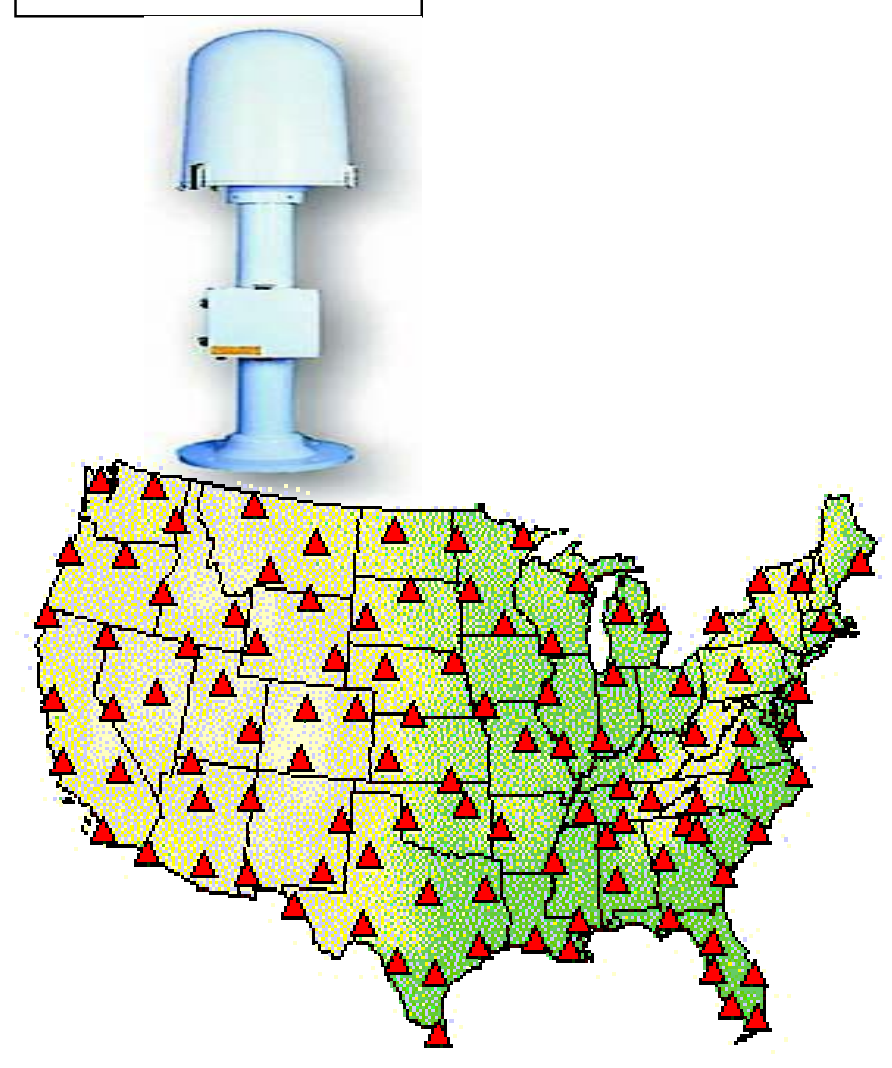

User Community:

- FAA, NWS, other Federal

- Emergency Mgmt

- Industry

- Airports

- Utilities

- Sports Events

- Insurance

- Other users/public

Figure 3-19 The National Lightning Detection Network Sensor and the Network Configuration 

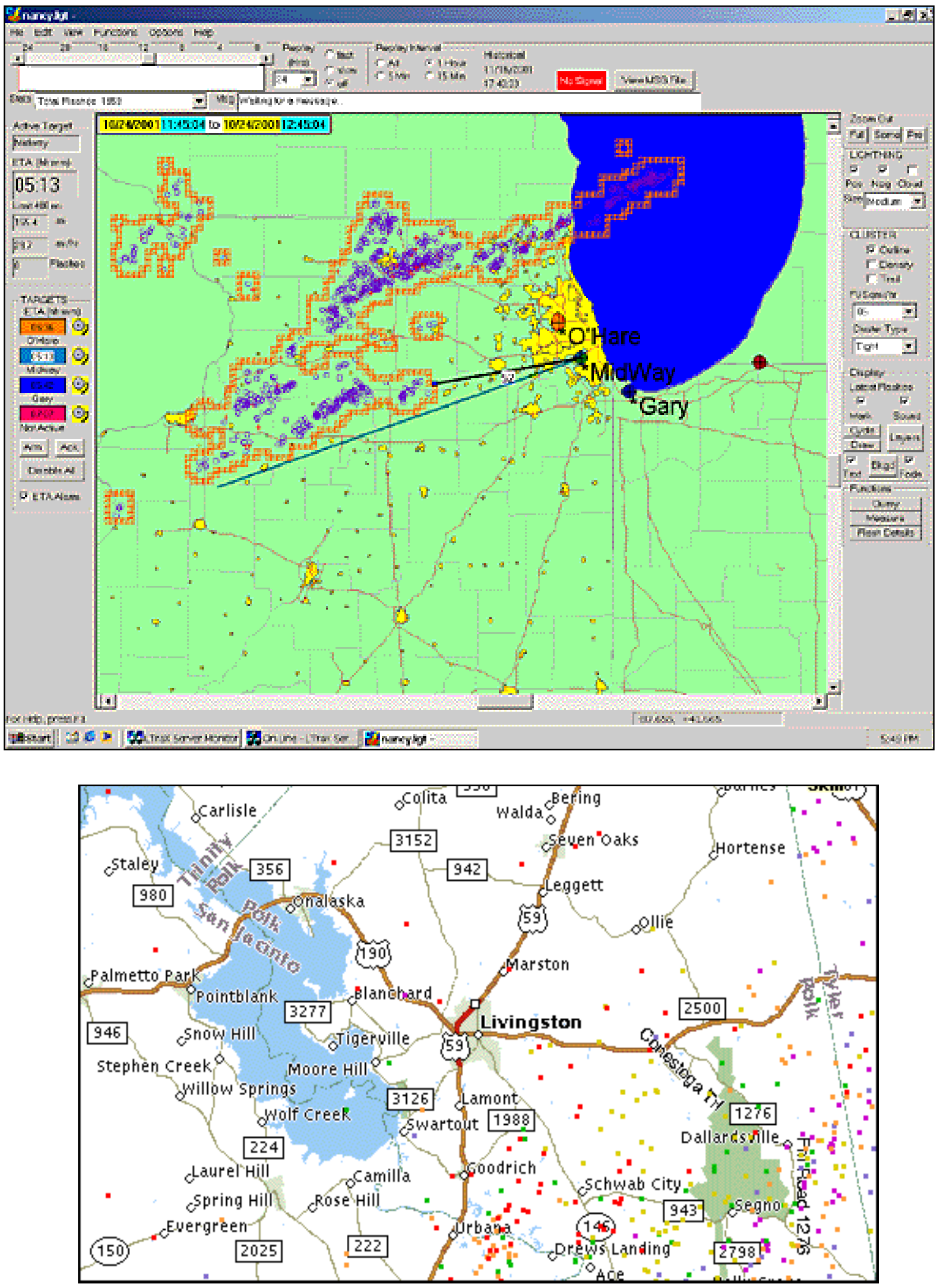

Figure 3-20 Typical NLDN Displays (fee-based tiered system) 
The bottom part of the figure shows the area to the northeast of Houston, Texas, and the associated lightning strikes. The strikes are colored to represent "aging." The red strikes are the most recent (last minute). The colors progress through the purples and greens and the yellows which are the most "aged" strikes" (about a half-hour old). The depiction of aging strikes can also help in determining movement of the storm.

\subsubsection{Geophysical-Astrophysical Data}

Space-based events or "space weather" can have an effect on buildings. The effect is most pronounced in terms of radio frequencies used for a wide variety of building functions, including wireless networking, some circuitry, the power grid itself, and some computer systems. Space-based data can also include tides and moon effects (moonlight, etc).

Space weather data are obtained from one source - the Space Environment Center (SEC). SEC is part of the National Center for Environmental Prediction (NCEP), which was described in Section 3.3 as the collection point for weather-related modeling in the United States. In coordination with NASA and the U.S. Air Force, SEC operates numerous space and land-based sensors including x-ray imagers and low-energy particle detectors.

While SEC produces many different products, the two of most use to this project are the Space Weather Bulletins and the Special Alerts. Space Weather Bulletins warn the user community of a space weather concern, such as major solar flares and solar radiation storms. In addition to time and duration of the storm, such a bulletin describes possible effects on radio frequencies, satellites, and other systems. Solar storms are rated by their potential effect on systems. The rating levels are $R$ for radio blackout potential, $S$ for solar radiation potential (affects mostly spacecraft), and $G$ for geomagnetic potential.

\subsubsection{Enhancing Real-Time Electric Energy Pricing Systems}

A wide variety of energy pricing systems appear on the web. These systems provide pricing information to various groups and users. These real-time systems could be linked to a 
BAS to enhance existing energy pricing systems. This would most likely be useful for a building complex or a campus rather than an individual building situation. For example, if a building complex generated excess energy, perhaps the excess could be priced accordingly into the energy marketplace. A larger complex could use real-time information from a web energy system to give it a "heads-up" that power interruptions could occur that day.

Many energy price/trading systems exist on the web today. One of the largest systems is the California OASIS (Open Access Same-Time Information Access System). The California Independent System Operator (ISO), a company formed to deal with managing energy in California, runs this site. The site is quite complicated and contains many pieces of information designed to facilitate the trading of energy in the state. For example, it shows the current loads at various points throughout California, as well as the load on the entire system. If there are problems, the site would identify their location and the effect they are having on the system. A subset of the site called CASIO provides current pricing information. 


\subsection{Accreditation of Real-Time Information/Sites/Providers}

Unlike some websites (such as those in the healthcare field) that are moving toward accreditation, the real-time websites related to this project are not subject to accreditation by any organization. However, there are many web accreditation initiatives that could be used to draw on some form of accreditation standards. But before we consider accreditation, we must first address the issue of quality control.

\subsubsection{Extent of Accreditation-The Quality Control Foundation of the Stakeholder}

The issue of accreditation of real-time websites is a difficult one because many real-time sites have their origin in the U.S. Government (e.g., National Weather Service sites). A key element of accreditation is quality control (QC), and government-oriented sites or sites that utilize government-oriented data (e.g., private weather radar sites) clearly have an edge over private-sector sites.

For example, NWS data go through vigorous QC procedures including a human discussion of the quality of data or predictive model output. Figure 3-21 provides an example of such a discussion. From the figure, the human interventionalist has agreed with the suggested computer generated QC scheme and has made all the corrections to the weather data set as indicated. Thus, if NWS weather data is used for any BAS-Internet interface work, users can be very confident of its quality. In addition, NWS data have a long history of use in the U.S. court system as a legitimate means to prove aspects of forensic meteorology cases (assumed good, unless otherwise noted). It is difficult to determine the quality of the private-sector weather data (e.g., the school AWS system described in Section 3.3.1/Figure 3-9). GEOMET contacted AWS for QC type information but did not receive a response. This network is quite extensive throughout the U.S. and has a detailed service and maintenance policy. The vendor monitors the condition of the equipment and offers quarterly maintenance procedures that can be utilized by the user. A recent agreement between AWS and NWS to share information should help in QC. 
201330Z... THE 12Z HCEP MODEL CYCLE IS OFF AHD RUNHIYG.. THE ETA STARTED OH TME AT 1315Z. . RAOB RECAP.. OVERALL GO0D COVERAGE AKD QUULITY OF $12 Z$ UPA DATA OVER HORTH AMERICA.. RHK/72318 . . HOT AVAILABLE. . KCR/78384 . . HOT AVAILABLE. .

SGF/72440 . . HO PART TTAA. . PLS SEYD IH. . TKS. .

TLH/72214 . . DELETED BAD/HIKDS ERRATIC 110MB AKD UP..

KJP/78397. . DELETED BAD/HIMDS ERRATIC 16GIB AMD UP..

ZAC/76526 . . DELETED BAD/HIUDS DIR 250MB AHD UP..

CRP/72251 . DELETED BAD/HIHDS ERRATIC BETHEEH 160-60MB LEVELS.. OHX/72327. . DELETED LOH/HGTS AKD COLD/TEHPS 125UB AHD UP.. PBZ/72520 . . DELETED LOH/HGTS AHD COLD/TEHPS 210MB AHD UP.. DTX/72632 . DELETED LOH/HGTS AKD COLD/TEHPS 1204B AHD UP.. AMT/70398. . DELETED LOH/HGTS ARD COLD/TEHPS 1004B ARD UP.. CUI/7659. . DELETED EHTIRE 12Z REPORT FOR AVH DUE TO CODIHG ERROR. .

AMD THERE HERE 9-MEXICAH UPA REPORTS IH FOR THE ETA/HGH..

FYI. . A GOES-8/EAST DOD RESEARCH SRSO HILL TAKE PLACE FROM $20 / 1843 Z$ TO $20 / 2143 Z$. .

Figure 3-21 Example of Human QC as a Form of Accreditation for NWS Weather Products

(Human QC below refers to deletion of various forms of weather data including Mexican data and the inclusion of GOES satellite data. This $Q C$ was based on a computer recommended $Q C$ approach, which the human agreed with.)

Table 3-13 provides a brief summary of other real-time systems and the QC process. For most real-time data streams, vendors either rely on equipment specifications to be within range or they will not fully release QC type information. 
Table 3-13 Summary of QC Procedures for Potential Real-Time Web Data Streams

\begin{tabular}{|c|c|c|}
\hline Real-Time Data Stream & $\begin{array}{l}\text { Some Form of } \\
\text { QC or } \\
\text { System/Sensor } \\
\text { Maintenance }\end{array}$ & Comments \\
\hline NWS Observations & Yes & Very comprehensive checks \\
\hline $\begin{array}{l}\text { Privately Enhanced NWS Observations } \\
\text { (private vendors take NWS products and } \\
\text { value-add to them) }\end{array}$ & Yes & Good \\
\hline NWS Models & Yes & Very comprehensive checks \\
\hline $\begin{array}{l}\text { NWS Radar and Privately Enhanced } \\
\text { NWS Radar }\end{array}$ & Yes & Very comprehensive checks \\
\hline Other Federal Weather Observations & Yes & Good \\
\hline Private Observations & Yes & $\begin{array}{l}\text { Maintenance done mostly by user } \\
\text { location; electronically monitored } \\
\text { by vendor for troubleshooting }\end{array}$ \\
\hline Traffic Data & Yes & $\begin{array}{l}\text { Only for sensors, not data } \\
\text { feeds/processing }\end{array}$ \\
\hline Intellitag Type Systems & No & $\begin{array}{l}\text { QC would need to be set up on a } \\
\text { per system basis }\end{array}$ \\
\hline Airport Status & Yes & FAA confirms data correct \\
\hline Aircraft Status & $?$ & Could not find this information \\
\hline Air Quality Systems & $\begin{array}{l}\text { Yes, } \\
\text { sometimes } \\
\text { limited }\end{array}$ & $\begin{array}{l}\text { States are required to audit AQ } \\
\text { systems, but only in retrospect } \\
\text { after ozone season is done. }\end{array}$ \\
\hline Pollen Systems & Yes & $\begin{array}{l}\text { Equipment maintenance \& } \\
\text { incorporates NWS data }\end{array}$ \\
\hline NLDN-Private Lightning System & Yes & Very comprehensive checks \\
\hline Space Weather Data & Yes & $\begin{array}{l}\text { Fair checks, government site } \\
\text { doesn't warrant data quality }\end{array}$ \\
\hline Energy Purchase/Real-time systems & Yes/limited & $\begin{array}{l}\text { Private and ISO, some formal QC } \\
\text { programs. Hard to determine, } \\
\text { quality situation believed } \mathrm{OK}\end{array}$ \\
\hline
\end{tabular}




\subsubsection{How to Provide Accreditation-Development of Guidelines}

Providing accreditation for real-time web data to be used by the BAS community may be difficult because the nongovernmental websites would need to see the value in being accredited specifically for BAS use. It may be helpful to consider the experience of other types of web accreditation efforts, such as that in the healthcare sector.

The URAC organization (www.webapps.urac.org) was developed to provide accreditation within the healthcare community, and one of its recent efforts has been to provide accreditation of all healthcare websites (Figure 3-22). This was driven by the need for accurate medical information and the sense that the public was getting cheated by some of the healthcare web developers.

Adopting the format of the URAC standards document, a real-time web accreditation document or a series of guidelines would need to have some or all of the following elements:

1. Mission and purpose of the accreditation process

2. Clear definition of terms

3. Disclosure of services provided

4. Content and service delivery

5. Linkages

6. Data security

7. Accountability

8. Policy and procedures

9. Quality oversight committees

The purpose of the accreditation process would need to be clearly spelled out. Here is where there may be the most resistance because private vendors may balk at accreditation especially if they perceive the marketplace as being narrow (even though it is not). 


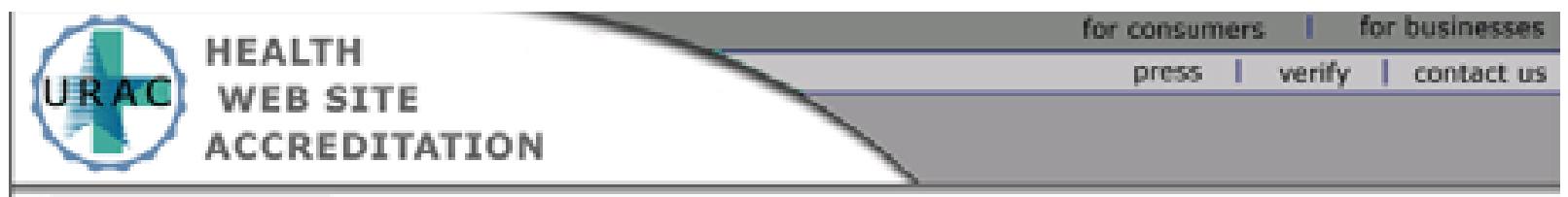

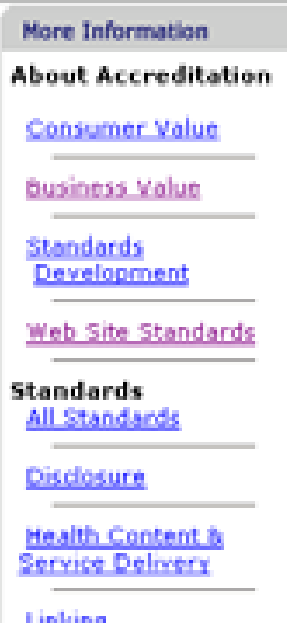

URAC's 50+ Rigorous Standards Help To Build Quality Health Web Site That Consumers Trust

When consumers see the URAC Health Web Site Accreditation Seal, they are assured that they are visiting a trustworthy site.

URAC has more than 10 years experience creating high standards of quality and accountability for health care companies. Our rigorous evaluation process, called accreditation, is a process to measure your ablity to meet more than so stringent, consumer and business-oriented qualty standards. URAC's Health Web Site Standards were designed to ensure that expectations for receiving quality. trustworthy services are being met

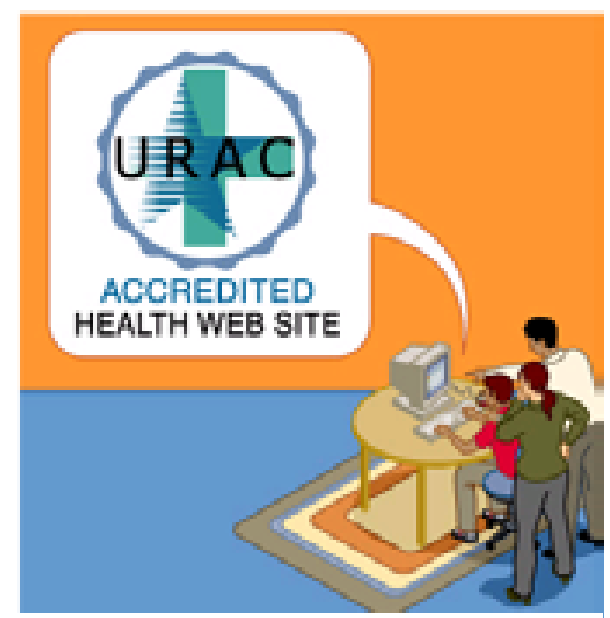

Standard wS 47

The ownerestablishes a grakity orersigit cowswitre. (see definition)

\section{Standard wS 45}

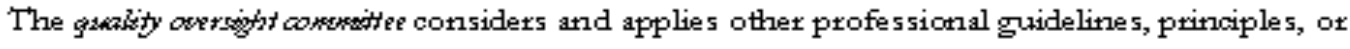
ethics codes as appropriate to its heabh content, andienoe, and goals.

\section{Standard wS 49}

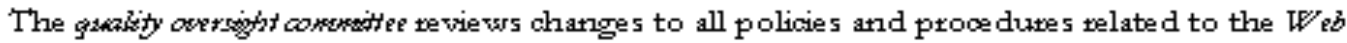
site.

\section{Standard wS 50}

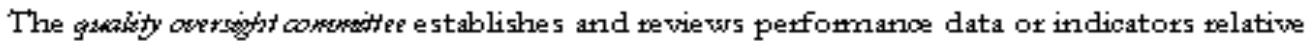
to the $W \mathrm{e} b$ side at le ast quatterly and implemerts irterventions incases where the data indicate deviations from stated policies.

\section{Standard wS 51}

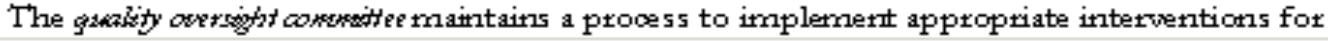

Figure 3-22 Example of Website Accreditation in the Health Services Field (WS = Web Standards (50+ standards). The example shown involves some of the QC oversight standards.) 
There would need to be clear definitions of terms used by the vendors.

The disclosure of services provided could include a comprehensive listing of the realtime data that the site provides and how the data are collected. This part of the accreditation process would allow the user community to understand the scientific foundations of the data collection process.

Content and service delivery would describe exactly how services and data would be delivered to the building-user community. It would specify certain file formats or other parameters to allow for communication to existing systems. Sites would need to meet these specifications in order to successfully transfer data.

While the URAC accreditation process for health websites puts considerable emphasis on linking, it is unclear how much attention needs to be paid to linking for the building-user community.

Data security would be paramount in the accreditation process given the already sensitive nature of BAS-related users and the sometimes sensitive nature of real-time website data vendors. Security audits of vendors' sites may be necessary in order to ensure that data are sufficiently secure to meet BAS specifications.

Accountability would refer to the enforcement of the guideline. This means who is going to do what to whom and when. In addition, following the URAC document, accountability also refers to providing a feedback mechanism to the user, so that he or she can hold the vendor (website) accountable for its information.

Some real-time sites already have extensive policies and procedures. Others have limited policies or none at all.

Finally, the quality oversight committee concept forces the website not only to have QC procedures in place but also to have a body that oversees those procedures to ensure compliance 
and enforcement. Implementation of this aspect of the accreditation guidelines or plan would require either housing such a body in an existing building systems organization or developing a new organization. The URAC healthcare website accreditation process calls for the QC committee to be at the vendor location. Thus, in a real-time web data situation, the committee could be composed of vendor personnel, representatives from the user community, and national representatives from a building systems organization.

The URAC approach holds some promise. However, the major stumbling block may be the opt-in/buy-in of the data vendor community. There needs to be an economic incentive for that community to buy into an accreditation plan. 


\subsection{DISCUSSION}

\subsection{Considerations for Integrating Real-Time Data}

This review takes a top-down approach to the analysis of a real-time Internet data system for use with building automation systems. An end-to-end review of the system is necessary to capture system constraints that limit the design parameters. Internet content is openly accessible, but the interaction of clients and servers is constrained by the context of Internet protocols. Our intent is not to provide a redesign of the network protocols but rather to identify the structural elements of a real-time data system that operates on the Internet.

The fundamental architecture of a real-time data system for building controls is similar to the standard client/server architecture used in most computer networks. In many computer networks, clients can become servers and servers can act as clients. Therefore, it naturally follows that the architecture of a real-time Internet data system is bounded by the underlying principles of computer networks.

The astounding growth in the use of the Internet, with its reliance on Internet Protocols (IP) for routing, the Transmission Control Protocol (TCP) for data packet management, and the Hypertext Transfer Protocol (HTTP) for requesting and receiving HTML data, has demonstrated the attractiveness of an open "highway" for data and a common language for worldwide clients and servers. The advantage of a direct and complete connection via a dial-up link must be weighed against the advantages that the Internet provides by always being on, the breadth and depth of available server connections, and a low marginal cost.

Private intranets offer many of the advantages of both a dedicated link and the Internet, but a significant amount of data traffic is needed to justify the high installation costs.

A dedicated line or a private intranet provides the option of developing and using specialized protocols for device addressing, data transfer, and client/server interaction. This approach works well when the network system is used internally within an organization or 
group, and throughput of application data is more important than interoperability. However, specialized protocols are time-consuming to develop, and protocol management by the application developers can impede the widespread adoption of those protocols. The protocols used by the Internet for data transfer and web browsing are open for discussion and recommendations, and they are adopted by broad consensus. This practice provides a stable and robust platform for the deployment of remote clients and servers running applications that are designed around stateless data transmission. Applications, which require significant client/server interaction, typically have been localized and have physically partitioned data channels, partly because most applications started from small-scale projects but also because of the significant challenge of properly implementing distributed computing.

It is often said that HTTP service over the Internet is stateless. However, it is more accurate to say that HTTP services do not implicitly maintain state. The HTTP/web service is conceptually designed to serve tagged HTML content to multiple clients with little provision for ongoing interaction. Also, to ensure a robust and stable backbone for text transfer services, TCP/IP was conceived and designed to allow data transfer between routing devices using data packets so that the impact of the loss of one or more data packets does not bring down the entire transmission, and alternative routes can be used if one route is momentarily blocked.

Data-packet routers make no connection between the packet before or after the one being routed. In contrast to services residing on a PC or a Local Area Network, with HTTP services it is not practical or efficient to maintain an open data stream between the HTTP service and the client; nor is it practical to maintain a listening connection for each of the many possible clients. Thus, each HTTP request for an HTML page normally starts a new session that is terminated upon completion of the response. Ongoing interaction between a client and server, an expected operational parameter of a real-time data system, will probably require a data-interface layer to maintain this interaction and ensure a robust system. 


\subsubsection{Remote Client/Server Interaction}

Real-time data system architecture is constrained by the type of data interface needed. Data interfaces can be grouped into three categories: broadcast, simple request/response, and Structured Data Services Data that are highly standardized and require no customization may be suitable for broadcast delivery, whereas highly specialized data may require multiple dialogs between the client and the server to refine the requirements of the request and achieve the appropriate response (structured data services).

Program content provided by cable system operators for television is a broadcast link. This architecture provides a one-way, simultaneous link between a central "station" and multiple reception clients: Clients select the data they need and ignore the rest. This type of data interface has potential problems regarding scalability and security, but access to cable connections are prevalent in urban and suburban areas for a relatively low cost. Additionally, the data-transfer process is robust, although the client interface is brittle because of the limited ability to update legacy clients. For example, the Weather Channel uses such a system to distribute data over cable TV. Because of bandwidth limits, the Weather Channel places a priority on the type of data it uses, which results in a variable latency for some data types.

A simple request/response data interface is used to serve HTML (web) pages over the Internet. An HTTP message is sent to an IP address specifying a Uniformed Resource Locator (URL), some information about the requestor, the type of data the requestor will accept, and possibly one or more name/value pairs. The HTTP service at the IP address receives the request, formulates a response, and sends it to the requesting IP address. This type of data interface has advantages over a broadcast data interface because the client can request data only as needed, and moderate customization can take place prior to responding to the data request. Thus, the scalability of the overall system is increased, and secure encrypted connections are possible.

The disadvantage of this type of data interface is that each connection requires processing overhead on the HTTP server, placing scalability constraints on the server. Also, although the robustness of the data interface is increased because clients can be notified of 
version changes in the server request/response structure, the simple request format limits the amount of customization of the interface and response to the needs of the client (e.g., if there is a delay in posting new data on the data server, then the client cannot be notified when it is available).

The final type of interface - Structured Data Services (SDS) — consists of customized data requests through remote procedure calls, remote object requests, and requests for servlets (data and applications provided to clients). Data services are highly customizable and are able to provide a broad range of data types and hold dialogs between the client and the server to refine data requests. This type of interface is oriented toward integrating applications rather than just transferring data. At first glance, a real-time data system seems to be about getting and serving data with little need to integrate applications, but there is a strong need to validate the inputs into the BAS and provide for intelligent fault recovery if the data system undergoes sudden change.

Structured data services also make use of data transfer protocols other than HTTP. The early years of the World Wide Web were focused on serving HTML and scripted forms to human users. In recent years, large global companies have discovered that the Internet offers excellent business-to-business (B2B) integration opportunities, where enterprise applications talk worldwide. These enterprise applications use XML and services and protocols in addition to HTTP. Developers in this field talk in terms of document-oriented object structures versus dataoriented object structures, reflecting the needs of the end users of the objects-man or machine. Because structured data services are based on many of the B2B concepts, they offer a more robust environment for data communication with the BAS. The disadvantage of these services is that they are complex to develop and implement, and require more processing overhead and bandwidth.

\subsubsection{Real-Time Data Management}

A simple model of the real-time data management process consists of four main steps: data acquisition,

- Data validation, 
- Data channeling and,

- Data utilization.

This model presumes that the communication flow is mostly one-way: from the data source to the building control system. This type of process would lend itself to a broadcast data interface because data are merely being pushed to the BAS client.

However, there is a high likelihood that the data-utilization part of the process will need to refine the data received because of the data limits of a broadcast system. The broadcasting source must send out all the data for all clients in each transmission, which works well for general parameters in the area of the broadcast, but as the resolution of the parameters is increased, the size of the data sets increases rapidly. Because building managers tend to be interested in localized data, this is a legitimate constraint on the design of a real-time data management system.

The nature of real-world environmental and human-sourced data is also a consideration when these data are being collected, validated, and used. Unlike Internet transmission data packets, data points for real-world phenomena typically have some spatial and temporal relationship to nearby data points. These relationships are useful for determining data collection needs, validating the quality of data, and compressing data transmissions. They also provide opportunities to optimize the data-transfer process because the client can instruct the data server to provide greater resolution of specific parameters as those parameters change. There also is a fundamental aspect of distributed computing in the real-time data management process, where the client and the server not only collaborate to manage the data-transfer process but also may collaborate to enhance the usefulness of the real-time data provided to the BAS. Where each component of the data management process will reside is dynamic and not limited to one physical location. Although it is expected that the data servers for this process will be specialized enterprise application interfaces, the data server in each case is any IP address providing data to a BAS client. BAS clients may also act as servers to share data with other data servers and, possibly, with other BAS clients. 


\subsubsection{Data Acquisition}

Data acquisition is the process of gathering real-time data from a measurement point. The acquisition process is not central to the data management process, but it is central to the data quality. The quality of the data should be verified as early in the data-acquisition process as feasible. Each new conversion or translation of the data will very likely interject additional error into the measured values. Self-calibrating measurement devices are a good start in quality control, but it is clear that sensors with the intelligence and ability to report their quality assurance (QA) parameters are needed to make this part of the system more robust. Three important characteristics can affect the quality of data acquired from measurement devices: latency, precision of measure, and accuracy to measured result (see Table 4-1). Most measurement devices provide high-quality data within only a narrow range of environmental conditions. Thus, the use of raw readings without knowledge of the environmental conditions impacting the device increases the potential for error.

\subsubsection{Data Validation}

Validation of acquired data is a key part of the data management process. It is vitally important to verify the quality of data prior to use in a BAS. Ideally, the data should be validated at each step in the collection and distribution process, but that is difficult to achieve in practice. No data measure is 100 percent true, but some measures are more accurate than others. There are several simple approaches to determining the accuracy of a data measure range from percentage scaling to specification of error ranges. The simplest approach is to use a threshold criterion, whereby all data failing the minimum accuracy test are discarded.

\section{Table 4-1 Data Structure-Acquisition Characteristics}

1. Latency (timeliness): time difference between the proxy measure and the availability for posting

2. Precision: the degree of refinement or how closely the recorded result matches the measure of the proxy

3. Accuracy: includes the following sub characteristics:

3.1. Proxy accuracy: how close the measured proxy(ies) matches the behavior of the desired event measure.

3.1.1. Scaling accuracy [of the measurement magnitude]: Is the measured proxy similar in scale to the desired event measure? 
Table 4-1: Data Structure Acquisition Characteristics (continued)

\begin{tabular}{|c|c|}
\hline 3.1.2. & $\begin{array}{l}\text { Sampling accuracy: Does the sampling rate yield a match between the } \\
\text { direction of change between the measured proxy change and actual } \\
\text { proxy change? }\end{array}$ \\
\hline 3.1.3. & $\begin{array}{l}\text { Spatial accuracy: ow close the measured proxy matches the behavior } \\
\text { of a spatially separated event measure. Does not encompass } \\
\text { deterioration of a signal between measurement point and nominal } \\
\text { representation. }\end{array}$ \\
\hline \multicolumn{2}{|c|}{$\begin{array}{l}\text { 3.2. Conversion accuracy: pertains to changes due to remeasurement - substituting a } \\
\text { new proxy for the old proxy - of how close the nominal representation of the } \\
\text { proxy measure matches the behavior of the proxy measure. Signal deterioration } \\
\text { also falls under this characteristic (e.g., deterioration of an analog signal, such as } \\
\text { line pressure, prior to measuring with digital device). }\end{array}$} \\
\hline \multicolumn{2}{|c|}{ 3.2.1. Variance: changes in the measured proxy values due to: } \\
\hline & 3.2.1.1. Noise: unknown random changes. \\
\hline & $\begin{array}{l}\text { 3.2.1.2. Bias or drift: slow changes in measures of proxy values } \\
\text { relative to actual proxy measures. Systematic error. }\end{array}$ \\
\hline \multirow[t]{3}{*}{ 3.2.2. } & $\begin{array}{l}\text { Re-proxy (proxy conversion): matching a new proxy to an old proxy } \\
\text { (e.g., using a change in voltage to measure electrical resistance change } \\
\text { due to temperature change of resistor). }\end{array}$ \\
\hline & $\begin{array}{l}\text { 3.2.2.1. Scaling accuracy: how closely the scales of the pre-translation } \\
\text { measure match the post-translation measure. }\end{array}$ \\
\hline & $\begin{array}{l}\text { 3.2.2.2. Sampling accuracy and the proximity between old measure } \\
\text { output and new measure input are implicitly considered. }\end{array}$ \\
\hline 3.2 .3 . & $\begin{array}{l}\text { De-resolution: reducing the precision of the measure-- } \\
\text { snapping/rounding/truncating to the nearest order of magnitude. Occurs } \\
\text { if the representational scale is simpler than measured scale. }\end{array}$ \\
\hline \multicolumn{2}{|c|}{$\begin{array}{l}\text { 3.3. Translation accuracy (pertains to changes in the data due to transfer and mapping } \\
\text { of data values): how closely the post-translation value matches the pre-translation } \\
\text { value. }\end{array}$} \\
\hline 3.3.1. & $\begin{array}{l}\text { Scaling accuracy: how closely scales of pre-translation values match } \\
\text { the post-translation values (e.g., use of unit-measure designations). }\end{array}$ \\
\hline 3.3.2. & $\begin{array}{l}\text { Compression and extraction accuracy: How much data resolution is } \\
\text { lost between compression and extraction of data (e.g., averages, } \\
\text { dithering in images). }\end{array}$ \\
\hline 3.3.3. & $\begin{array}{l}\text { Accuracy change due to intermixing with other data sets: Are the data } \\
\text { mixed with other data measures by summation or multiplication ( e.g., } \\
\text { a weighted index value)? }\end{array}$ \\
\hline 3.3.4. & $\begin{array}{l}\text { Accuracy change due to degradation of data set: From loss of data } \\
\text { points or unknown changes in value (i.e., corrupted data). }\end{array}$ \\
\hline
\end{tabular}

Data validation can take many forms, from that requiring human intervention to complex mathematical analysis of data sets in terms of temporal and spatial conditions. In general, large and diverse data sets help improve the calibration of the data, but much depends on the accuracy 
of the data-acquisition process and the relationship between the measured proxy and the intended parameter of measure (most parameters are measured indirectly via a proxy of the measure).

Complex algorithms for smoothing and conditioning data can greatly improve the quality of the measured data, but a simple statistical-conditioning algorithm consumes an order of magnitude more in computing resources than a simple clipping algorithm. Although natural parameters, such as weather data from nongovernmental sources, lend themselves to conditioning by Fourier analysis, these algorithms consume two or more orders of magnitude more computing resources than a simple statistical-conditioning algorithm. It is clear that there are trade-offs here among computing power, data latency, and data quality.

The end user (the BAS) should also have some input into the data-validation process. If the BAS does not need high-quality data or can tolerate some variation in data quality, then it could elect to accept lower quality data for a reduction in data latency. Moreover, with the appropriate data interface, interactive adjustments to data quality would be possible in response to changes to the building's internal conditions. This would be consistent with some of the accreditation strategies advanced in Section 3.

\subsubsection{Data Channeling}

Data channeling is a term used for the posting, distribution, transfer, and client-side reception of data. Many factors figure into the configuration of the data management system. The specific operational objectives may lean toward a client module of the BAS that sorts through a constant data stream to find relevant data; a client can act like an agent for the BAS, registering with known data services and seeking out new data services; or a BAS client can interact with a data-server-based agent that acts like a personal assistant for the BAS, finding data based on a specified set of acquisition rules.

\subsubsection{Data Utilization}

There are three levels of benefit from the use of remote real-time data as BAS inputs: 
1. Improvement of the environmental conditions in the facility, yielding productivity, health, and safety benefits for building occupants (primary benefits)

2. Improvements in the operational efficiency and effectiveness of the building systems (secondary benefits)

3. Improvements in the building's interaction with the community (tertiary benefits). Connectivity plays an important role in this process. The BAS should be able to interact with building occupants through scheduling tools and with the community via alerts and alarms. Many boundary issues must be resolved to adequately connect building occupants with the BAS; having building occupants arbitrarily reset building temperatures is not desirable, and having the BAS track occupant movement and behavior raises serious concerns about privacy. However, many of these issues can be resolved with appropriate access privileges between occupant schedules and building controls; therefore, the benefits of having closer interaction between the building and its users can be realized.

In order to determine what information is useful for building control, we would need to review the system description, which would require a large number of parameters. However, describing a system or component that is changing often requires only a relatively few parameters (e.g., a change in differential temperature or pressure at the chilled water system head may roughly define change occurring within the system). Describing a change within a system enables the simplification of a system into a few key parameters.

The simplification or compression of information is not without trade-offs though. Similar to the linearization process to create an easy-to-use model of a nonlinear event, the simplification of the selected parameters only holds for specific parts of a performance or event curve. If the system moves outside the bounds of the performance curve, then system control may degrade or become unstable. For example, using a differential temperature (return minus supply) at the head of a chilled water system to control chiller loading is simple and, in most cases, sufficient for good system performance. But if the supply temperature drifts upward, the differential temperature can narrow, resulting in an inappropriate control signal to the chiller. 
Correcting for unstable or uncertain conditions is often a matter of obtaining additional data about the system.

This data compression process is the subtle acknowledgment that there is a difference in the sampling rates needed across system parameters to provide robust and stable control of the system. A full system description is needed when the control system is being initialized or reinitialized. Periodic checks for changes in significant system parameters, which would determine whether the system is within a linear range of operation, are needed at low or moderate sampling rates. The system parameters used as real-time system control points need to be sampled at rates that provide a stable control response.

The constraints on data collection within the building, due to cost and usability, also largely apply to Internet-based data collection. Higher quality data will require more robust and reliable hardware and software, placing cost constraints on the types and amounts of data collected. Likewise, retrieving large amounts of data requires additional processing power and complex algorithms to make use of the additional information. Moreover, the different sampling needs of different types of data strongly suggest that it is beneficial for the BAS to interact with the Internet data server using a Structured Data Services interface so that the BAS can query the data server at less frequent intervals for slow-changing parameters or when reinitializing the control system.

Early in this project, the general concept of the real-time data management system was that of a "gopher" agent, possibly built into the BAS, that goes to specified websites to retrieve textual data to be converted into control inputs. During our analysis, however, it became clear that many of the steps in this data-retrieval process could be managed on the client or the data server. Indeed, the control algorithms for novel types of building controls using real-time data could reside entirely off-site, sending only the needed control inputs to the BAS. 


\subsection{Parameters for Development of Real-Time Information}

GEOMET used a three-step process to define applications of real-time parameters:

1. Identify all possible real-time sources on the web that affect buildings (Section 3.3)

2. Extract parameters from those sources that relate to various aspects of buildings (this section)

3. Cross-reference those parameters with the results of the survey and focus group discussions (this section).

In the first step, each individual parameter from the real-time data stream was identified to determine whether it had the following three characteristics: was regional in nature, had a rate of change (or "delta") association, and had a linked parameter association.

In addition, parameters could be real-time or predictive in nature. All weather-related and air-quality parameters were found to be both real-time and predictive in nature. Several other parameters, such as intellitags and traffic, could not be predictive.

Where possible, parameters that affected a region were identified. Buildings in the region could share these parameters. Parameters were also examined in terms of a "rate of change" $(\mathrm{dt} / \mathrm{dz}, \mathrm{dx} / \mathrm{dz}$, etc.) association. Finally, parameters were examined to determine whether any had links via some form of association.

Sixteen parameters were identified from the extraction process (Table 4-2). These parameters ranged from outside temperature, to geophysical data and aircraft/rail data. 
Table 4-2 Real-Time Parameters and Their Attributes

\begin{tabular}{|c|c|c|c|c|}
\hline Parameter & Local & Regional & $\begin{array}{l}\text { Rate of } \\
\text { Change }\end{array}$ & $\begin{array}{l}\text { Linked } \\
\text { Parameters }\end{array}$ \\
\hline $\begin{array}{l}\text { Temperature, } \\
\text { Outside Air } \\
\text { (OA) }\end{array}$ & Yes & Possible & Yes & Yes \\
\hline Pressure, OA & Yes & & Yes & Yes \\
\hline $\begin{array}{l}\text { Relative } \\
\text { Humidity, OA }\end{array}$ & Yes & & Yes & \\
\hline $\begin{array}{l}\text { Wind Speed \& } \\
\text { Direction }\end{array}$ & Yes & & Yes & Yes \\
\hline Solar Radiation & Yes & & Yes & Yes \\
\hline Lightning & Yes & & & \\
\hline Sunspots & & Yes & Yes & \\
\hline $\begin{array}{l}\text { Air Quality } \\
\text { Related }\end{array}$ & Yes & & & Yes \\
\hline Precipitation & Yes & & Yes & Yes \\
\hline Visibility & Yes & & & Yes \\
\hline Traffic & Yes & Yes & & Yes \\
\hline $\begin{array}{l}\text { Intellitag- } \\
\text { Parking }\end{array}$ & Yes & & & \\
\hline $\begin{array}{l}\text { Airport — Rail } \\
\text { Arrivals }\end{array}$ & Yes & Yes & & Yes \\
\hline $\begin{array}{l}\text { Geophysical } \\
\text { (tides/planets) }\end{array}$ & Yes & Yes & & Yes \\
\hline $\begin{array}{l}\text { Maintenance } \\
\text { Interaction* }\end{array}$ & Yes & & & \\
\hline $\begin{array}{l}\text { Occupant } \\
\text { Interaction* }\end{array}$ & Yes & & & \\
\hline
\end{tabular}

* Covered more fully in Section 5

Each parameter is discussed below in relation to particular applications. The information is presented in a template format with information about the particular parameter listed in the box, while text and graphical data appear as warranted.

It is impossible to cover all possible combinations and applications. Instead, the focus is on commonly known applications, as well as some of the advanced building (building of the future) applications. 


\footnotetext{
Web Parameter: Temperature, Outdoor, Local*

Use of Parameter: Activate economizer

Linked Parameters: Dew point

Building Systems Affected: Heating and Cooling

How Obtained? FTP of Temperature Data

Where Obtained? NWS-Free

Weather Vendors - Fee

Type of Building for Use: All

*Regional application of temperature network is possible

The local temperature is used to determine if and when economizer functions are activated. Whenever the outside air is mild and the relative humidity is average, an economizer can save energy. Outside air can be brought in which would avoid using more refrigeration equipment to cool recirculating air.

The linked parameter is dew point or relative humidity. This must be taken into account because a key trigger of an economizer is relative humidity. Economizers tend to perform less efficiently in more humid climates.
}

Temperature and dew point data from the web can be utilized to improve economizer sensors, a notorious point of failure with economizer systems. Having web-based temperatures may actually be more accurate and therefore provide better input to the economizer because onboard temperature sensors are influenced by a number of factors including corrosion of the surrounding area, failure, and accuracy. In fact, some maintenance personnel have been known to trick economizers into different positions by increasing relative humidity with spray bottles or increasing temperature with hairdryers. (Source: esource.com.) 
Web Parameter: Temperature, Outdoor, Local Predictive -Rate of change

Use of Parameter: Advanced set-point control

Linked Parameters: Dew point (predictive)

Building Systems Affected: Heating/Cooling systems

How Obtained? FTP of NWS model data Model Output Statistics (MOS) FOUS Data

Where Obtained? NWS-free Weather Vendors-fee

Type of Building for Use: All, but requires energy model to be run on/off-site
The use of advanced set-point controls has been well researched.

However, what is not as well researched is the use of an energy model to predict future energy use in a building and to therefore minimize energy consumption.

A predictive energy model would naturally depend on the data quality received by the model. This input data could include predictive weather data such as Model Output Statistics (MOS) or FOUS (FOrecast U.S.) data.

Data could be input into a whole building type diagnostic system such as the WholeBuilding Diagnostician (WBD) developed by a group led by Pacific Northwest Laboratories (www.buildings.pnl.gov). The predictive NWS data would drive the energy model in order to produce results out to 12 hours and thereby suggest pre-cooling or heating strategies to the building operator.

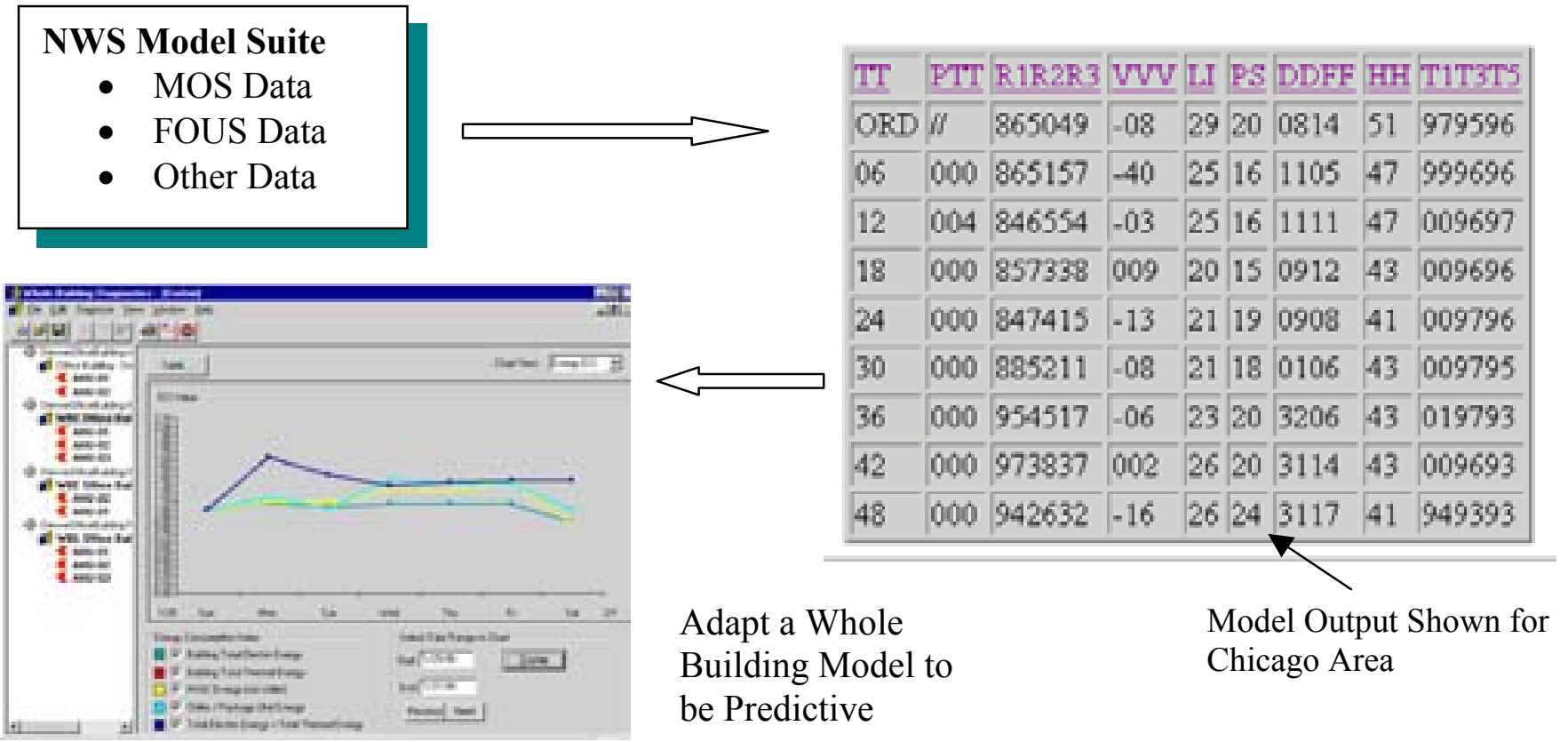


Web Parameter: Temperature, Predicted -Rate of change-

Use of Parameter: Thermal load shifting

Linked Parameters: Dew point

Building Systems Affected: Cooling and heating systems

How Obtained? FTP of NWS model data Model Output Statistics (MOS) FOUS data Meteogram Output

Where Obtained? NWS-free Weather Vendors-fee

Type of Building for Use: All buildings (temperate climates)
The predicted outside temperature

for the next 12-24 hours is used to determine whether to use on-site thermal storage for greater energy efficiency and cost savings. Cool/warm storage mediums are cooled or heated at times requiring less energy and then used to heat or cool when the demand for heating and cooling is greater or more expensive.

The BAS would have input similar to other predictive type uses. The BAS would require input from the NWS model suite. In addition, linkage to an

energy pricing system could also be beneficial. (It makes sense to have thermal load shifting only if power is cheaper at night than during the day.) As shown in the figure below, model data to be utilized would be in meteogram form, which indicates rate of temperature change over a given time.

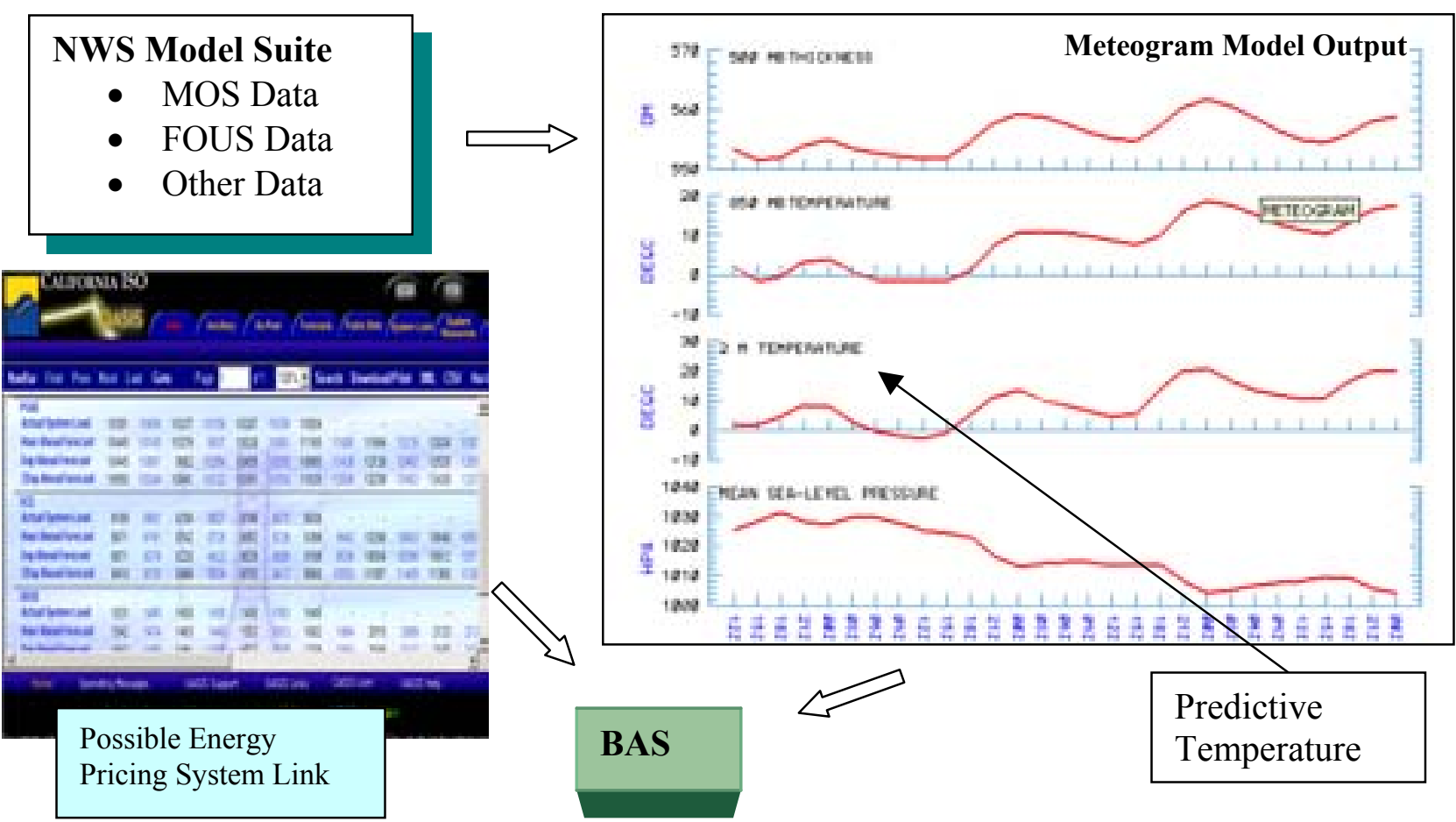


Web Parameter: Temperature, Outdoor, Local

Use of Parameter: De-icing of walkways, driveways, parking lots

Linked Parameters: Precipitation

Building Systems Affected: Outside walks and driveways

How Obtained? FTP of NWS model data Model Output Statistics

(MOS) FOUS data

FTP of live NWS data for realtime situations

FTP of traffic weather sensor data from state highway adm. (shows concrete/pavement temperatures)

Where Obtained? NWS-free

Weather Vendors - Fee

State Highway Adminfree

Type of Building for Use: All (northern climates)
The local outside temperature in conjunction with a precipitation parameter is used to determine if walkways and driveways are de-iced by heat or chemical reaction.

The potential for icing situations can be determined by using either predictive model output (as in other cases within the temperature parameter) in combination with a precipitation parameter (frozen precipitation).

The probability of frozen precipitation can be fed into the BAS to determine appropriate action (manual or automated de-icing such as preheating surfaces with an underground pipe system). Use of real-time temperature

can aid in dealing with current de-icing situations including proper use of chemicals above and below $28^{\circ} \mathrm{F}$, a common de-icing chemical decision point.
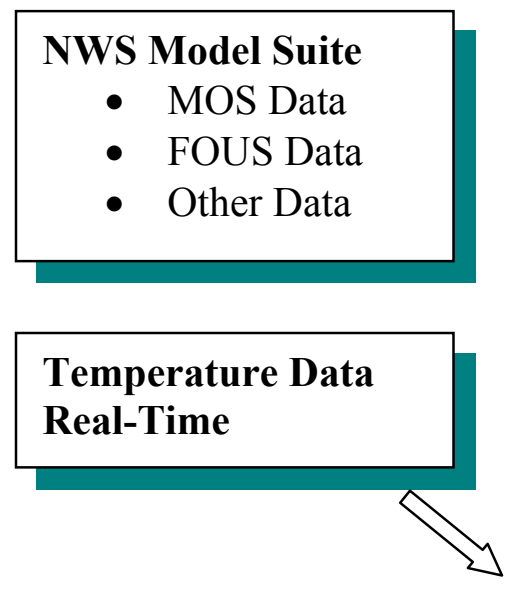
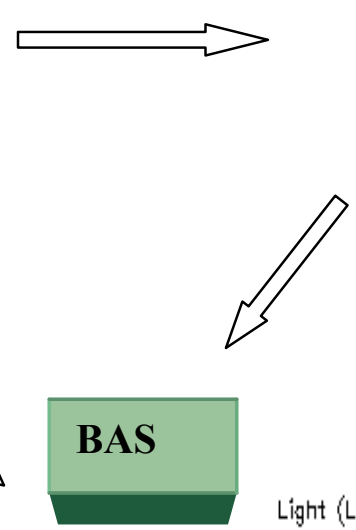
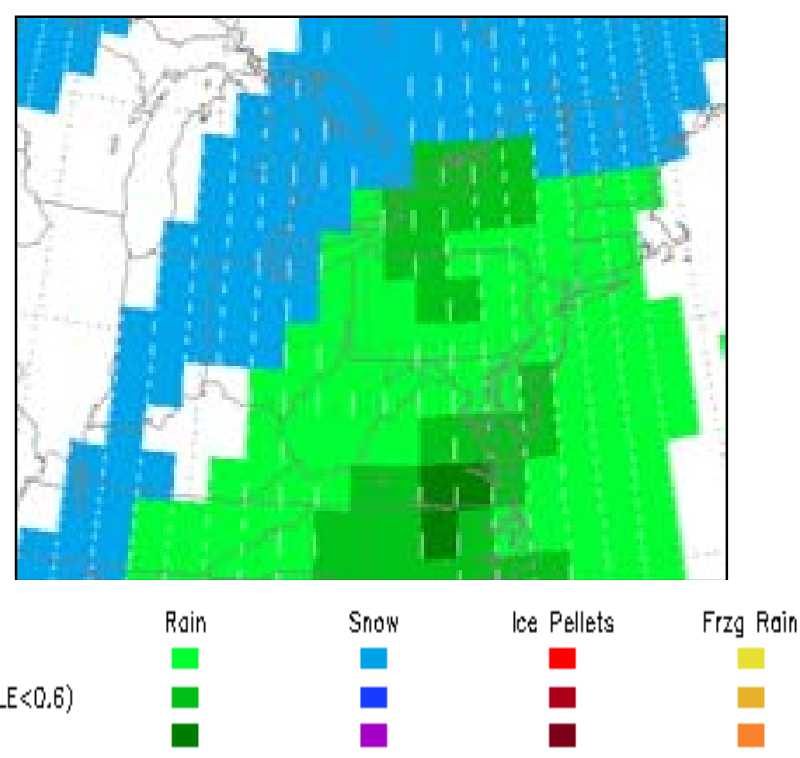
Web Parameter: Temperature, Outdoor, Local

Use of Parameter: Evaporative cooling of outdoor gathering areas

Linked Parameters: Dew point, derived wet bulb and similar values

Building Systems Affected: Cooling systems

How Obtained? FTP of Temperature and Dew

Point Data (also predictive model data)

Where Obtained? NWS-free

Weather Vendors-fee

Type of Building for Use: Restaurants, conference centers, outdoor plazas (arid southwestern US climates)
The local outside temperature in conjunction with the dew point can be used to determine whether to use evaporative cooling in arid southwestern U.S. climates. The evaporation of a water spray reduces the energy in the air and increases the humidity to a more comfortable level.

Real-time temperature and dew point data can be input into a BAS in order to begin the evaporative cooling process. Key data such as wet bulb can

also be derived. This data can be obtained from either NWS or private weather data vendors.

Similarly, predictive data can be used to forecast the use of the evaporative cooling system, although this application lends itself more to a real-time than to a predictive mode.

\begin{tabular}{|c|c|c|c|c|c|c|c|c|c|c|c|c|c|c|c|}
\hline \multicolumn{3}{|c|}{ Temp Range: Deg(f) } & \multicolumn{3}{|c|}{ May } & \multicolumn{3}{|c|}{ June } & \multicolumn{3}{|c|}{ July } & \multicolumn{3}{|c|}{ August } & \multirow[t]{2}{*}{ Total } \\
\hline Low & High & Mean & Hours & $\mathrm{Wb}$ & Tout & Hours & $\mathrm{Wb}$ & Tout & Hours & $\mathrm{Wb}$ & Tout & Hours & $\mathrm{Wb}$ & Tout & \\
\hline 115 & 120 & 117.5 & & & & 1 & 70 & 72.4 & 2 & 73 & 75.2 & & & & 3.0 \\
\hline 110 & 114 & 112 & & & & 12 & 70 & 72.1 & 16 & 72 & 74.0 & 3 & 74 & 75.9 & 31.0 \\
\hline 105 & 109 & 107 & 4 & 66 & 68.1 & 41 & 69 & 70.9 & 69 & 72 & 73.8 & 31 & 73 & 74.7 & 145.0 \\
\hline 100 & 104 & 102 & 18 & 65 & 66.9 & 65 & 67 & 68.8 & 117 & 71 & 72.6 & 89 & 73 & 74.5 & 289.0 \\
\hline 95 & 99 & 97 & 53 & 63 & 64.7 & 90 & 65 & 66.6 & 119 & 71 & 72.3 & 115 & 72 & 73.3 & 377.0 \\
\hline 90 & 94 & 92 & 74 & 61 & 62.6 & 97 & 63 & 64.5 & 135 & 70 & 71.1 & 128 & 71 & 72.1 & 434.0 \\
\hline 85 & 89 & 87 & 86 & 59 & 60.4 & 103 & 62 & 63.3 & 139 & 68 & 69.0 & 146 & 71 & 71.8 & 501.0 \\
\hline 80 & 84 & 82 & 97 & 57 & 58.3 & 103 & 59 & 60.2 & 96 & 67 & 67.8 & 133 & 70 & 70.6 & 429.0 \\
\hline 75 & 79 & $n$ & 108 & 55 & 56.1 & 88 & 57 & 58.0 & 42 & 66 & 66.6 & 78 & 69 & 69.4 & 316.0 \\
\hline 70 & 74 & $\eta 2$ & 101 & 53 & 54.0 & 64 & 54 & \multirow{3}{*}{\multicolumn{8}{|c|}{$\begin{array}{l}\text { Phoenix, Arizona, Evaporative Cooling } \\
\text { Climatology Chart. Shows Average number of } \\
\text { hours within each temperature range and discharge } \\
\text { temp. Wb = Wet Bulb, Tout = discharge temperature } \\
\text { Source: Premier Industries, Inc. Phoenix, AZ (piec.com) }\end{array}$}} \\
\hline 65 & 69 & 67 & 90 & 51 & 52.1 & 37 & 52 & & & & & & & & \\
\hline & & & & & & & & & & & & & & & \\
\hline
\end{tabular}


Web Parameter: Air pressure, barometric

Use of Parameter: Combustion control, speed of air handling motors because of mass flow rates; airflow in building, smoke control

Linked Parameters: Wind, Dew Point

Building Systems Affected: Combustion processes, such as heating, direct-fired absorption cooling, and materials heat-treating, air handling systems (for zonal flow)

How Obtained? FTP of pressure data / usually coupled with other weather

Where Obtained? NWS-free Weather Vendors-fee

Type of Building for Use: Buildings using combustion heating. Industrial processes.
There are multiple applications of air pressure to building efficiencies. The air pressure is used to optimize combustion settings, such as for heating, direct-fired absorption cooling, etc. Knowing barometric parameter values could aid in tweaking combustion settings.

Another application of barometric pressure is in the area of airflow within buildings and the wind flow against buildings. Huang et al. (1999) of Lawrence Livermore Labs have shown

how the COMIS (Conjunction of Multizone Infiltration Specialists) multizone airflow model can be coupled with DOE's newer EnergyPlus model in order to predict airflow within a building. The model utilizes various inputs, including barometric pressure, in order to determine airflow throughout the building. Wind is also a key component in terms of the pressure coefficient exerted along the building interface.

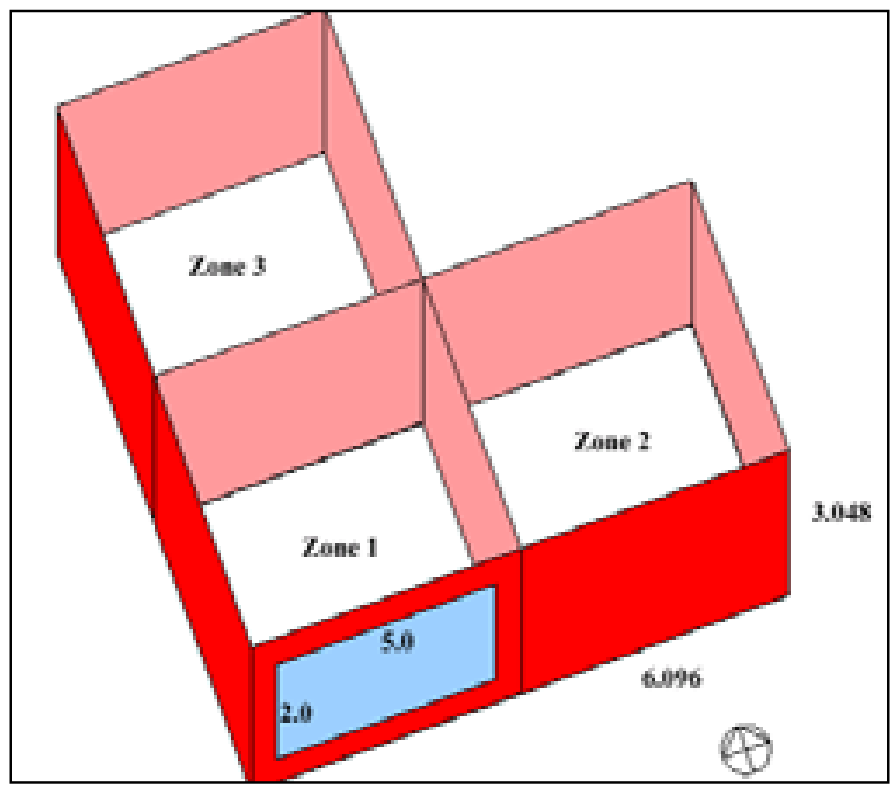

Depiction of building zones with coefficients of pressure shown (blue is a window interface). Model data is from COMIS-Energy Plus Link utilizing Chicago area wind data/pressure.

(From Huang et al., 1999)

Reference: Huang, Joe, F.C. Winkelmann, W.F. Buhl, C.O. Pedersen, D.E. Fisher, R.J. Liesen, R.D. Taylor, R.K. Strand, D.B. Crawley, L.K. Lawrie. Sept. 1999, Proceedings of Building Simulation '99. 
Web Parameter: Temperature, Outdoor, Local Predictive

Use of Parameter: Override use of natural ventilation (operable windows)

Linked Parameters: Precipitation, Solar type parameters (angle, etc.) Wind, Dew point. Predictive parameters as well.

Building Systems Affected: Cooling and heating systems

How Obtained? FTP over Web, Model output, Radar feed/site

Where Obtained? NWS-free, Weather Vendorsfee, Other Federal sites-free, NWS-for radarfree...vendors-fee

Type of Building for Use: All buildings (temperate climates)

use of operable windows. Finally wind data, particularly in terms of the prevailing winds of the day, are useful in determining the configuration of the windows.

Wind, temperature, dew point and precipitation data (radar) are all available in terms of real-time data that can be input into a BAS controlling an operable window. These parameters are also available in predictive mode.
Several obvious linked parameters affect the use of operable windows. These include temperature and dew point (comfort), precipitation (practicality), and wind (air movement).

The local outside temperature in conjunction with the dew point can be used to determine whether operable windows should be closed if the OA temperature is above or below a specified temperature range.

\section{Radar data could be used to} determine if precipitation can affect the 
Web Parameter: Dew point, temperature, outdoor, local. Also predictive

Use of Parameter: Determine hygric behavior of buildings. Moisture control, moisture management, corrosion control. Links to hygrothermal models

Linked Parameters: Precipitation, derived relative humidity and related parameters

Building Systems Affected: Cooling and heating systems

How Obtained? Real-time data- FTP over Web, Model output, Radar feed/site

Where Obtained? NWS-free, Weather Vendorsfee, Other Federal sites-free, NWS-for radar-

free...vendors-fee

Type of Building for Use: All buildings
The hygric behavior of buildings

has contributed to millions of dollars worth of moisture damage and lost business.

High levels of moisture in any building can lead to indoor air quality problems, structural problems, and energy inefficiency.

Several hygrothermal models exist that, when linked to a BAS, along with real-time and historical data, could aid in characterizing a building's hygric behavior. One such model has been developed by Oak Ridge and the Fraunhofer Institute for Building Physics

(Germany). WUFI-ORNL/IBP can be run on a PC and can determine when condensation can occur in a building, along with other exterior and interior moisture-type calculations. One application of this model would be to link it to the BAS and the real-time web data stream in order to compile historical data on the building. A user could look back on the evolution of moisture management over the course of six months or a year. 
Web Parameter: Air quality indicators, local, regional

Use of Parameter: IAQ control of outdoor pollutants

Linked Parameters: Wind direction/speed

Building Systems Affected: Ventilation systems, air intakes

How Obtained? File transfer/extraction over web

Where Obtained? State air pollution control boards or like agency

Type of Building for Use: All buildings
In 2002, more than 121 million

U.S. citizens lived in areas deemed

unhealthy for ozone. Many areas of the country had one or more ozone standard exceedences.

Air quality indicators such as ozone levels are monitored on an hourly averaged and eight-hourly averaged basis. When the levels rise above 120 ppb, a Code Red ozone action alert is issued. The BAS would receive input

from a real-time air quality indicator web stream that would provide current conditions (e.g., Code Red or no Code Red present). The BAS could react to the Code Red situation by automatically closing off fresh air intake. The BAS would reinitiate fresh air intake after the Code Red expired. The figure below shows how such a system would work.

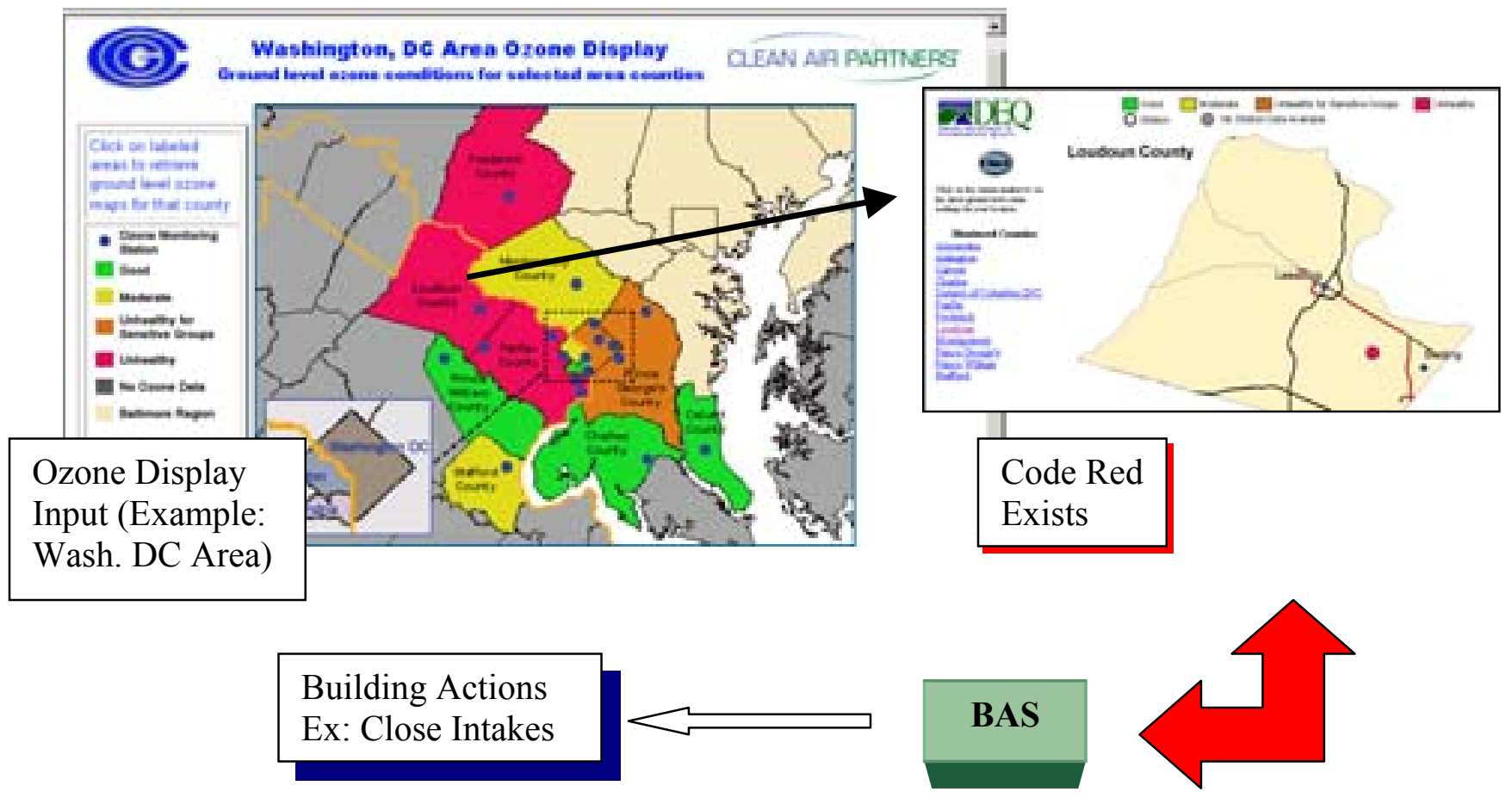


Web Parameter: Energy pricing data, multiple weather parameters, predicted

Use of Parameter: Real-time pricing Optimization of cogen. Versus energy purchasing. Use predicted weather factors.

Linked Parameters: Energy model of campus

Building Systems Affected: All

How Obtained? File transfer

Where Obtained? Energy pricing firm/service, NWS model predictive data, cogen. data, energy model output about the campus/complex

Type of Building for Use: All buildings - but for large campus/complex that generates its own power (e.g., university, military)
More traditional energy savings strategies have focused on the reduction of energy consumption through conservation means. Demand/peak shaving strategies also exist but can have long time peak demands (e.g., 10 hours) and overall contractual time (e.g., 9month) commitments.

An interesting strategy couples real-time data on short-term flucutations in pricing with selling excess generating capacity from cogen facilities located at large complexes. Russo, Tabors, and

Cooper (2001) have shown that the MIT cogen facility could save between $\$ 150,000$ and $\$ 600,000$ per year by making operational changes and strategically selling/buying power from the New England Pool. (The broad range is dictated by a number of control strategies they introduced.)

Reference: Russo, C., R.Tabors, P. Cooper: Taking Advantage of Real-Time Pricing to Optimize Plant Operations, International District Energy Association Conference-IDEA 2001. 
Web Parameter: Weather warnings/ watches/ advisories

Use of Parameter: Disaster plan implementation, automatic lockdown of exterior equipment, protection of personnel

\section{Linked Parameters: None}

Building Systems Affected: All

How Obtained? File transfer

Where Obtained? NWS is the only source of official weather warnings/watches/advisories in the United States.

Type of Building for Use: All
The National Weather Service is the only officially recognized group that can issue weather warnings, watches, or advisories. A weather warning means that the warned weather condition (tornado, severe thunderstorm) is imminent (in less than one hour). A watch means that conditions are favorable for the type of weather during a certain period of time. An advisory is usually issued in the wintertime to indicate a less severe winter storm (less than four inches of snow) or a light-moderate icing event.

The BAS would receive the weather warning/watch/advisory message and issue the appropriate commands to building systems and to operators. This could include automatic shutdown of systems or a display of building disaster plan information if such a disaster plan exists. The figure below illustrates one application of such a system.

BULLETIN - EAS ACTIVATION REQUESTED

SEVERE THUNDERSTORM WARNING

NATIONAL WEATHER SERVICE STATE COLLEGE PA

THE NATIONAL WEATHER SERVICE IN STATE COLLEGE PA HAS ISSUED A

* SEVERE THUNDERSTORM WARNING FOR...

CAMERON COUNTY IN PENNSYLVANIA

CENTRE COUNTY IN PENNSYLVANIA

* UNTIL 415 PM EST.

* AT 317 PM EST...NATIONAL WEATHER SERVICE DOPPLER RADAR INDICATED A LINE OF SEVERE THUNDERSTORMS FROM 23 MILES NORTHWEST OF PINE GLEN TO 5 MILES SOUTHWEST OF SANDY RIDGE...MOVING EAST AT $20 \mathrm{MPH}$.

* SEVERE THUNDERSTORMS WILL BE NEAR..

PINE GLEN AND MOSHANNON AT 340 PM.

PORT MATILDA AT 345 PM.

SNOW SHOE AT 355 PM.

STATE COLLEGE AT 410 PM.

THESE ARE A DANGEROUS STORMS. STORMS HAVE A HISTORY OF KNOCKING TREES DOWN STAY INDOORS AWAY FROM WINDOWS. SEVERE THUNDERSTORMS CONTAIN DAMAGING WINDS 58 MPH OR STRONGER OR HAIL THREE QUARTERS OF AN INCH OR LARGER.

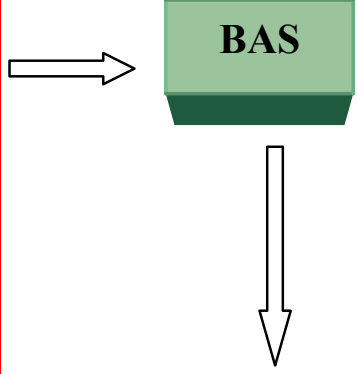

Actions to protect personnel and property. Notifications, automatic responses etc. 
Web Parameter: Solar radiation, local, regional, predictive

Use of Parameter: Multiple uses: solar shading, solar screening, daylighting controls

Linked Parameters: Solar angle, visibility (aesthetics), cloud cover, temperature. Derived parameters: \% light, \% sunshine. Linked technology: operable windows

Building Systems Affected: Shading systems, daylighting sensors/controls, passive and active systems

How Obtained? File transfer

Where Obtained? NWS model data Model Output Statistics (MOS) FOUS data Current weather data: NWS Private vendors, other Federal, Space Weather Center

Type of Building for Use: More modern or retrofitted buildings.
Many modern facilities are starting to incorporate solar or daylighting devices to reduce glare and cooling loads as well as to increase occupant thermal comfort. These devices include solar shades on the interior and exterior as well as the more common daylighting devices.

Many parameters can be obtained from the real-time weather data and used to determine solar radiation, percent lighting, percent sunshine, etc. Predictive data can also help determine the most opportune times for solar shading strategies, daylighting, etc.

The BAS would receive

incoming solar information and, via some processing, derive values necessary to advise on the particular solar strategy. If linked to operable windows, the BAS could adjust the windows in conjunction with the solar data. 
Web Parameter: Lightning, local

Use of Parameter: Building asset protection, personnel protection

Linked Parameters: None

Building Systems Affected: Electronics, power systems

How Obtained? File transfer

Where Obtained? Private Vendors - Fee

Type of Building for Use: All, but in particular data centers and critical infrastructure housed buildings. Also useful for building operator personnel.
Lightning causes hundreds of millions of dollars worth of damage each year. Florida is the leading state for lightning strikes.

Knowing that lightning is occurring near a building can be valuable. Some buildings have backup systems that can be turned on if a lightning warning is received. This is particularly important in buildings that house critical applications, such as data

centers or emergency services.

In this lightning concept, the BAS would receive information on lightning threats a certain distance away, based on real-time lightning strikes within any range desired (1-2 miles, 35 miles, etc.). The BAS would then execute any necessary actions and notifications. The figure below illustrates this concept.

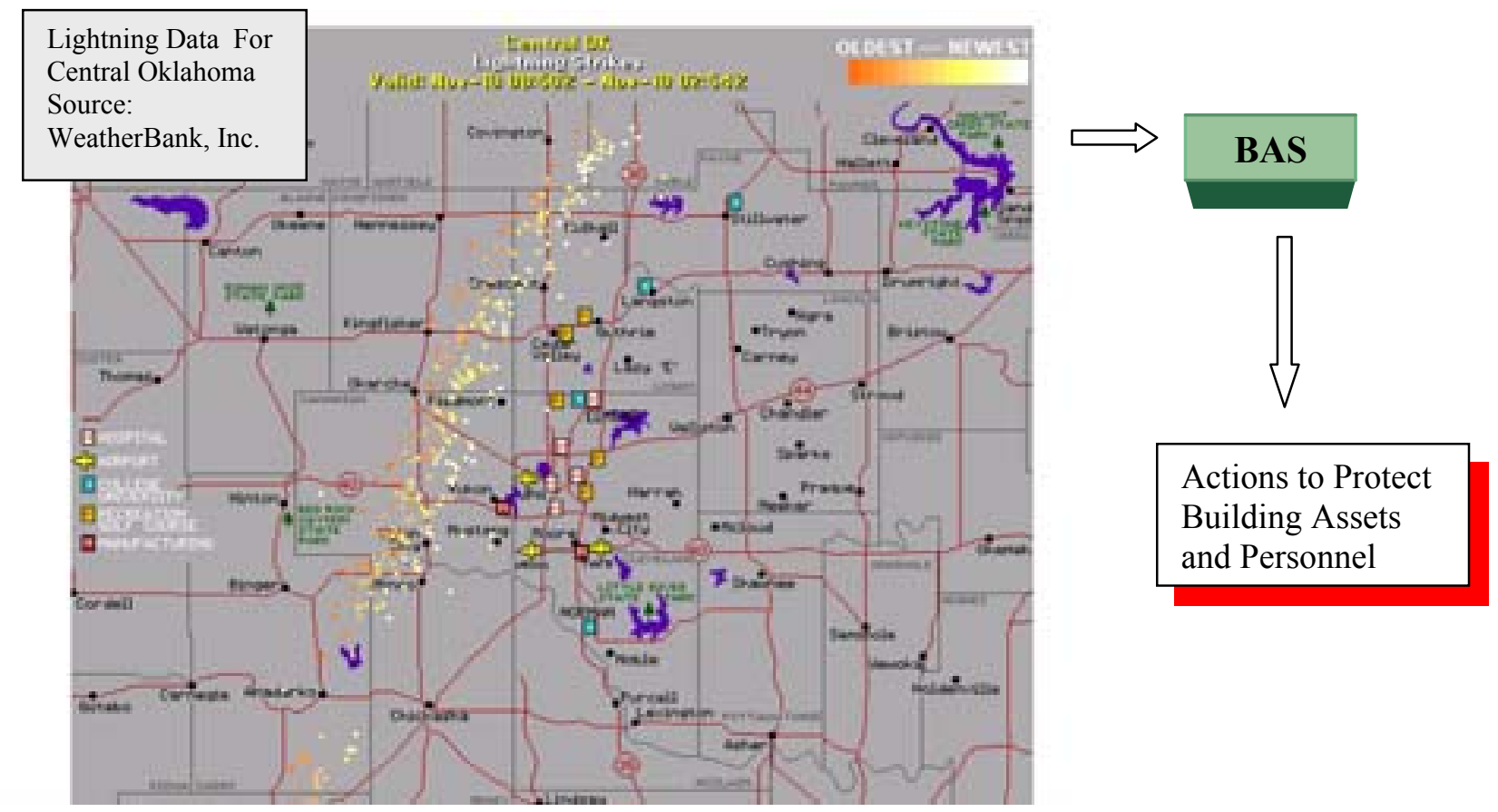


Web Parameter: Solar activity, regional, predictive

Use of Parameter: Building asset protection,

Linked Parameters: None

Building Systems Affected: Electronics, power systems

How Obtained? File transfer

Where Obtained? Space Weather Center (NOAA)

Type of Building for Use: All, but in particular data centers and critical infrastructure housed buildings.
There are many space

weather types, but all originate on the sun. Space weather in the broadest sense includes phenomena such as energy plasma (particles) or electromagnetic radiation (light). One common phenomena are solar flares, which are electromagnetic radiation bursts. This radiation can affect many radio frequencies, Global

Positioning Satellite receivers, electric power grids, etc. Satellite electronics may be severely harmed by solar disruption. On March 23, 1989, Hydro-Quebec had a nine-hour blackout affecting 9 million people. The cause was a geomagnetic-induced current (GIC) resulting from a large geomagnetic storm

The following figure shows one possible application of space weather to a BAS.

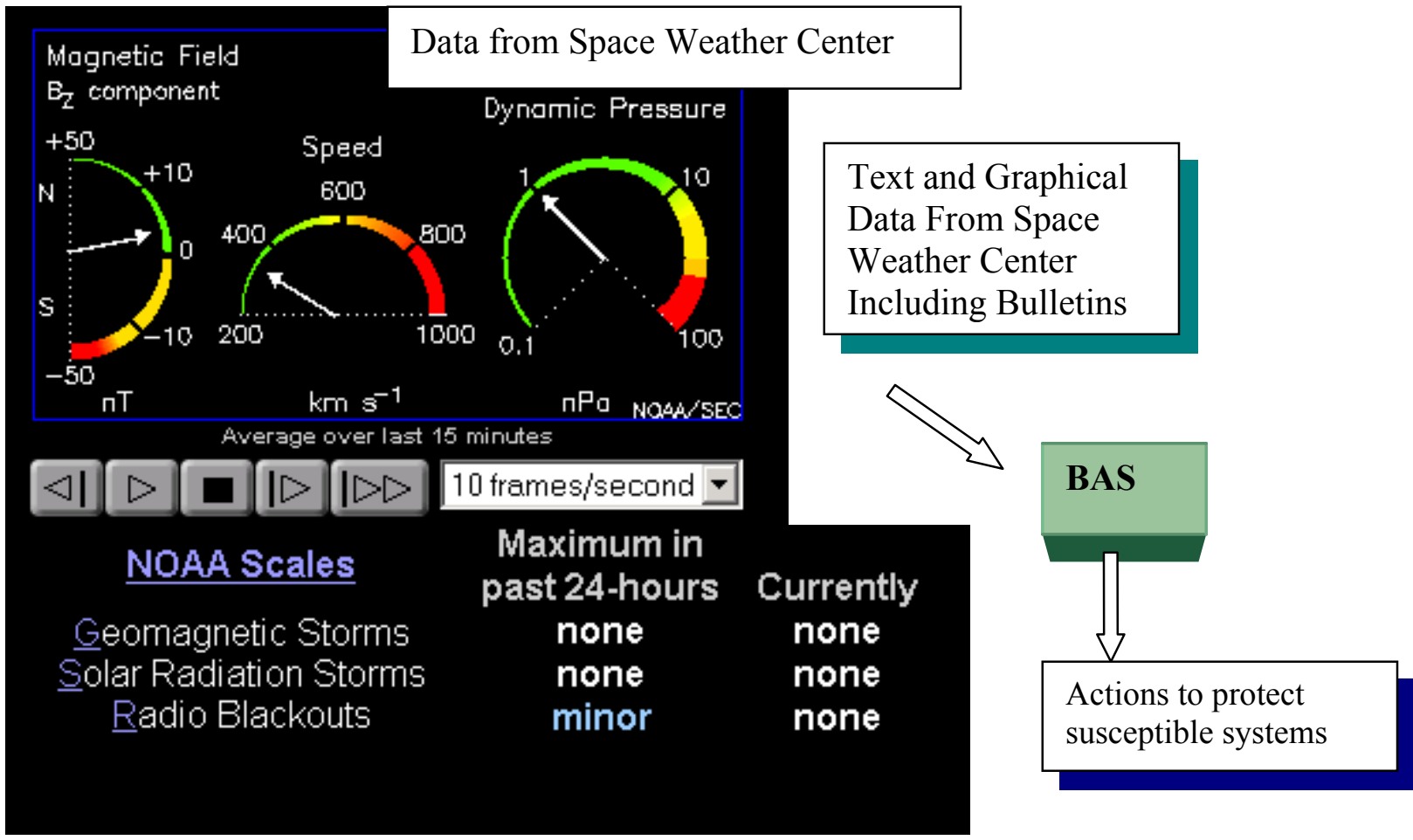

Reference: J. Kappenman, Minnesota Power \& Electric Paper, Lessons Learned from Solar Cycle 22 and Outlook for Solar Cycle 23, www.mpelectric.com/storms). 
Web Parameter: Chemical-biological data Hypothetical -Speculative Concept

Fire information/smoke (for fires/hazmat incidents nearby)

Use of Parameter: Provide in-place sheltering of building personnel

Linked Parameters: Possible wind speed/direction Building Systems Affected: Ventilation, intakes, personnel.

How Obtained? File transfer

Where Obtained? Not known/available

Type of Building for Use: Buildings in metropolitan areas that could have sensor data available
Buildings provide sheltering in place from chemical and to a lesser extent biological attack. The anthrax events in Fall 2001 in Florida, New Jersey, and Washington, D.C., show the need to take seriously threats of chemical or biological agent being dissiminated. The Hart Office Building ventilation systems in Washington were shut down in time to prevent even more spread throughout that complex.

The concept of utilizing a building to shelter in place would require

the BAS to be linked to any existing sensor systems. These sensor systems would exist in large cities. For example, the Washington Metro Rail System has now deployed chemical agent detection systems in many Metro underground locations. These detection systems send information back to a central location for processing and further action. If a BAS could be linked to such a system outside, then some time can be saved if an attack occurs because the BAS would be able to implement procedures for building protection. A biological and chemical agent detection system is in place near the Pentagon. It is not clear whether this is directly linked to the BAS systems. 
Web Parameter: Precipitation, local, predictive

Use of Parameter: Provide rain harvesting information and irrigation guidance

Linked Parameters: Possible derived evapotranspiration rates

Building Systems Affected: Rain harvesting systems, irrigation systems

How Obtained? File transfer

Where Obtained? NWS-free, Private VendorsFee. NWS Model Predictive Data

Type of Building for Use: Any building that utilizes rain harvesting methods for eco/stormwater management
Rain harvesting is utilized in many areas to collect rainwater for onsite use in various processes such as irrigating surrounding landscape, wastewater treatment concerns (if the facility is large enough to have wastewater treatment), and other uses. In the U.S. Virgin Islands, rain harvesting, including storage of water, is mandated by law for all buildings (Title 29, Section 308, V. I. Code). Bortman (1997) found that this rain harvesting lessened the rainfall runoff/erosion factors and aided in minimizing water pollution concerns.

An indication of predicted precipitation would obviously be a useful indicator to a BAS that is involved with rain harvesting. Building operators could determine whether the rain harvesting system or irrigation system needed to be supplemented with conventional means of watering. A semi-automatic rain harvesting system at Harrah's Casino in New Orleans was described at the New Orleans focus group. That system, while not connected to the Internet, allows the casino to monitor the condition of the palm trees, which can cost up to $\$ 1,000$ each to replace.

Reference: Bortman, M: Trends in Land Use, Sewage and Stormwater and Their Relationship with Coastal Water Quality in St. Thomas, U. S. Virgin Islands, Ph.D. Dissertation, State University of New York at Stony Brook, New York, 1997. 
Web Parameter: Astro-geophysical parameters (tides, moonlight, etc.), regional

Use of Parameter: Provide information related to flood control, marinas/traffic, security

Linked Parameters: warnings, precipitation

Building Systems Affected: Basement systems, (water table issues), sewers, marina traffic/customers

How Obtained? File transfer

Where Obtained? NWS-free, National Ocean Service-free (for tidal Information)

NWS Predictive Data, NASA

Type of Building for Use: Buildings that are located in a tidal flood area or affected by water table fluctuations. Also, buildings with marinas such as casinos, hotels, condos. This area of concern was brought to us by the New Orleans focus group due to problems with water table issues during periods of astronomical higher tides.
Geophysical parameters such as tides can affect buildings that are susceptible to water table fluctuations in their lower levels and buildings that rely on marina/boating traffic. Astrophysical parameters such as moonlight can affect building security systems, as reported by the New Orleans focus group.

\section{Buildings in certain areas are} susceptible to water table fluctuations. Sometimes these fluctuations are a function of groundwater supply. However, many times these fluctuations are due to tidal influences. In particular, buildings in New Orleans are very susceptible to Mississippi water flow along with any rainfall in the area. In fact, many buildings in New Orleans

have emergency sump pumps in their basements to handle water table fluctuations (e.g., the New

Orleans Library, www.nutrias.org, planning section).

Buildings attached to marinas may be concerned about tidal influences. Casinos in Atlantic City, New Jersey, could be affected by tidal concerns and flooding, which affects occupancy. Similarly, any coastal building could have tidal concerns that a BAS may address.
SPECIAL WEATHER STATEMENT NATIONAL WEATHER SERVICE MOUNT HOLLY NJ 210 PM EDT SUN SEP 162001

MINOR TIDAL FLOODING IS EXPECTED AGAIN THIS EVENING...

THE COMBINATION OF HIGH ASTRONOMICAL TIDES AND AN ONSHORE WIND SHOULD RESULT IN MINOR TIDAL FLOODING AGAIN THIS EVENING. MINOR TIDAL FLOODING IS EXPECTED AROUND THE TIMES OF HIGH TIDE THIS EVENING...WHICH OCCUR BETWEEN 7:00 AND 8:00 ALONG THE COASTS OF DELAWARE AND NEW JERSEY.

THOSE AREAS THAT ARE MOST SUSCEPTIBLE TO TIDAL FLOODING WILL LIKELY BE AFFECTED. THEY INCLUDE...BUT ARE NOT LIMITED TO...WEST ATLANTIC CITY AND NORTH WILDWOOD IN NEW JERSEY AND FENWICK ISLAND IN DELAWARE.

DO NOT PARK YOUR VEHICLE IN A LOCATION THAT IS PRONE TO TIDAL FLOODING 
Web Parameter: Traffic data, local, regional: Intellitags

Use of Parameter: Scheduling and control of parking facilities, walking/navigation instructions based on intelligent tags

Linked Parameters: Possible air quality linkage

Building Systems Affected: Parking/support facilities, security, potential occupancy

How Obtained? File transfer

Where Obtained? Numerous sources-state highway admin. local jurisdictions-free. Intellitags from several vendors-fee

Type of Building for Use: Any with parking concerns or larger occupancy rates
Use of traffic data can be divided into two parts: (1) use of traffic data to predict potential delays that would affect parking facilities and (2) use of intelligent tags for access into parking areas. (Tags contain information to be used by the building.)

Traffic data may be useful in determining specific delays near the building. It would be helpful to know when key commuter routes are blocked, and if the building could serve as an information source by providing traffic information to the tenants. Intelligent tags can be used to track movements of cars into/out of parking areas. This can be a first predictor of building occupancy. In addition, intelligent tags can also serve as a means to provide directions to building users based on encoded information on the tag.

The figure below shows a possible application of the traffic concept.

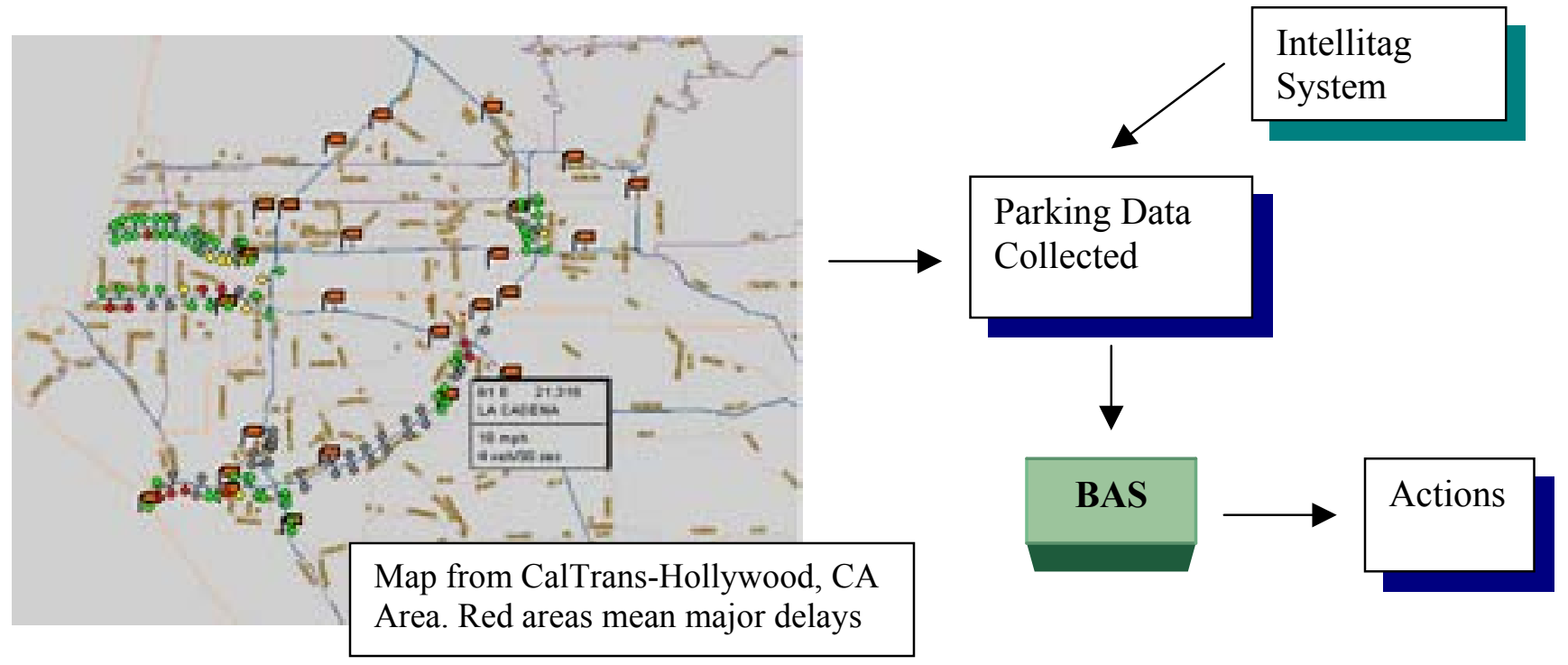


Web Parameter: Aircraft arrival time, status of air traffic control, rail status

Use of Parameter: HVAC and lighting control based on arrival times

Linked Parameters: Requires reservation system linkage

Building Systems Affected: Heating, cooling, anything occupancy driven, parking

How Obtained? File transfer

Where Obtained? Vendors-fee, some free Sites

Type of Building for Use: Hotels, motels, convention centers, any building with a reservation type system.
Use of sophisticated reservation

systems has increased dramatically

during the past several years. Many

reservation systems have adopted an

energy-oriented module. One such

module is HOTELGYR NT by Siemens.

This system, more prevalent in Europe

than in the United States, incorporates

automatic shutdown of a room when it is

not occupied. Siemens reports, "In a

hotel, the amount of energy required for

the guest rooms amounts to a maximum

of $35 \%$ of the hotel's total energy

consumption, depending on the type of

plant. However in a city hotel, ... guests

are only present during $40 \%$ of their stay. In view of this, there is a considerable energy savings potential available." While many systems are linked to room occupancy, a link out to the reservation system which, in turn, would have information related to the delay of the guest, could be quite beneficial. For example, the Hilton Hotel in Antwerp has an energy system that links to a reservation system, but it is not clear whether guest arrival information is tracked.

The Derag Hotel Russischer Hof located in Weimar, Germany is an example of a hotel utilizing a full energy management system linked to a front desk management system.

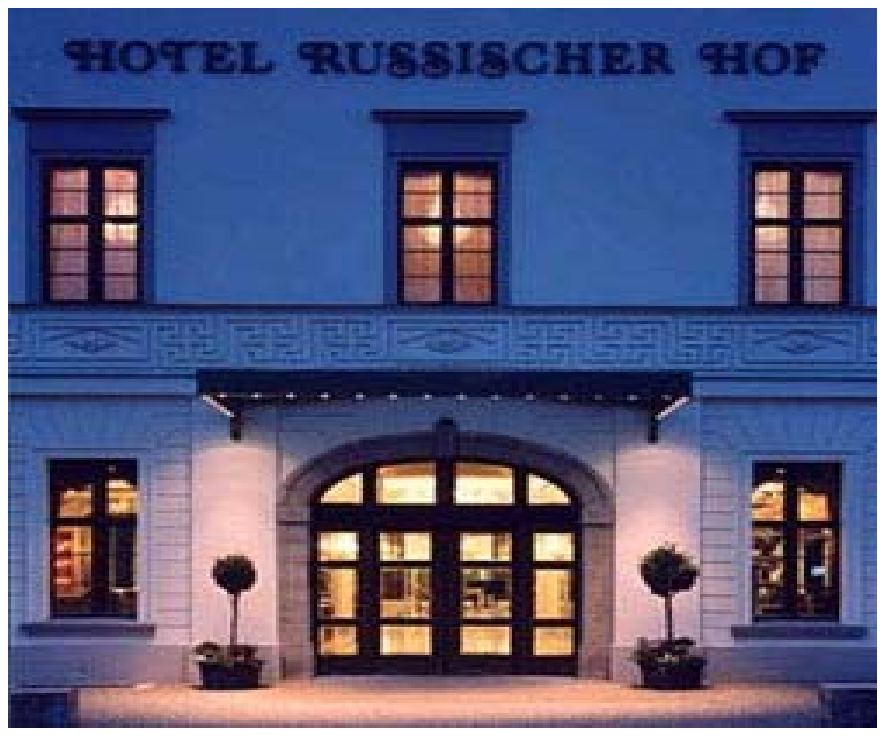




\subsection{Issues and Challenges for Data Management}

Implementing a real-time, web-based data management system brings a number of issues and challenges concerning the data collection process, the scalability of the data system, interoperability between clients and servers, and the security of the data services.

\subsubsection{Data Collection}

One of the fundamental challenges to be resolved is how and where to obtain reliable, high-quality data. There is a massive amount of information available on the Internet, but much of it is unqualified and only a small percentage of the data could be classified as real-time. One solution is to accredit selected sites so that a BAS seeking data will be reasonably assured that the data on that site meet a minimum level of validation. However, this raises two datamanagement issues. First, the requirements for reliability for some data will be stricter than for other data (e.g., air pressure versus relative humidity). A minimum level of validation may not be sufficient, and each data point should contain its own range of reliability. Second, the object registry services described as a part of Web Services/Structured Data Services (SDS) in Section 4.1 are processes similar to an accreditation process. Ambitious developers in this area have coined the term "global registry," but in reality the registration of SDS objects will take place within, and as a part of, an industry trade group. Most likely this trade group will also offer accreditation services for registered objects, such as validated traffic maps and air quality forecasts.

\subsubsection{Scalability}

The type and configuration of hardware and software can limit the number of clients who can interact with a network or a server. In the case of a real-time data system, scalability refers to the ability of the system, or a component of the system, to adapt to a greater or lesser intensity of use while still meeting fundamental data latency and availability requirements. In many respects, improving scalability is about reducing or eliminating bottlenecks in the data transfer process, for which there is a micro and macro focus. The micro focus looks at the multitude of 
concerns with capacity management at the component level, which is application- and hardwarespecific.

Such a discussion about aspects of database design, load balancing methods, or the separation of application logic from data logic is beyond the scope of this report. A more useful focus is on the constraints that system architecture places on client/server interaction or more specifically on the scalability of the data interface. In general, scaling (and security) is improved by using a multi-tier architecture, but adding additional layers of abstraction into the system adds complexity in design and implementation and increases the maintenance requirements.

The simplest data interface is the broadcast interface. Its scalability, in terms of the number of clients connected, is good because more clients can be connected to the same data stream, assuming the availability of signal replication functionality. However, if additional clients require further localization of the data or an increase in the number of locales, this additional localization will limit the scalability of the interface. The broadcast interface is somewhat inefficient in terms of data transfer because the same data are going out even though they may not be fully used by all system locales; whether there are zero clients or a million, the same bandwidth is used.

The request/response data interface is more scalable than the broadcast interface because the request and response can be optimized to limit extraneous data transfers. It is possible to implement load-balancing methodologies on the data server that can reduce system bottlenecks, provided that the data source provider is an active participant in the real-time data management system. However, the request/response does little to relieve the problem of redundant data transfers, which arises when the request rate from the client is higher than the refresh rate of the data at the server. Ideally, it would be desirable to request data shortly after updating on the server, but in practice such synchronization is difficult to achieve. Thus, redundant requests for data are often made to ensure that the latest data are available at the client. (This is not a problem with the broadcast interface because the latest data are always sent out when available.) 
The Structured Data Services interface is a step toward relieving the problem of redundant data transfers and improving the synchronization between the client and the data server. It is the most scalable of the data interfaces but would be the most complex to implement in a BAS atmosphere. Structured Data Services also bring with them a significant amount of processing overhead; while this approach normally implements additional important functions and features, the data latency can be increased by the additional data handling.

\subsubsection{Interoperability}

The ability of the real-time data management system to work with multiple types and generations of systems is important. Within the scope of HTTP services, interoperability is ensured as long as all parties adhere to the Hypertext Transfer Protocol and HTML standards. However, it is clear that the client and server interaction within the data management system must be refined further than just HTTP and HTML. Posting data to a web page is a very straightforward process and can be automated easily, but to an automated agent/client such an implementation is very brittle. The data must be labeled or tagged consistently so that the client can find the data reliably. Modifications or additions to the posting may cause the client not to find the data, breaking the system.

To avoid these types of potential problems, the extensible markup language (XML) has stepped in to offer a better approach to handling data. It provides a significant amount of flexibility on the server end of the process to deliver recognizable data to multiple types of clients. It also forces designers building distributed computing applications to separate data handling from application logic, eliminating one of the main stumbling blocks to interoperability. The use of XML is not without side effects, however. The data held within XML is barely human-readable and will rarely display in a web browser without a scheme for the display. Additionally, the flexibility of XML can encourage the extension of data fields and types without taking into account the effects within legacy clients.

For data handling systems, a significant issue is legacy clients based on older data types and older methods of client/server interactions. It is normal for functionality to be added as the 
application interface improves and, thus, the types of data and methods of handling the data change over time. Mechanisms such as Servlets, which are typically small web-based applications written in Java, provide both the application and the data to the user at the time of interaction.

This approach gives the user the latest application and ensures better compatibility between the application and data. The major drawback is that as the application's size and scope increases, the data transfer requirements increase, adding significant latency into the datatransfer process. Structured Data Services offer an alternative solution to the problems of maintaining currency with all remote clients and the data-transfer overhead of Servlets, by providing registration and versioning services for applications. Moreover, discovery services that allow clients to seek out new services may add a degree of intelligence to SDS, whereby new solutions can be found or competing alternatives can be selected, thus automatically increasing the effectiveness of the BAS control method.

\subsubsection{Security}

Security-conscious people refer to security as a process, not a tool. This distinction emphasizes that good network security is more than establishing an SSL connection; it needs to be designed into the data management system. There is a distinct trade-off between security and functionality. Most PCs are intended to be very functional with little to moderate security. In office network settings, most people begin to chafe when they are required to change their password on a monthly or even a quarterly basis. High security impedes functionality by limiting connections across systems and actions within applications.

Within the framework of this trade-off between security and functionality, an important aspect is determining what level of security to apply to groups of data and actions. In general, the more critical the data are to the needs of the BAS, the greater the need for security. On the other hand, data that are available from one or more public sources should need only a low level of security. 
Among the data interfaces described in this report, the broadcast interface offers the least security, other than the anonymous use of data within the data stream. While it is technically possible to encrypt the broadcast signal and build decryption services into clients, in practice this security is highly vulnerable because of practical limits on the encryption strength and because the similarity of the data sent to separate clients would dramatically increase the vulnerability of all clients if one client is compromised.

The request/response interface offers better security than the broadcast interface by using the SSL protocol and the HTTPS gateway, but this security only protects the data channel and does not prevent a malicious intrusion into the data acquisition or data validation processes. While the boundaries of the real-time data management system have not been firmly defined and such security could lie outside the bounds of the system, if this component of the system is not secure, the data management system must incorporate a data verification step after the data are transferred, to prevent the use of false or destructive data.

The Structured Data Services interface offers the most opportunities for security because these services can work better with firewalls, authentication services, and more granular security mechanisms. This security does come with a cost in terms of data latency because of transfer delays due to the authentication process at firewalls and with other data management services. But in the end the gains outweigh the costs, so that if for no reason other than good security, the SDS interface should be preferred over the other types of data interfaces. 


\subsection{Building Manager Perspectives}

Results from the web-based surveys and focus-group discussions form the basis for discussion of building manager perspectives. Their insights are an important input to the assessment of potential BAS enhancements tied to real-time Internet data.

Responses of the building managers to selected questions in the web-based surveys are summarized in Table 4-3. For discussion purposes, managers were asked on open-ended survey questions concerning (1) ways to avoid critical incidents, and (2) types of automation or functionality that are perceived as having the potential to improve efficiency. Survey participants cited two primary means of avoiding critical incidents — detailed inspection/maintenance at regular intervals and predictive diagnostics.

While inspection and maintenance inevitably involve human interaction with the building system and potential applications involving the Internet may be limited, there clearly is a role here for an automated system. First, if equipped with adequate sensing capability and appropriate rules or algorithms, the system can perform a certain amount of self-inspection or self-analysis and can alert managers/engineers when there is an apparent problem. Predictive diagnostics are a related concept, ideally enabling the system to detect potential problems before they occur or become severe. Second, it should be possible to program the system to establish inspection/maintenance schedules and to track adherence to these schedules/procedures, with inputs from maintenance staff coupled with appropriate sensing technology.

State-of-the-art equipment and Internet access are integral elements of the managers' ideas related to automation and functionality. Sensing the presence of occupants is seen as a means of promoting efficient use of both ventilation and lighting (and, by analogy, space conditioning as well). Factors related to the sun - minimizing solar gains through automatic blinds and making use of its energy through solar generation - are viewed as important, as is the general concept of weather stations. Factors such as the proximity of weather stations and the extent of regional variation in weather patterns become important in determining the role of Internet-based real-time data for such applications. 
Table 4-3 Summary of Responses to Selected Web Survey Items

\begin{tabular}{|c|c|c|}
\hline Survey Item & \multicolumn{2}{|l|}{ Responses } \\
\hline $\begin{array}{l}\text { Common Methods of Monitoring } \\
\text { Building Performance }\end{array}$ & \multicolumn{2}{|c|}{$\begin{array}{l}\text { Scheduled maintenance } \\
\text { Written logged reports } \\
\text { Automatic monitoring/notification systems } \\
\text { Responses to occupant complaints }\end{array}$} \\
\hline $\begin{array}{l}\text { Factors Contributing to Poor } \\
\text { Performance }\end{array}$ & \multicolumn{2}{|c|}{$\begin{array}{l}\text { Aging system } \\
\text { Immature technology } \\
\text { Inadequate knowledge or poor planning } \\
\text { Weather } \\
\text { System users and staffing } \\
\text { Unforeseen demands }\end{array}$} \\
\hline $\begin{array}{l}\text { Means of Avoiding Critical } \\
\text { Incidents }\end{array}$ & \multicolumn{2}{|c|}{$\begin{array}{l}\text { Closer inspection } \\
\text { Routine maintenance } \\
\text { Predictive diagnostics } \\
\end{array}$} \\
\hline $\begin{array}{l}\text { Existing Energy-Efficient Practices } \\
\text { by Occupants }\end{array}$ & \multicolumn{2}{|c|}{$\begin{array}{l}\text { Shutting off lights } \\
\text { Using light sensors } \\
\text { Shutting off certain equipment when not in use }\end{array}$} \\
\hline $\begin{array}{l}\text { Existing Procedures/Components } \\
\text { Relating to Automation }\end{array}$ & \multicolumn{2}{|c|}{$\begin{array}{l}\text { Heating and cooling systems } \\
\text { Backup power sources } \\
\text { Security systems } \\
\text { Ventilation (including occupancy-based) } \\
\text { Interior/exterior lighting } \\
\text { Automatic operator paging/alerts } \\
\text { Daylighting systems/occupancy-based lighting } \\
\text { Fuel switching } \\
\text { Seasonal changeovers }\end{array}$} \\
\hline $\begin{array}{l}\text { Existing Types of Functionality } \\
\text { Related to BAS }\end{array}$ & $\begin{array}{l}\text { Operator workstations } \\
\text { Pneumatic or DDC controls } \\
\text { Central plant controllers } \\
\text { Field panels } \\
\text { Data logging } \\
\text { Trending analysis }\end{array}$ & $\begin{array}{l}\text { Terminal unit controllers } \\
\text { Alerts via email or pagers } \\
\text { Built-in weather stations } \\
\text { TCP/IP gateways } \\
\text { File servers } \\
\text { Internet access } \\
\end{array}$ \\
\hline $\begin{array}{l}\text { Ideas on Automation/Functionality } \\
\text { to Maximize Efficiency }\end{array}$ & $\begin{array}{l}\text { State-of-the-art equipment } \\
\text { Variable-frequency drivers } \\
\text { Occupancy-based } \\
\text { ventilation } \\
\text { Occupancy-based lighting } \\
\text { Automatic paging }\end{array}$ & $\begin{array}{l}\text { Internet access to controls } \\
\text { Weather stations } \\
\text { Automatic blinds } \\
\text { Solar generation } \\
\text { Software for energy- } \\
\text { efficient operations } \\
\end{array}$ \\
\hline
\end{tabular}

Table 4-4 summarizes building managers' responses to the key topics covered in the focus groups. The last four topics, which required greater originality from participants, form the 
basis for this discussion. Participating managers expressed a great deal of concern over maintenance, particularly the need to ensure proper performance of maintenance activities. Consistent with results of the web-based surveys, weather-related information was seen as a key additional element for building operations; this is not surprising. GEOMET expected that this would be a major concern. The novel twist added by facility managers is the idea of tying in weather information with major regional or local events (e.g., how the weather might affect tourism-related needs). Other novel suggestions included linking security systems to the BAS and posting on the Internet scheduled use of conference or meeting rooms and tying that information into the BAS (e.g., to prepare the rooms for occupancy).

Managers' concepts of the "perfect" building system provide further insights into potential BAS enhancements, with or without ties to real-time Internet data. Knowing the locations of occupants and operators is viewed as one key. Beyond the use of motion sensors to detect the general presence of occupants, it is not difficult to envision an Internet-based system whereby occupants/operators input their planned location schedule for the day, with updates in the event of major deviations. Thus, at any point in time, the system could "know" the approximate number of occupants in various areas of the building. Self-analysis/calibration and diagnostic capabilities are also viewed as essential elements. However, such features should not result in the system being overly complex - quite the opposite; it should be user-friendly with the capability for remote access through the Internet.

These suggestions are not without concerns, however. Chief among these concerns are Internet-related security issues (e.g., potential for hackers to invade the system) and occupant privacy concerns (e.g., the sense of being watched). As a final note, the types of enhancements suggested or contemplated here carry with them associated costs and training requirements, in the latter case possibly for occupants in addition to operators. 
Table 4-4 Summary of Responses to Focus Group Topics

\begin{tabular}{|c|c|}
\hline Discussion Topic & Responses \\
\hline Skilled operator better than BAS? & $\begin{array}{l}\text { Constant operator attention required } \\
\text { Need central location combined with pneumatic controls } \\
\text { BAS better able to spot trends and "tweak" } \\
\text { Feedback from many sensors needed for BAS } \\
\text { Perhaps optimal approach combines operator and BAS }\end{array}$ \\
\hline $\begin{array}{l}\text { Information from regional events } \\
\text { useful for increasing control } \\
\text { system stability? }\end{array}$ & $\begin{array}{l}\text { Possibly for weather-related phenomena such as frontal } \\
\text { movements or rain/snow events } \\
\text { Defined region would need to be fairly small }\end{array}$ \\
\hline $\begin{array}{l}\text { Internet access to OEM } \\
\text { equipment data or access to } \\
\text { remote diagnostic services } \\
\text { helpful for maintenance? }\end{array}$ & $\begin{array}{l}\text { Some aspects already Internet-based, but not tied into BAS } \\
\text { Need validation that maintenance has been performed as } \\
\text { planned }\end{array}$ \\
\hline $\begin{array}{l}\text { Types of additional information } \\
\text { useful for building operations? }\end{array}$ & $\begin{array}{l}\text { Weather-related information, especially in relation to major } \\
\text { regional/local events } \\
\text { Use web to schedule use of conference/meeting rooms, tie } \\
\text { information into BAS } \\
\text { Links to security systems } \\
\text { Links to real-time information on traffic, catastrophic events, } \\
\text { fuel pricing, energy use }\end{array}$ \\
\hline $\begin{array}{l}\text { What is the perfect building } \\
\text { system? }\end{array}$ & $\begin{array}{l}\text { Knows locations of operators and occupants at all times } \\
\text { Self-calibrating with self-analysis and diagnostic capabilities } \\
\text { Not overly complex, user-friendly with remote access } \\
\text { Able to automate some adjustments before "calling" engineer } \\
\text { Can provide a log of key events } \\
\text { Can prepare routine or special reports }\end{array}$ \\
\hline Potential barriers to success? & $\begin{array}{l}\text { Security concerns for Internet-based operations } \\
\text { Occupant privacy concerns (i.e., feeling "watched") } \\
\text { Cost issues } \\
\text { Training needs }\end{array}$ \\
\hline
\end{tabular}




\subsection{EVOLUTIONARY CONTROL STRATEGIES}

The evolutionary control strategies have been grouped into four categories:

- Building control using real-time weather data,

- Building control based on occupancy considerations,

- Building control tied to maintenance functions, and

- Other potential strategies.

These categories broadly reflect the types of data that are available over the web, noted in Section 4.2. The last category is a catch-all for strategies based on future changes in building technologies. These last strategies are described briefly.

While the detailed discussions of control strategies in Section 4.2 were meant to answer the question, "Is this possible?" this section turns to the question, "Is this worth implementing?"

\subsection{Preliminary List of Control Strategies}

A preliminary list of possible building control strategies was based on sources of realtime data available over the Internet and comments from the focus groups. The initial list contained slightly more than 40 applications and included both existing and potential strategies. However, it was ultimately decided to forego analysis of several "potential" strategies at this time, in order to maintain focus on more near-term applications. These "potential" strategies, which could conceivably be analyzed for applicability at a future date, include:

- Security -- protecting interior ventilation systems against hazardous air-borne materials and compounds;

- Scheduling and control of facility parking garages or decks using traffic data;

- Integrating traffic data into air quality measures for indoor air quality control;

- Security -- parking control using intelligent tags; and

- Optimizing solar generation or shading control with data on sun position. 


\subsection{Grouping and Prescreening}

We reviewed the final straw man list for feasibility and functional grouping. If the control strategy seemed to be too narrow in scope or of minimal value to building owners, it was eliminated. Eventually the list was narrowed down to thirty applications that were then grouped into four categories:

- Building control using real-time weather information,

- Building control based on occupancy considerations,

- Building control tied to maintenance functions and,

- Other potential strategies.

\subsection{Strategy Analysis}

The control strategies were then analyzed along four dimensions:

- Cost and savings,

- Reliability of the real-time data,

- Feasibility of the technology and,

- Validity of the proposed approach.

We used the flow chart in Figure 5-1 to add structure to our assessment so that each strategy would be analyzed consistently and the main criteria addressed. The control strategies have been further categorized as traditional or innovative. Traditional control strategies were compared against existing methods to determine if there was added value in using real-time Internet data. For innovative strategies, the analysis assessed cost, technology, and constructability constraints.

Cost Analysis. The assessment of cost and savings to determine an order of magnitude estimate for the implementation cost and the potential cost savings from the control strategy. Cost savings will also include an estimate of the non-energy benefits, although such estimates are very subjective. 
Sensitivity Analysis. The assessment of reliability of the real-time data to make an estimate of how robust the data are in terms of reliability and latency. This sensitivity will normally be noted in three categories-low, medium, and high.

Technology Analysis. The assessment of feasibility of the technology used to determine if there was a similar implementation of this control strategy's technology in any industry or discipline or if contextual limits affect the implementation or use If the technology has not been field-tested, it is not consider viable for consideration within the final strategy grouping.

Methodology Analysis. The assessment of the validity of the application to determine if this is the best or a better way of performing this type of control. If the strategy may be integrated into other control methods or be eliminated because of changes in building services, this will be noted. Also noted will be potential paradigm shifts in how users, managers, and owners view buildings. If data for the control strategy are critical for building operations, the strategy will be discarded because the security of that operation should not be trusted to a webbased real-time data system until such systems are thoroughly field-tested and debugged. 


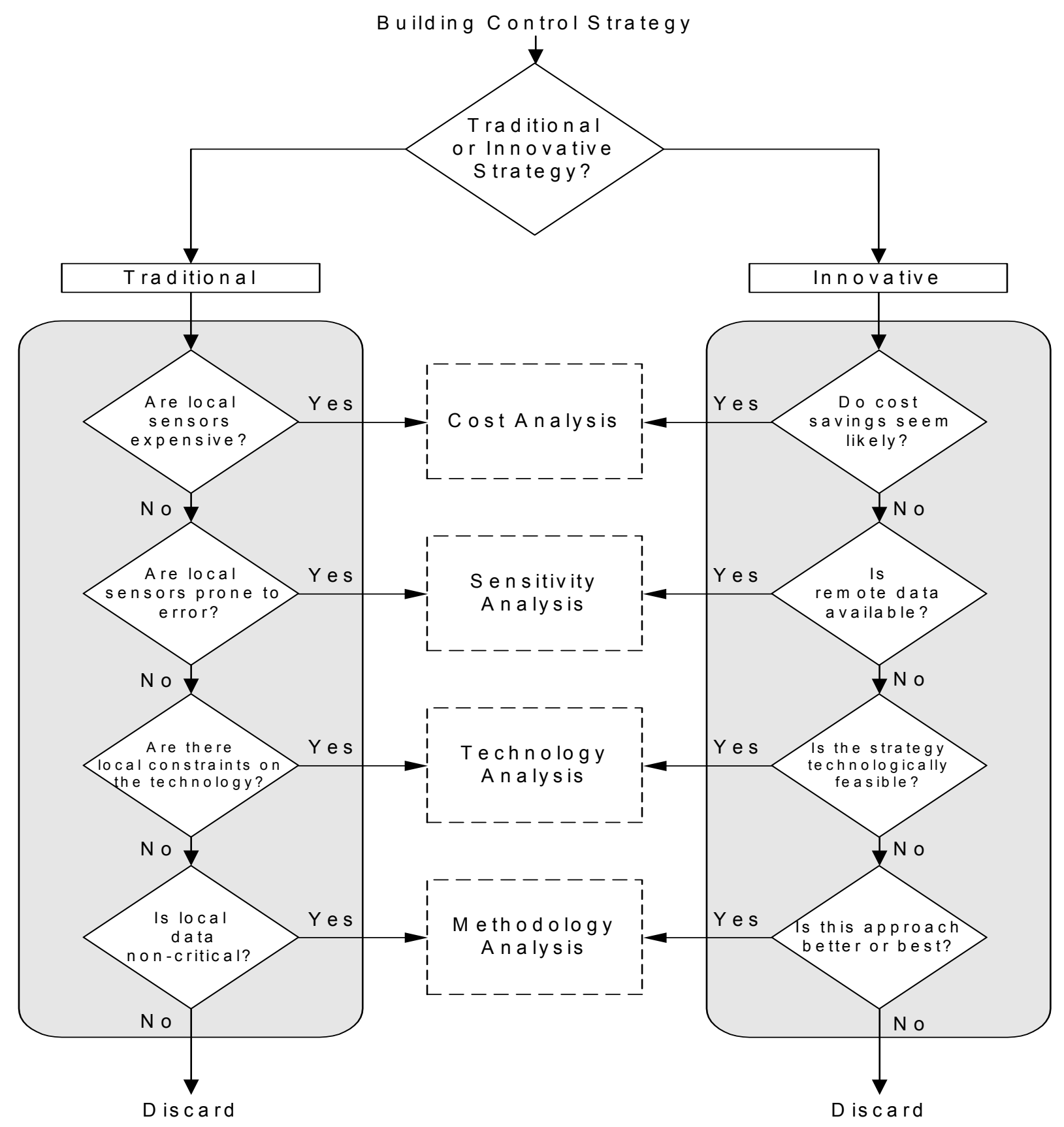

Figure 5-1 Decision Rules Flow Chart

The prescreened strategies are analyzed by group below. Each analysis includes a short description of the recommended action to be taken. The objective is to arrive at a short list of viable control measures for further development. Therefore, the proposed action will either 
recommend selecting the strategy for development, not selecting the strategy, selecting but not developing the strategy, or integrating the strategy into other strategies. In some cases, a strategy is selected as being viable, but its development is not feasible within the scope of this report.

\subsubsection{Strategy Group A: Building Control Using Real-Time Weather Information}

A.1: Economizer Control Based on Local Weather Data. This traditional strategy was not selected because better maintenance can correct the problems it addresses. Although local sensors are not expensive and there are no local constraints on the technology, local sensors are prone to error. Poor maintenance can leave the sensors nonfunctional or uncalibrated.

A.2: Advanced Set Point Control Based on Weather. This innovative strategy was selected although it was judged to be viable only if real-time data from the Internet are used. Cost savings seem likely. The cost of this strategy is mostly in the development of software although a sensor for occupancy is needed (i.e., CO2). TCO is estimated at $\$ 20$ to $\$ 35$ per square meter, and savings are estimated at 2 to 5 percent of total heating and cooling costs. Remote data are available - there are many weather service sources with a high level of robustness. Although the strategy is technologically feasible, the biggest constraint is that many buildings have no high-speed connections to the Internet.

A.3: Evaporative Cooling of Outdoor Venues. This traditional strategy was not selected; the analysis determined that better maintenance can fix the problems it addresses. Local sensors are not expensive, there are no local constraints on the technology, and the local data are non-critical. However, local sensors are prone to error and require good maintenance. Ideally the information derived from the sensors should be augmented with local weather data from the Internet.

A.4: IAQ Moisture Control. The results of the analysis of this traditional strategy suggested that it be integrated into the Strategy A.5 (discussed below). Local sensors are not expensive, but they are prone to error; IAQ problems with mold growth are not measured in realtime. There are no local constraints on the technology; mold growth, which negatively affects 
IAQ, results from too much moisture accumulation in the building. The normal practice is to maintain the dew point at or below preset values $-55^{\circ} \mathrm{F}\left(13^{\circ} \mathrm{C}\right)$ in summer and $40^{\circ} \mathrm{F}\left(4^{\circ} \mathrm{C}\right)$ in winter. This yields a drying action indoors that is fundamentally similar to Strategy A.5. Local data are noncritical.

A.5: Moisture Management. Although this innovative strategy is only viable when real-time data from the Internet are used, it was selected as being a better or best approach to resolve IAQ problems caused by mold. Managing the hygric buffer capacity of a building is more appropriate than monitoring mold growth directly. Cost savings are likely; the TCO of developing the software and installing sensors for moisture levels in critical parts of the building structure is estimated at $\$ 20$ to $\$ 35$ per square meter. Savings come from an extended structure life, better IAQ, and lower emergency maintenance costs. Many weather service sources with a high level of robustness make remote data readily available. The strategy is technologically feasible; the biggest constraint is that many buildings have no high-speed connections to the Internet. Because local sensors for continuous monitoring of moisture levels are not widely deployed, this application has not been thoroughly tested.

A.6: IAQ Control for Ambient Pollutants. This innovative strategy was selected but not developed. Although cost savings seem likely (from greater productivity and lower healthcare costs), the strategy is not technologically feasible at this time. Real-time air quality measurement technology is still immature and largely driven by environmental regulations. However, remote data are available; weather parameters are available with a high level of robustness, but other measures of air quality, such as ground-level ozone, PM count, pollen count, NOx and SOx are available only in selected regions. Nevertheless, this approach was judged to be a better or best approach: The standard approach to improving IAQ is to increase the amount of outside air brought into the building, but this doesn't make sense if the outside air quality is poor. If poor outside air quality is a temporary problem, then temporarily limiting outside air is a viable solution.

\section{A.7: Incorporating Operable Windows and Protection Against Wind and Water}

Damage, and Physical Security. This traditional strategy was selected but not developed. Local 
sensors are expensive and prone to error. Maintaining a weather station that is capable of reliably measuring wind speed and precipitation is relatively expensive, and a local weather station needs good maintenance. There are also local constraints on the technology; operable windows significantly complicate the HVAC design of a building. Existing buildings with manually operable windows would require retrofits to allow the windows to be opened and closed remotely.

A.8: Optimize Cogeneration Using Predicted Weather. This traditional strategy was also selected but not developed. Although the impact of decisions to use cogeneration capacity or purchase energy on the market is felt locally, there is little technological need to locate these tools at the building. Analysis and decisions can be made remotely and instructions passed along to the BAS controlling the cogeneration equipment. At this time cogeneration is only economically feasible at large sites.

\section{A.9: Disaster Proofing and Automatic Lockdown of Exterior Equipment. Although}

this innovative strategy was judged to be a better or best approach (automated weatherization of equipment is good practice), the strategy was not selected because of limited vendor support. It is technologically feasible, but the functionality for automated wind and weather protection will need to be designed into the equipment. As in the strategy involving operable windows, the device must allow remote opening and closing of its systems. Remote data (weather parameters) are available with a high level of robustness. While cost savings are likely (including lower insurance costs and the avoided cost of repairing damaged equipment), control interfaces and some protection devices would have to be custom built, resulting in a very specialized and costprohibitive application.

A.10: Solar Shading and Screening. This traditional strategy was not selected because it would need better maintenance. Although local sensors are not expensive and there are no local constraints on the technology, local sensor data can be incorrect if sensors are not properly maintained. 
A.11: Davlighting Control. As in the previous strategy, this traditional strategy was not selected because of the need for better maintenance. Although local sensors are inexpensive, they are prone to error; good maintenance is required, and sensors must be periodically examined for positioning and availability (in the case of occupant modifications). There are also local constraints on the technology: Solar radiation is a very local event, and there is significant question as to whether remote data are granular enough to properly control local devices.

\section{A.12: Automated Computer Network Protection for Data Centers and Emergency}

Response Center. This innovative strategy was not selected because of technology limits on grounding shunts. Cost savings seem likely because the cost to restore computer networks can be very high, especially if data are also destroyed. Remote data (detailed lightning information) are available with a high level of robustness. The strategy is technologically feasible. For simple surges or sags in line voltage caused by lightning strikes on the transmission system, power conditioners are the solution. Once installed, power conditioners are available 100 percent of the time. For a direct lightning strike, grounding shunts that act as massive fuses are installed. At this time, however, these grounding shunts are designed for a one-time use. Although the approach is a better or best approach, reusable grounding shunts are needed.

A.13: Rain Harvesting for Irrigation (Lawns and Gardens). This innovative strategy was not selected because of high installation costs. Although cost savings are likely from the reduction in water (and possibly sewer) bills, and these savings could be very significant in arid climates, they must be balanced against certain drawbacks, including the high cost of the installation of a water-holding tank and the difficulty of finding space and a suitable location for it. Remote data (predicted precipitation) are available through many sources with a high level of robustness. There are no technological constraints to this technology, which would make sense in areas with low or moderate rainfall.

A.14: Irrigation Control Based on Long-Range Predicted Precipitation Data.. This innovative strategy, like the preceding one, was not selected because of the high installation costs of water-holding tanks. It too would make sense in areas of low or moderate rainfall, and it could use the available remote data on predicted precipitation. Costs savings would come from 
reduced water (and possibly) sewer bills. If water storage is not used, then possible applications of an irrigation control system would include rationing water within prescribed limits and preventing the over watering of irrigated areas.

\subsubsection{Strategy Group B: Building Control Based on Occupancy Considerations}

B.1: Advanced Set Point Control Based on Forecast Conditions. This innovative strategy was selected. This approach is a complementary strategy to A.2 in that includes measures of building occupancy in specific system areas, using such methods as $\mathrm{CO}_{2}$ monitoring and occupant schedule sharing. Cost savings seem likely. The additional cost of Strategy B.1 is in the installation of $\mathrm{CO}_{2}$ sensors and the development of an application interface between the building occupant and the BAS. Additional savings are estimated at 1 to 2 percent of total heating and cooling costs. Remote data are available although not all of the occupant data would come from a location physically removed from the building. The schedule that occupants shared with the BAS would come over an HTTP gateway.

The strategy is technologically feasible. Occupancy-based ventilation control using $\mathrm{CO}_{2}$ has undergone significant field-testing. Many of the constraints on the use of $\mathrm{CO}_{2}$ sensors have been resolved, such as high cost and problems with calibration. Strategy B.3 specifically addresses occupant interaction with the building's HVAC systems, but it is within the context of occupancy-based control that building occupant schedules would be integrated into the BAS's control strategy. Note that for privacy reasons, the sharing of schedules by the occupant must be voluntary. An outstanding issue, which will also be noted in other control strategies, is the inability of the HVAC system to use occupancy data because of a lack of granularity in which to provide thermal comfort to the individual occupant.

Analysis indicated that this strategy was a better or best approach. It is a very attractive control strategy when integrated with Strategy A.2 (i.e., integrating occupancy data with predicted temperatures and dew points). Then heating and cooling systems can be optimized to provide an effective indoor climate with the most efficient use of energy. Additionally, this 
control strategy may be more effective if used in conjunction with Strategy B.4, which is the sharing of work schedules with the BAS.

\section{B.2: Parking Instructions and Navigation Instructions Based on Intelligent Tag}

Interface. Although this innovative strategy was not selected because the demand for these services is unknown, it was judged to be a better or best approach that should be linked with other building services. Cost savings seem likely; they would be in the form of productivity benefits (minimizing the time spent searching for parking spots, etc.). The strategy makes use of the intelligent tag technology to deliver specific information to building occupants while they are in their cars. At this time, remote data are not available, but the strategy is technologically feasible. Intelligent parking tags are currently being implemented on a large scale across the U.S., but these systems are intended for data collection and building security, not data exchange. Driver parking services have often fallen within the scope of valet services, so the demand for interactive services may be limited.

\section{B.3: HVAC and Lighting Control Based on Flight and Rail Schedules. This} innovative strategy was selected but not developed. The cost savings would come from a more effective use of energy based on the schedule of the arriving future occupant. Remote data are not available, but the strategy is technologically feasible and is currently being used at some travel-related sites (e.g., hotels and rental car agencies). The approach is a better or best one, but a significant challenge to its implementation is security and privacy concerns. Many Internet travel sites will allow the user to specify a flight number when booking a hotel, rental car, or other services. While this can increase the quality of service for the agency or business providing the service, there is only an implied assumption about how these businesses will use the information and little assurance that they will use it in good faith. Aside from these security concerns, the proposed strategy might fail the face validity test: "How does this benefit me?" Does the client get bonus miles, an extra chocolate on the pillow, or additional services?

The initial cost of building HVAC systems has always been a limiting factor in their design and installation. Thus, many HVAC systems lack the granularity to be able to resolve services to individual occupants, and they may even be designed to serve 100 or more occupants 
and workspaces with only one control input. Moreover, thermal comfort conditions must be maintained even if only one occupant is working in the space served by the HVAC system. In addition, human thermal comfort has psychological and physiological aspects that make it nearly impossible to estimate the "best" temperature for a group of occupants. It is clear that building operators would wring their hands in despair if such fickle groups were given full control of the HVAC system. Nevertheless, a services interface that functionally mirrors the informal interface between building engineers and occupants, which exists in most buildings, could be developed and implemented to the satisfaction of building operators and occupants.

The savings from this strategy would come from two sources: energy savings from resetting temperatures in unoccupied spaces and productivity benefits due to building users having a more refined control of the comfort of their environment. The development costs associated with this interface are not trivial and could become large if customized interfaces between the BAS and building tenant networks are planned.

Remote data are available; the portal would be accessed via HTTP and a globally addressable IP address. Properly authenticated building occupants could access the BAS locally or remotely.

As discussed above, the strategy is technologically feasible. The technology has undergone extensive development and is mature enough for deployment of an application at this time, if such an application existed. As has been stated in the analyses of previous strategies, most buildings do not have a connection between the BAS and the Internet. Making the BAS web-aware is a fundamental first step.

B.4: Occupant Interaction: Shared Schedules of Building Occupants. This innovative strategy was selected for integration into building services Strategy B.6. Although this control strategy is technologically feasible, there are constraints because of legacy HVAC issues and sociological issues around how buildings are operated. The initial cost of building HVAC systems has always been a limiting factor in their design and installation. Thus, many HVAC systems lack the granularity to be able to resolve services to individual occupants, and they may 
even be designed to serve 100 or more occupants and workspaces with only one control input. Moreover, thermal comfort conditions must be maintained even if only one occupant is working in the space served by the HVAC system. In addition, human thermal comfort has psychological and physiological aspects that make it nearly impossible to estimate the "best" temperature for a group of occupants. It is clear that building operators would wring their hands in despair if such fickle groups were given full control of the HVAC system. Nevertheless, a services interface that functionally mirrors the informal interface between building engineers and occupants, which exists in most buildings, could be developed and implemented to the satisfaction of building operators and occupants.

The savings from this strategy would come from two sources: energy savings from resetting temperatures in unoccupied spaces and productivity benefits due to building users having a more refined control of the comfort of their environment. The development costs associated with this interface are not trivial and could become large if customized interfaces between the BAS and building tenant networks are planned.

Remote data are available; the portal would be accessed via HTTP and a globally addressable IP address. Properly authenticated building occupants could access the BAS locally or remotely.

As discussed above, the strategy is technologically feasible. The technology has undergone extensive development and is mature enough for deployment of an application at this time, if such an application existed. As has been stated in the analyses of previous strategies, most buildings do not have a connection between the BAS and the Internet. Making the BAS webaware is a fundamental first step.

B.5: Occupant Interaction: Safety and Security Advisories to Occupants. This strategy was also selected for integration into Strategy B.6. It is a better or best approach providing a value-added service to building occupants. 
It is technologically feasible: Safety advisories would be an adjunct service to other building services. Therefore, these services would most likely be integrated into the same HTTP services available through a building portal. Email alerts and notifications, emergency pages, text messaging to mobile phones and PDAs, and text-to-speech voicemails are additional technologies that use the Internet backbone.

Although this strategy would yield few cost savings for the building operator or tenants, there is significant value in ensuring the safety and welfare of building occupants. When this strategy is integrated with a services portal, such as that proposed in Strategy B.6, this becomes a relatively low-cost service addition.

Remote data (storm warnings and advisories) are available and highly robust. On the other hand, online security advisories are virtually nonexistent outside those for the IT industry.

B.6: Occupant Interaction: Interface for Services. This innovative control strategy was selected and judged to be a better or best approach. The face validity for offering web portal services for a building is strong. But developing and maintaining web portals is time-intensive. Much of the information that is useful to building occupants expires quickly. If a building portal is not integrated into the BAS, or vice versa, then the building portal can easily be pushed to the side and quickly become stale and dysfunctional. For this reason, a core assumption in this strategy is that building services, internal and external to the building, will be offered from the same interface, and this strategy will be integrated with the occupant interface for the HVAC system or systems.

Cost savings seem likely. There are possible productivity enhancements from being able to access services over the local web portal for the building. If the portal is properly localized, such a service offering to building occupants seems to be very useful. Remote data are available because this would be much like a normal website with links to useful local services.

The strategy is technologically feasible. At least one web-hosting company has oriented its hosting services toward building portals for commercial residential and commercial 
properties. The physical location of the proposed building portal need be at the building, and given the paucity of Internet connections into many building systems, an off-site location with large bandwidth capability would be a recommended start. However, there is a paradox in buildings where the building engineer has a 56k dial-up connection to the Internet and the building's tenants connect internally and externally through fiber optic cable. The telecommunication infrastructure is laid in the building but does not connect to the BAS!

\subsubsection{Strategy Group C: Building Control Tied to Maintenance Functions}

C.1: Maintenance: Alarms and Notifications. This traditional strategy was selected. Local sensors are not expensive or prone to error, and local data are noncritical, but there are local constraints on the technology. There are several network services that need to be properly configured for a BAS to send email or pages. These come in many flavors and capabilities, but in all cases, this technology is very mature and can be implemented quickly once the BAS has a presence on the Internet (world-addressable IP address). Recent offerings from building control software vendors include the ability to script emails in response to alarms or specific system conditions, all within the vendor's Integrated Development Environment (IDE) for the BAS.

\section{C.2: Maintenance: Remote and/or Self-Reporting Diagnostics. This innovative} strategy was selected for integration into Strategy C.1. It was judged to be a better or best approach. A large change is on the horizon for devices within building systems because of the relentless improvements in computing technology. A relatively innocuous step by PC motherboard makers highlights this change. Rather than use an expansion Ethernet network card, Ethernet chips are now incorporated onto the motherboard; thus, in a small way the bond between the CPU and a network address is cemented. It is foreseeable that all smart electronic devices will be networkable and will be addressable via an IP address. Organizations such as the Industrial Ethernet Association (IEA) and the Open DeviceNet Vendor Association (ODVA) are pushing vendors toward industrial and building devices that connect using TCP/IP. Initially the installation of such devices may be technological overkill, but economically the additional processing power will only add moderate cost to the raw cost of the device. 
The strategy is technologically feasible. Although not a functional necessity, the ability to run an Operating System (OS), embedded or otherwise, is a key step toward self-diagnostics. An application that is acting as a listening service (receiving signals) has difficulty monitoring itself; therefore, it is advantageous to have another layer of abstraction (the OS), which is capable of monitoring and preempting these services for diagnostic reasons. IBM incorporated an OS into a watch (June 2001), demonstrating the feasibility of embedding OSs into small devices. The question "Can it be done?" has been answered, but response to the question "Should it be done?" is still unclear. Using the OS-embedded in IBM's watch to monitor a temperature sensor is an extreme case of overkill.

\section{C.3: Maintenance: Automatically Notification of Maintenance Problems. This} innovative strategy was selected for integration into Strategy C.1. The approach was judged to be a better or best strategy. Service organizations and equipment manufacturers will develop closer ties, and a natural outgrowth of those ties — using the Internet — is to automate reports of error conditions and send notifications of updates to client systems. Management consultants have a concept that applies to this; it is called "Supply Chain Management."

The strategy is technologically feasible. This type of service is currently being used within the IT industry. The advent of smart devices with the capability to self-report (discussed in the analysis of Strategy C.2) is a necessary precondition for this control strategy to be fully functional.

Cost savings are likely. The increased speed of response from service agencies will reduce system downtime and lost production or business. Remote data are available; if a repair can be self-administered by the BAS, then these data can be downloaded over the Internet. There is no indication that this practice is available for building systems, but such services are common for the administration of large computer network systems.

C.4: Maintenance: Assist in Staff Scheduling. This traditional strategy was selected for integration into Strategy C.1. There are local constraints on the technology, however. [Larger building/maintenance services firms are already implementing this maintenance practice as they 
squeeze labor efficiency out of a widespread workforce. The new application proposed here is to use self-reported building data to smooth out and simplify the scheduling and notification process for maintenance technicians and building managers. Local sensors are not expensive or prone to error, and local data are noncritical.

C.5: Maintenance: Provide a Gateway for Remote Repairs. This innovative strategy was also selected for integration into Strategy C.1. This approach was judged to be a better or best strategy. Remote maintenance is a way for corporations with global IT networks to manage far-flung servers and routers. Many property management firms have similar demands and presumably would be interested in using similar tools to more efficiently use highly trained technicians.

Cost savings seem likely. The increased speed of response from service agencies will reduce system downtime and lost production or business. The strategy is technologically feasible. This type of service is currently being used with the IT industry for software bug fixes and updates. If developments in the IT industry are a guide to the future of building systems, then those systems will contain significantly more software code, much of which may be repairable remotely via a controlled gateway.

\subsection{Selected Strategies}

Based on the analysis the following strategies were selected for further development into a preliminary specification for implementation:

- Strategy A.2: Advanced set point control based on forecast conditions external and internal to the building Strategy B.1 is also integrated into this strategy.

- Strategy A.5: Moisture management based on predicted dew point and rate of precipitation

- Strategy B.6: Occupant Interaction: Services interface for services (occupant comfort improvement, traffic updates, local restaurants and shops, transportation links, express 
delivery assistance with food and perishables, and security assistance with deliveries and visitors)

- Strategy C.1: Maintenance: alarms and notifications to on-call and remote technicians

\subsection{Preliminary Protocol/Design Specification}

A preliminary protocol or design specification has been developed for the proposed strategies. This preliminary specification includes a description of the strategy, description of the input parameters and parameter(s) to be controlled, general hardware requirements, software functionality, and the control methodology. None of these strategies have been field-tested although specific components of their respective systems have been field-tested or are being used within other applications. A salient feature of these control strategies is that they have a relatively low requirement for additional hardware beyond an additional workstation/server.

\subsubsection{Strategy A.2: Advanced Set Point Control Based on Forecast Conditions}

Weather data are by far the most abundant and useful information on the Internet. If the content available over the Internet roughly indicated the questions and issues of most relevance to us, then this abundance indicates the impact climate and weather have on our lives. Consistent with this analogy is the selection of two weather-based control strategies for further specification: (1) advanced set point control based on forecast conditions external and internal to the building parameters and (2) moisture management based on predicted dew point and rate of precipitation.

The advanced set point control concept integrates regional and local weather into inputs for the BAS so that the building can optimize energy use while maintaining building environmental standards. By forecasting the energy needs of the building, the BAS can prevent the overshooting of temperature set points and smooth out energy consumption variations in time windows of one to three hours. Because of the thermal mass of the buildings and its contents, there is a time lag between outdoor thermal conditions and the thermal effects inside the building. This time lag allows for transient conditions to build up that will deviate from long- 
term steady state conditions; thus, the intent of this strategy is to minimize unnecessary energy consumption that occurs during transient conditions. To increase the effectiveness of this strategy, a measure of predicted occupancy must be used in conjunction with predicted thermal conditions.

Figure 5-2 shows a rough correlation between outdoor temperature, occupancy, and energy consumption. This is only a conceptual rendering of the relationships, so the parameters are not scaled with respect to each other. Temperature is noted by a " $T$ " with a subscript for either the outside air temperature, inside air temperature, the inside strategy-modified temperature, or the temperature band.

Occupancy is noted by "OCC." As the title of this strategy indicates, the basic intention of this control method is an advanced control of set points. The basic HVAC control scheme modulates heating or cooling fluid to maintain a set range of temperatures around the desired average temperature. This temperature range or band allows the system to modulate in a stable and predictable manner, and also allows this control strategy to exploit the full range of the temperature band for greater energy efficiency with minimal impact on occupant comfort.

The conceptual energy savings for this strategy are the shaded regions depicted at the bottom of the figure. This control method is predicated on having an adequate predictive model of the building's behavior, so that the BAS is able to float the actual building temperatures near the edge of the band without overshooting.

Figure 5-3 is a graphical flow chart of the interaction of the strategy components. Each component is briefly described below the figure. 


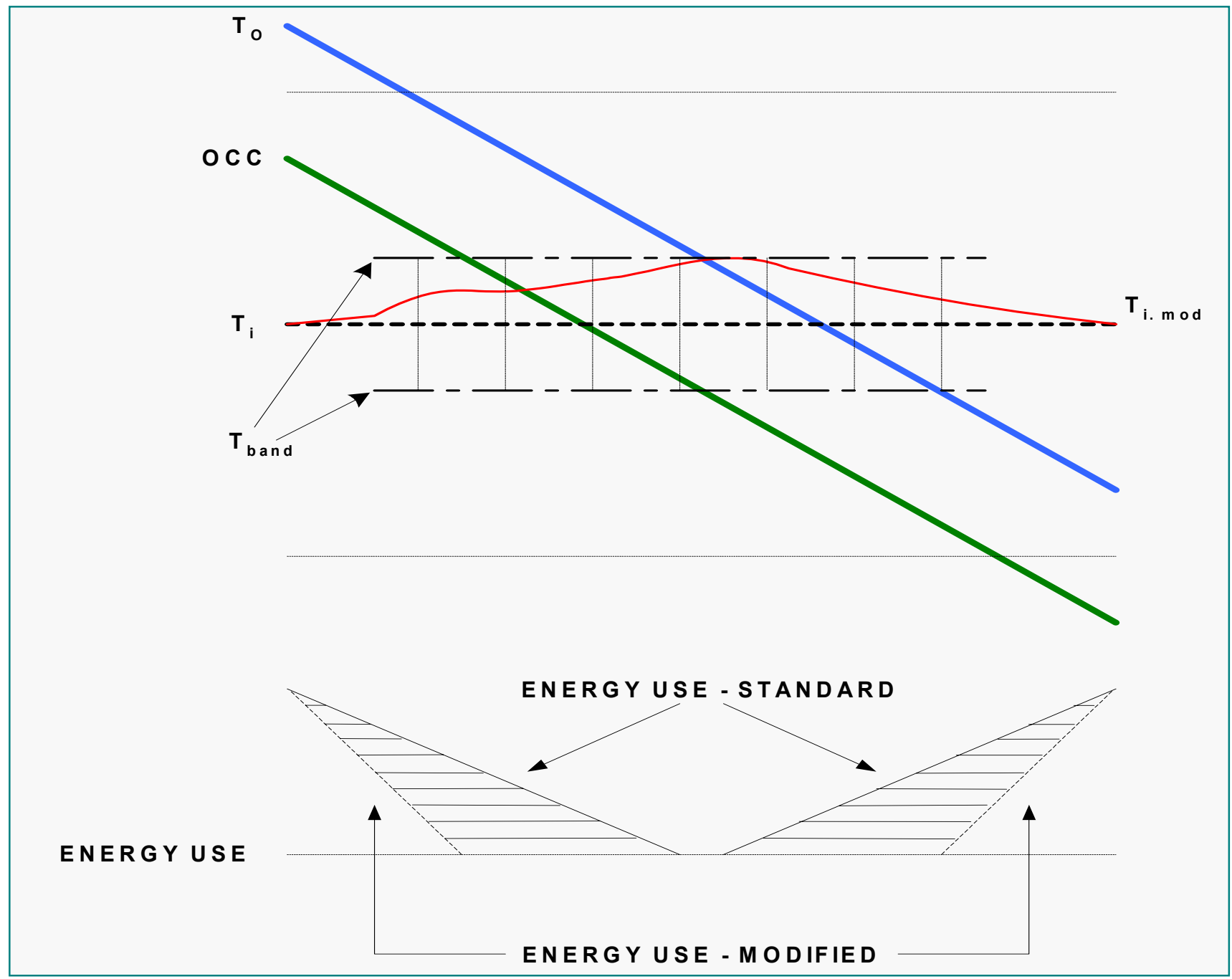

Figure 5-2 Dynamic Effects of Temperature and Occupancy 


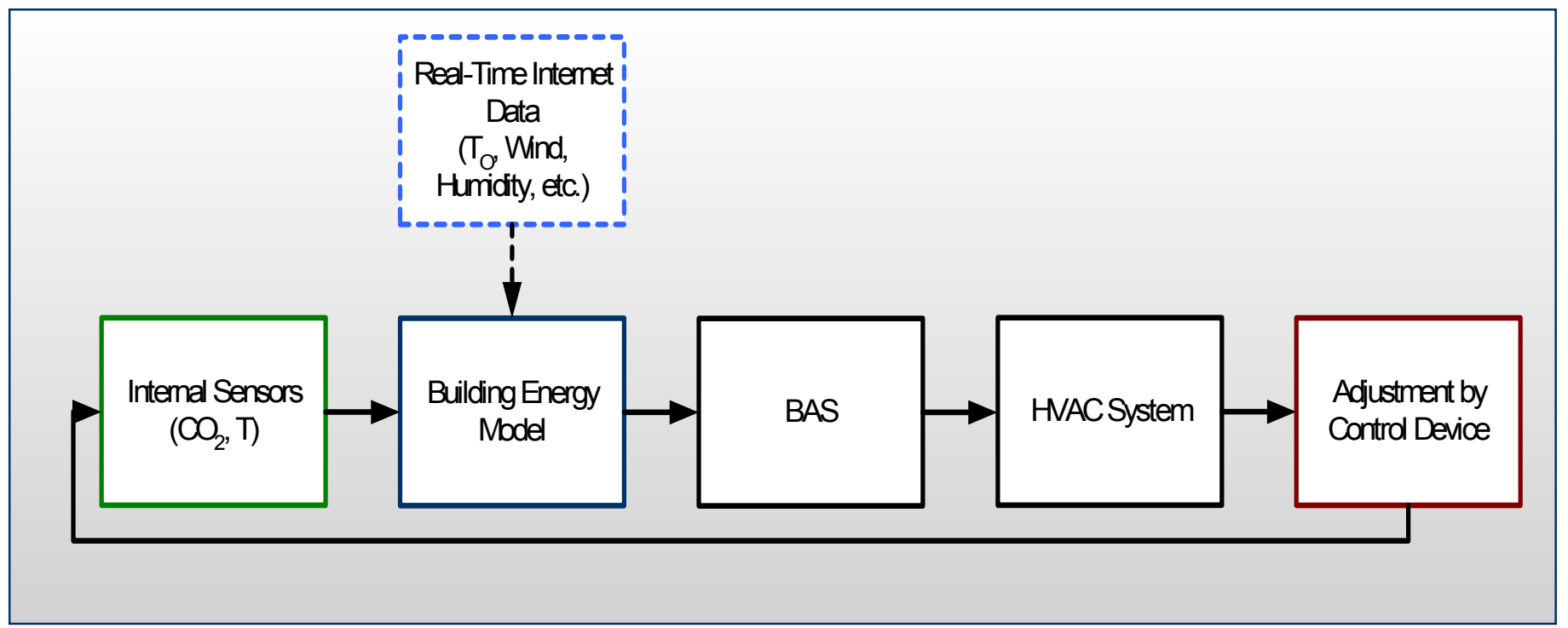

Figure 5-3 Control Strategy Components for Advanced Set Point Control

Control System Inputs. This control strategy requires the following inputs. Weather data is requested at the current time and for intervals one to three hours into the future.

- Local outside temperatures

- Local outside dew point (or relative humidity)

- A measure of occupancy - preferably $\mathrm{CO}_{2}$ levels

- Historical occupancy schedules

- Leaving supply air temperature

- Space (or return air) temperature

- Space (or return air) relative humidity

This control strategy will provide the following output to the HVAC system:

- Modulated control input to chilled water valves, heating water valves, or mixing boxes

- Or on/off control to refrigeration motors/pumps or steam control valves

- Integration with economizer controls, as necessary 
Optional real-time Internet parameters include predicted wind direction and speed, predicted solar radiation levels, and predicted precipitation.

Hardware. This control strategy will use an existing BAS workstation/server if it exists. If not, an additional server or workstation will be required. $\mathrm{CO}_{2}$ sensors in each return air path for air handling systems are required, and signal wiring is needed to connect the sensor to the building model server. At this time, a data management device (i.e., a data logger) that supports the TCP/IP is needed to provide an interface between the building model server and the sensing node, but it is expected that in the future a system designer will have the option of directly connecting to the sensing device with an Ethernet cable.

Software. This control strategy uses a building energy model calibrated to each building. The software will be developed from existing tools and algorithms. Listening services will be created to receive data from field devices and store that data to temporary data files. Once a new output signal is created by the calculation routines within the building model, an agent will be needed to send this signal to the BAS or the modulated HVAC device. Process management software is also needed to manage the listening services, the main energy model calculation routines, the signal agent, and the data storage systems. Depending on the type and configuration of the Building Automation System, a software translation service will also need to be developed for communicating with the BAS.

Control Configuration. This control strategy requires the development of a building energy model that incorporates the appropriate building parameters into the energy simulation algorithms. The type of building model could range from the very simplistic, using a single equation, to a much more complex model, e.g., using an iterative genetic algorithm. In each case, the goal is similar: to determine a new signal value for the HVAC control components.

If this strategy is integrated into the BAS control processes, then the signal agent in this software may take over the handling of the control signal to control valves or on/off switches from the BAS. If this strategy is not integrated into the BAS, then the building energy model will act as a black box between the sensors and the field bus (or its representative), essentially 
replacing the old control signal with a modified control signal that conforms with the desired output of this strategy.

Strategy A.5: Advanced Moisture Management. This control strategy uses predicted rainfall and dew points to lower moisture content in the building structure at optimal times, improving operational efficiency and structure life. This also minimizes bacteria growth by maintaining the building hygric buffer level below that needed for mold growth. Mold growth is a known cause of poor indoor air quality, so minimization or elimination of mold is very beneficial to building occupants.

Building water absorption and dissipation has long lead and lag times. Therefore, information about precipitation 24 to 72 hours in advance would allow the BAS to properly choose between mechanical drying using the building HVAC system or normal atmospheric drying.

Specific climate and weather conditions will also determine if the drying action should occur toward the interior or exterior of the outside walls (Lstiburek, ASHRAE Journal, February 2002). Although vapor barriers and permeable membranes are usually installed to retard or remove moisture from either the interior or the exterior of the building, breathable vapor barriers can offer more flexibility in drying control and thus garner greater benefit from this novel control strategy.

Figure 5-4 shows the main components for the advanced moisture management control concept. Note that there is a need to collect data on the moisture content within the structure at key points. This data collection methodology has not been field-tested. 
BUILDING PARAMETERS

- Orientation (Sun and Prevailing Winds)

- Shape

- Material (Steel, Wood, Masonry)

- Outside Color

- Landscaping

\section{OUTDOOR CONDITIONS}

- Temperature

- Dew point

- Solar radiation

- Wind speed and direction

- Season

INDOOR CONDITIONS

- Supply air temperature

- Supply air dew point

- Return air temperature

- Return air dew point

- Moisture content in structure

- Differential air pressure, supply fans

Figure 5-4 Control Concept for Building Moisture Management 
Control System Inputs. This control strategy requires the following inputs: Expected precipitation over next 24-72 hours:

- Predicted dew point over next 24-72 hours

- Predicted local air temperatures over next 24-72 hours

- Predicted solar radiation over next 24-72 hours

- Predicted wind speed and direction over next 24-72 hours

- Sunrise and sunset times

- Water content measures of building structure at key locations

- Leaving supply air temperature

- Leaving supply air dew point

- Space (or return air) for temperature or dew point

- Differential air pressure across the supply air fan

This control strategy will provide the following output to the HVAC system:

- Increase/decrease air handling fan speeds

- And/or modulated control input to chilled water valves and heating water valves to increase or decrease dehumidification

- Or on/off control to refrigeration motors/pumps or steam control valves to increase or decrease dehumidification

- Or on/off control to other dehumidification systems

Hardware. This control strategy will use an existing BAS workstation/server if it exists. If not, an additional server or workstation will be required, with a dedicated Internet connection. Two sets of sensors to measure air temperature and relative humidity (or other water vapor measure) in both the supply and return air systems are needed in order to monitor the drying capacity of the mechanical systems. Moisture content sensors at key locations in the building structure, such as building corners, areas below grade, and door and window jambs, will be installed with signal wiring routed back to a data collection device (data logger) that supports the 
TCP/IP. Also, the data collection device is connected to the building model server via standard Ethernet cabling.

Software. Like the previous control strategy, the moisture management control strategy uses a building model; in this case, however, it uses moisture balance equations instead of thermal transfer equations. This model must be constructed around each building's structural characteristics and building orientation. Listening services will need to be created to receive data from field devices and store that data to temporary data files. Once new output signals are created by the moisture balance calculations within the building model, an agent will be needed to send these signals to the BAS or the controlled HVAC devices.

Process management software is needed to manage the listening services, the moisture balance calculations, the signal agent, and the data storage systems. Depending on the type and configuration of the Building Automation System, a software translation service will also need to be developed for communicating with it.

Control Configuration. This control strategy requires the development of a building model that determines the moisture content of the building by a moisture balance calibrated with moisture measurements within the structure. This is a novel control strategy for building HVAC systems, so the effectiveness and the robustness of the control method have not been tested. The building model must determine not only the rate of moisture gain or loss to minimize building energy consumption and moisture retention, but also whether to maintain a higher positive air pressure to minimize infiltration.

Within this control strategy there are two sometimes-conflicting goals: lower energy consumption and lower moisture content. This requires a relatively complex calculation algorithm that will have more calculation latency between data input and the control response. However, changes to a building's moisture content happen relatively slowly, so the latency due to the additional calculation effort is not a significant constraint. 
Also, as in the previous strategy, if this strategy is integrated into the BAS control processes; the signal agent in this software may take over the management of the control signal to HVAC system control valves and on/off switches. If this strategy is not integrated into the BAS, the building moisture management model will act as a black box between the sensors and the BAS's field bus.

\subsubsection{Building Control Based on Occupancy Considerations}

Strategy B.6: Occupant Interactive Services. This real-time information control strategy interactively links building occupants with building status and control parameters and relies on the BAS's ability to gather information about building occupants to generate energy savings. Because of significant privacy issues associated with tracking personnel, any energy savings under this strategy are realistically viable only if building occupants voluntarily participate in this data-gathering process. Moreover, building occupants will probably not provide data voluntarily if they cannot see a benefit to themselves. However, if they are able to interactively participate in the building environmental control process, it is possible that they will provide data about their work schedules in exchange for more control of their environment. Therefore, the basic premise for this control strategy is that the BAS will interact with building occupants, providing information about the workspace environment, allowing the occupants to reset parameters within predesignated ranges, and accepting and integrating workspace schedules into the building's environment control system.

Additionally, the BAS will provide a building services interface for other functions, such as security and safety advisories, traffic information, local food service, and personal agent services. The building occupant's interface to the BAS will be through multiple interfaces, such as a desktop PC, a phone, or possibly an on-board link from an automobile. In the latter case, a potential building occupant could notify the BAS of his or her future arrival and possibly receive driving and parking guidance, too. This control strategy will unsettle many building engineers because the occupants become a part of the data and building management system. However, with appropriately structured occupant-to-building interfaces, the BAS will be able to make a much more refined assessment of interior conditions. And with the assistance of building 
occupants, it will be able to provide better scheduling of building services. Figure 5-5 shows this control and service concept.

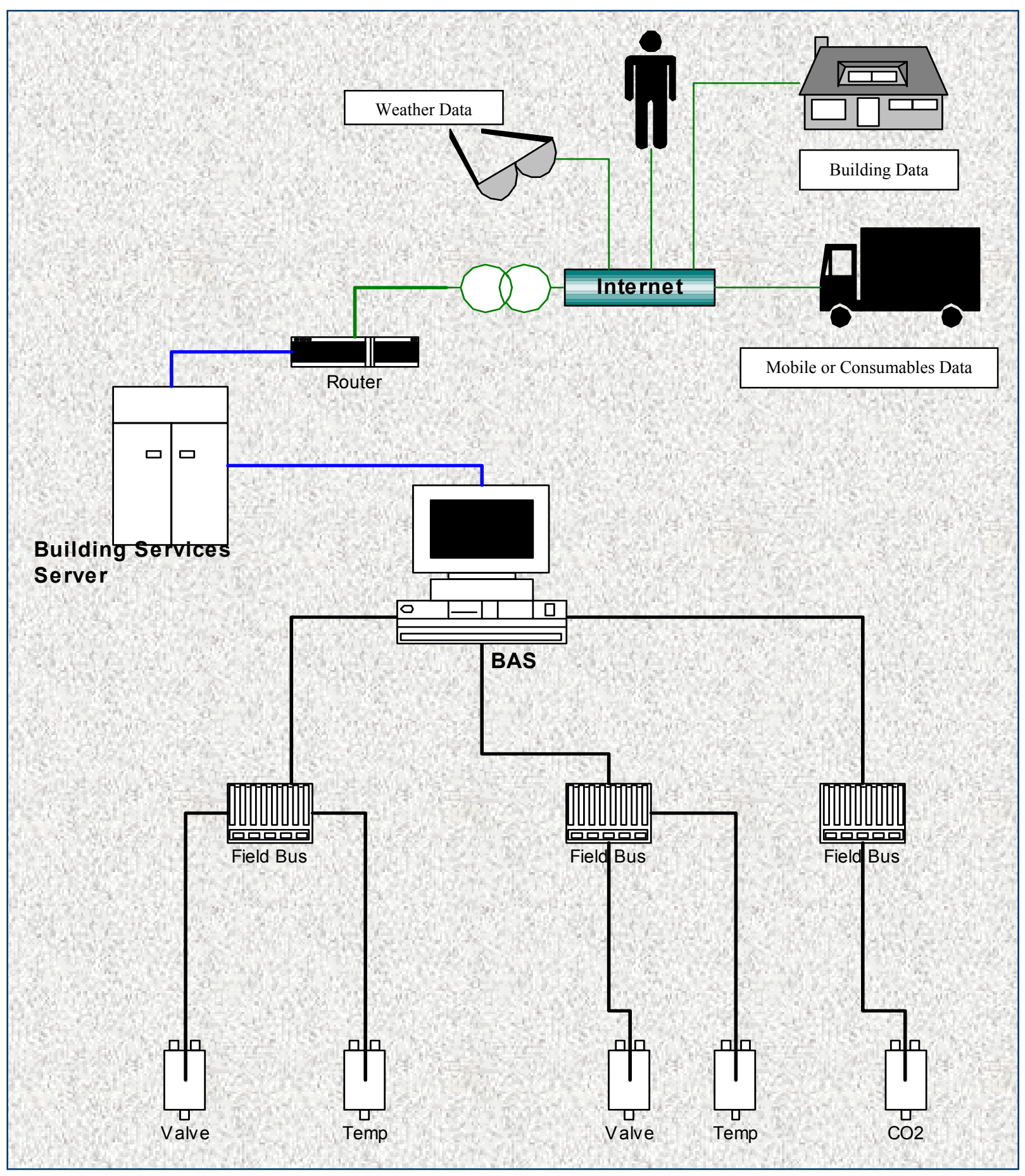

Figure 5-5 Concept for Occupant Interactive Services 
Types of Services. The types of services that would be expected from this control strategy/building service strategy are:

- Building environment conditions, temperature and relative humidity

- Schedules of building-specific systems and services

- Security alerts

- Safety alerts about weather conditions and building construction

- Acute healthcare services

- Restaurants

- Lodging

- Car care

- Shops and local retail businesses

- Specialized delivery services

- Local weather reports

- Tourist services (for hotels)

- Recreation and entertainment

- Local events and points of interest

- Personal agents for shopping, valet service, pick-up and delivery, travel arrangements, information searches

- Messaging and alerts

Hardware. It is possible to enable nearly 100 percent of the functionality of this interface at a remote web hosting service, so there is minimal need to install hardware to support these services at the building. The argument for outsourcing the web hosting is strong because of the need to hire specialized IT personnel to manage this system and the relatively low cost of leasing web-hosting services with $24 \times 7$ uptime and high speed connections. Much of the desired interaction between the building services interface and the BAS is also programmable through Structured Data Services (SDS) discussed in Section 4.1. 
On the other hand, this research indicates that buildings should be moving toward greater connectivity between the BAS and the Internet, so high speed access and the operation of a web server at the building should become standard fare. If the building management elects to install a building services interface at the building, then a server or workstation capable of running HTTP services is needed. Also a high bandwidth connection and a point of presence on the Internet (a world-addressable IP address) are needed.

Software. If the building services interface is installed at the building, software services in addition to an HTTP server are needed. A basic configuration would include:

- $\operatorname{HTTP}($ web) server

- FTP server

- Firewall and proxy services

- Email services

- DNS services

- Remote administration software

- Backup agents

Most vendors will preconfigure web servers with a plethora of standard services and packages that can be partially or wholly configured before the vendor ships the hardware.

In terms of software development for the user interface, so many options exist, with a multitude of trade-offs for functions and features, that an analysis and recommendation of the best software application packages is fraught with so many caveats that in the end any general catch-all recommendation would be virtually useless. In general, packages that stress interoperability, such as that offered by the Java programming language, have greater merit for integrating the BAS software services.

A point often missed in a debate about which package or language is better is that the website user interacts with the HTTP service using the standard Hypertext Transfer Protocol and HTML web pages. Thus, the debate about which software to use in the construction of a 
building services interface does not impact the user and is ultimately an internal usability decision on the part of the building management.

Service Interface. Publishing web pages can be accomplished very easily with many of the office tools on a normal office PC. However, the ease of converting documents and spreadsheets to HTML is somewhat beguiling, because the maintenance overhead of the content and the interconnections between pages will grow geometrically as the number of pages increase. At an unspecified level of complexity of the building services site, it makes sense to automate the display of content through template and database engines. Additionally, parts of a website are normally farmed out to several content czars who keep their relevant slice of the website upto-date, while programmers manage the scripting that glues all of the content pieces together for display on the services interface.

This can be very intimidating, but it need not be. There are many options for buying website construction and the ongoing maintenance of the site and its services. Most of these options will provide the results needed and are a fair exchange of service and time. Also, if the building management is committed to developing a valuable services interface for building occupants, then the management of online contents and processes will become a normal part of their business practice.

\subsubsection{Building Control Tied to Maintenance Functions}

\section{Strategy C.1: Improved Operational Effectiveness Through Real-Time Maintenance}

Management. This control strategy interactively links maintenance scheduling, diagnostics, and notifications with the BAS, the on-site maintenance staff, and maintenance management staff. Three main benefits are seen from this maintenance interaction: reduced turnaround times for repairs and thus less downtime for the business, more efficient scheduling of maintenance personnel due to automated notices and self-reported diagnostics, and possible remote emergency repairs or bypasses that prevent catastrophic failure (Figure 5-6). Much of this technology is already in use in the IT industry, so the implementation within a building or a BAS would not be breaking new ground. The greatest constraint to implementation of these new 
technologies is the lack of connectivity at the buildings. This has created the odd situation where the building may be wired with the latest telecommunication infrastructure, but the BAS connects to the outside world via a dial-up link.

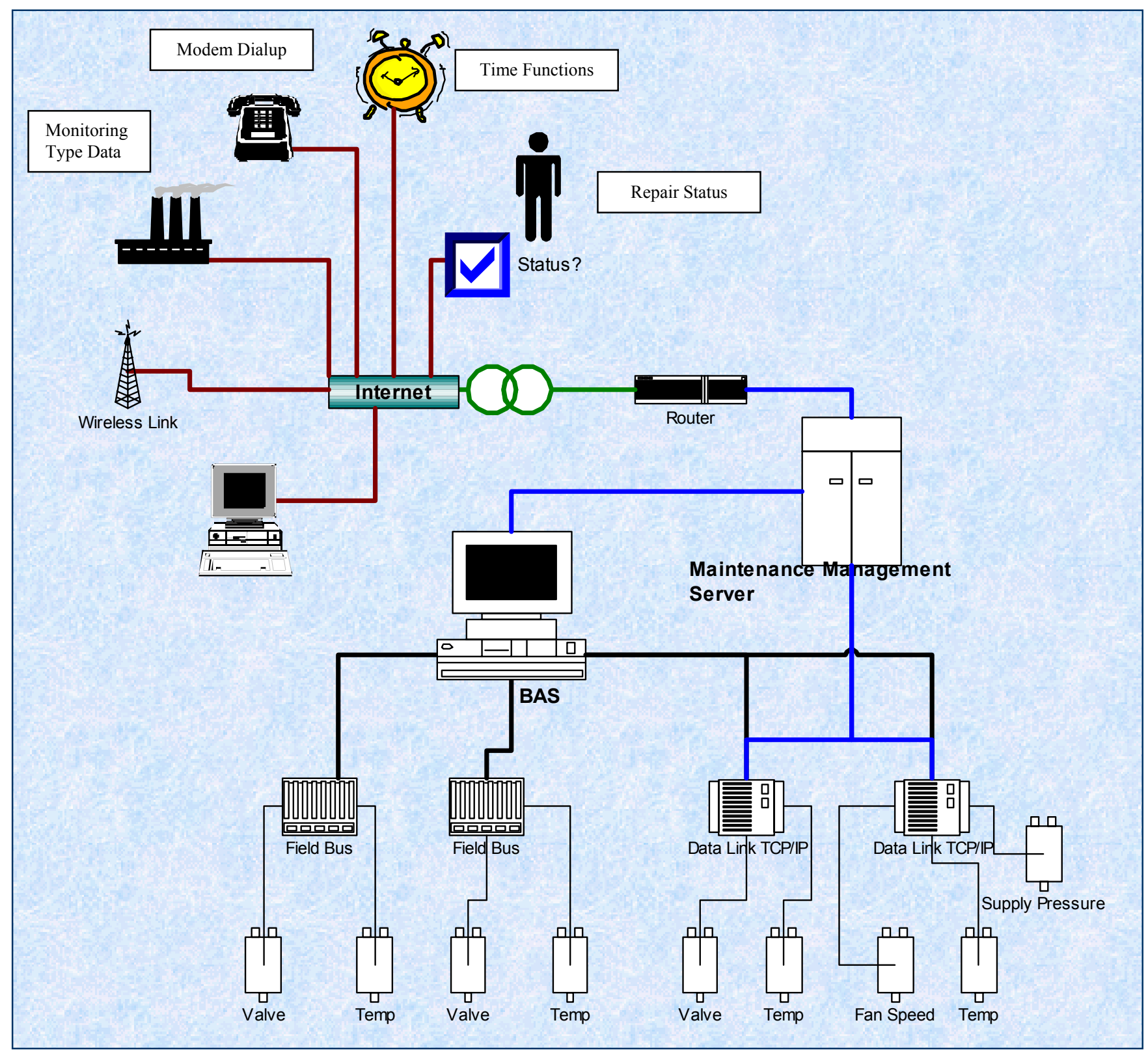

Figure 5-6 Concept of Real-Time Maintenance Management Services 
However, building managers and large property management firms have begun to recognize this inconsistency and are looking at ways to improve the connectivity of their systems. The orientation of automation and computerization in buildings has been inwardly focused, so there has been little or no perceived need to look to the outside of the building or campus for interaction. The importance of maintenance management should change that view.

Intelligent Building Systems (DOE, 2001) and Network Building Systems (Cimetrics, 2000) point out many of these same issues with connectivity and interoperability. They also echo some of the frustration of knowing that the functionality of the network architecture and interoperability in many homes may pass that contained within the BAS of most commercial property.

Types of Services. Services that would be expected from a maintenance management strategy include the following:

- Services alerts and notifications from OEMs

- Paging alerts for emergency conditions

- Email alerts of warning status or system summaries

- Online analysis of systems

- Remote modification of system parameters

- Automated diagnostics and self-reporting devices

- Remote repairs of software or resets of building systems

- Automated technician scheduling or schedule management of remote service techs

- Automated alerts to third-party service centers

Hardware. As has been noted under the previous control/service strategy, the webhosting function can be outsourced to a reputable web-hosting company as a cost-effective lease. However, because of the requirement for detailed information about the BAS and specific control system devices in the building, a gateway service on a workstation or server is needed to access this information. This gateway will require a world-addressable IP address and dedicated connection to the Internet. 
Software. The most desirable configuration of the maintenance management services would be the installation of an HTTP service on a workstation or server at the building, which provides a web interface using prepackaged software from a vendor. This suggestion comes with several caveats because this area of software development is still immature and will inevitably go through some growing pains as new solutions become evident. Following are some current issues and points to keep in mind:

- An HTTP service can be added to most advanced workstations, so a BAS operating on a Unix, Windows NT, or OS/2 platform can be configured to also start an HTTP service.

- Network data and HTTP service load management is an important issue, but it is also important to look outside the building for load management solutions. Structured Data Services offer methods of transferring resource-intensive applications to faster servers and faster links.

- It may be easier to simply abandon-in-place legacy hardware and software of the existing BAS instead of attempting to upgrade. If the BAS computing platform is more than three years old, it has little value and may be fundamentally incompatible with newer OSs and applications. This leads to difficult decisions on what to attempt to salvage as the maintenance management network and the BAS move to TCP/IP.

- As odd as it may seem, it may be easier to implement web cam monitoring at critical locations in the building for remote maintenance purposes than to program an interface into an older control system.

- The lack of connectivity between building systems and the Internet has had the benefit of providing network security to the BAS. Although the functionality of maintenance services listed above could be added quickly and at a relatively low cost, the need for highly reliable, highly available, and highly secure software should remain the top priority in the consideration of software solutions.

Service Interface. Requirements for the service interface of a maintenance management system can be summarized in terms of interoperability, reliability, and priority availability. Service technicians, building operators, building managers, and maintenance managers will be accessing the same information from multiple types of interfaces, such as desktop PCs, field 
laptops, handheld PDAs, and text messaging services, so the maintenance management system must work with a wide range of devices to provide an effective interactive environment.

This system also must be reliable because it will be accessed 24 hours a day, 7 days a week. And it must also give availability priority to emergency or high priority services, such as allowing service technicians who need to do critical system restarts first priority in data transfers. This last functionality is a known limitation of HTTP services, but flexibility of Structured Data Services can offer communication paths (ports) other than HTTP, so a preemptive functionality is possible if not widely noted at this time.

Finally, note that the maintenance management interface could be integrated into the building services interface to offer a more complete solution and a single point of entry into the BAS for improved security.

\subsection{Other Potential Strategies: Intelligent Service Provision}

The BAS has been limited to mostly providing a temperature-controlled environment in the interior of the building. Smart buildings of the future may be able to handle parking, office scheduling (hot desks), food service, digital recreational services, and waste services. There may be synergies between the future automobile and the future building. Leading thinkers are contemplating on-board agents in automobiles that seek out fuel, lodging, and food services and present the best selection to the driver. This can be metaphorically extrapolated to a building, where in-building agents will seek out similar services in the local area, present those selections to the building user, process the orders for goods or services, and then receive the delivered goods.

Also of recent concern is security against airborne hazards, such as the anthrax virus, which was delivered to post offices and mailrooms at locations in the United States. Very few HVAC systems are capable of properly handling such a lethal situation, and the building operator's only recourse in these situations is to shut down the ventilation system to limit potential damage to occupants within that system and adjacent systems. 
Because of cost and technology constraints, HVAC systems typically are designed as ventilation blocks with only minor configuration options to vary ventilation air paths, and they are installed with the minimum amount of control functionality to manage day-to-day operations. Greater granularity in delivery of HVAC services to building users, with smart control devices, will significantly increase a building's capability to respond to interior and exterior airborne contaminants. This increased capability would also improve the ability of the BAS to deliver thermal and lighting services with greater specificity, improving the energy efficiency of the building. 


\subsection{CONCLUSIONS AND RECOMMENDATIONS}

The primary conclusions from the overall assessment are presented in Section 6.1. Recommendations for future directions and priorities are provided in Section 6.2.

\subsection{Conclusions}

The following conclusions, derived from the web survey and focus group discussions involving building managers, are considered speculative due to the relatively small sample size involved:

- Critical incidents in building management can be avoided by (1) detailed inspection and maintenance at regular intervals (including system "self analysis"), and (2) predictive diagnostics (to detect potential problems before they occur or become severe).

- Buildings could be operated at maximum efficiency with state-of-the-art equipment, variable frequency drivers, occupancy-based ventilation/lighting, automatic paging, access to building controls via the Internet, weather stations, automatic blinds, solar generation, and software for energy efficiency.

- Current information about events at regional facilities (e.g., weather-related phenomena such as rain and snow or tracking of frontal system) would be useful in increasing the stability of control systems. However, such information would be of use only for fairly small regions, as there can be too much variability within larger regions.

- One critical aspect of building maintenance - validation against plans, both in terms of adherence to schedule and covering all prescribed activities - could be completely or at least partially Internet-based.

- Internet-based weather information can be useful for building operations, particularly in relation to schedules for major regional/local events. The web could play a role in scheduling meeting or conference rooms and in tying that information into the BAS. Links to security systems and to real-time information on traffic, catastrophic events, fuel pricing, and energy consumption also may be useful. 
An ideal building control system requires knowledge of occupant and operator locations at all times. An ideal system also would be self-calibrating with self-analysis and diagnosis capabilities, but it should not be overly complex. It would be user-friendly with remote access, and it would need to be checked routinely by humans. Ideally, the system should be able to automate some adjustments before "calling" an engineer and should be capable of providing a $\log$ of key events and preparing routine or special repo ts. Potential barriers to success in implementing such a system include security concerns for Internet-based operations, occupant privacy concerns, cost issues, and training needs.

In general, the building managers surveyed under this project consider state-of-the-art equipment and Internet access to be integral elements of automation and functionality. They view the ability to sense the presence of occupants as a means of promoting efficient use of ventilation and lighting. They also consider factors related to the sun to be important, along with the general concept of weather stations.

Based on the technology review and previous discussion of parameters/considerations for integrating real-time data, a number of parameters (or groups of parameters) have potential use as real-time data elements via the Internet (see Table 6-1). An approach currently used by the healthcare community serves as a potential model for accreditation of real-time information, websites, and data providers. Certain elements of that approach are integral to a document or series of guidelines for real-time web accreditation:

- The mission and purpose of the accreditation process

- Clear definition of terms

- Disclosure of services provided

- Content and service delivery

- Linkages

- Data security

- Accountability

- Policy and procedures

- Quality oversight committees. 
Table 6-1. Parameters of Potential Use as Real-Time Data Elements

\begin{tabular}{|c|c|}
\hline Parameter(s) & Potential Use \\
\hline $\begin{array}{l}\text { Local outside temperature (with dew point } \\
\text { or relative humidity) }\end{array}$ & $\begin{array}{l}\text { Determine whether economizer functions are to be } \\
\text { activated or evaporative cooling is to be used, or as } \\
\text { an input to a hygrothermal model for building } \\
\text { moisture management }\end{array}$ \\
\hline $\begin{array}{l}\text { Local outside temperature, dew point, } \\
\text { precipitation, wind and solar radiation }\end{array}$ & $\begin{array}{l}\text { Determine the configuration/setting for operable } \\
\text { windows }\end{array}$ \\
\hline $\begin{array}{l}\text { Local outside temperature (with a } \\
\text { precipitation parameter) }\end{array}$ & $\begin{array}{l}\text { Determine whether walkways or driveways need to } \\
\text { be de-iced via heat or chemical reaction }\end{array}$ \\
\hline $\begin{array}{l}\text { Predicted outdoor temperature (up to } 12-24 \\
\text { hours in advance) }\end{array}$ & $\begin{array}{l}\text { Input to energy model, to suggest pre-heating or } \\
\text { cooling strategies or determine whether to use on- } \\
\text { site thermal storage for greater energy efficiency }\end{array}$ \\
\hline Barometric pressure & $\begin{array}{l}\text { Optimize combustion settings, or as an input to a } \\
\text { model for airflows within or around a building }\end{array}$ \\
\hline Air quality indicator (e.g., ozone) & $\begin{array}{l}\text { Automatically close fresh-air intakes under certain } \\
\text { conditions (i.e., poor outdoor air quality) }\end{array}$ \\
\hline Energy pricing data & $\begin{array}{l}\text { Support the decision to sell excess power from } \\
\text { cogeneration back to the grid (for larger facilities } \\
\text { or complexes) }\end{array}$ \\
\hline Weather warnings/watches/advisories & $\begin{array}{l}\text { Automatically shut down selected building systems } \\
\text { or prompt display of appropriate disaster plan } \\
\text { information }\end{array}$ \\
\hline Solar radiation (including predictive data) & $\begin{array}{l}\text { Determine the most opportune times for strategies } \\
\text { such as solar shading or daylighting }\end{array}$ \\
\hline Local lightning strikes & $\begin{array}{l}\text { Automatically activate selected backup systems or } \\
\text { take actions to protect building assets/personnel }\end{array}$ \\
\hline Space weather (e.g., solar flares) & Prompt actions to protect susceptible systems \\
\hline Chemical/biological sensor systems & Prompt building use for sheltering in place \\
\hline Local precipitation (predicted) & Rain harvesting applications \\
\hline Geophysical parameters (e.g., tides) & Buildings susceptible to water table fluctuations \\
\hline Astrophysical parameters (e.g., moonlight) & Potential effects on security systems \\
\hline Local traffic data & Potential effects on parking facilities \\
\hline Intelligent tags & $\begin{array}{l}\text { Track movement of cars into/out of parking areas, } \\
\text { as a preliminary predictor of building occupancy }\end{array}$ \\
\hline Aircraft/rail arrival times & $\begin{array}{l}\text { Determine potential delays in guest arrival (e.g., } \\
\text { for hotels) }\end{array}$ \\
\hline
\end{tabular}


The following conclusions relate to the use of real-time data in building control systems:

- Important considerations for integrating real-time data include the remote client/server interaction and real-time data management, with the latter having four main steps of data acquisition, validation, channeling and utilization.

- Three levels of potential benefit from use of remote real-time data as BAS inputs are improvement of environmental conditions in the facility, improvements in the operational efficiency and effectiveness of building systems, and improvements in the building's interaction with the community (e.g., with building occupants through scheduling tools and with the community via alerts and alarms).

- Different sampling needs for different types of data suggest that it would be beneficial for the BAS to interact with the Internet data server using a Structured Data Services interface.

- Many of the steps in the data-retrieval process could be managed on the client or the data server. Control algorithms for novel types of building controls using real-time data could reside entirely off-site, sending only the needed control inputs to the BAS.

Based on the considerations of cost and savings, reliability of the data, feasibility of the technology, and validity of the proposed approach, the following control strategies appear to be viable for use within a real-time data system:

- Advanced set point control based on forecast conditions external/internal to the building

- Moisture management based on predicted dew point and rate of precipitation

- Occupant interface for services such as comfort improvement, transportation links, traffic updates, express food delivery assistance, and security assistance with deliveries/visitors

- Alarms and notifications to on-call and remote technicians for system maintenance.

Smart buildings of the future may be able to handle tasks such as parking, office scheduling, food services, digital recreation services, and waste services. There also may be synergies between the future automobile and the future building. Greater granularity in delivery of HVAC services to building users, with smart control devices, will significantly increase a 
building's capability to respond to interior and exterior airborne contaminants. This increased capability also would improve the ability of the BAS to deliver thermal and lighting services with greater specificity, improving the energy efficiency of the building.

\subsection{Recommendations}

This report has identified a number of evolutionary control strategies and parameters that appear to hold the promise of potential benefits to building owners, managers, and occupants. Both proof of concept and feasibility of implementation need to be established. In addition, some strategies warrant further investigation and development of specifications.

The potential benefits of using predictive, real-time information need to be assessed in comparison with more traditional approaches that use local sensor information for HVAC-related control strategies. In parallel with this exercise, potential methodologies for implementation need to be proposed to address issues such as data latency, proactive versus reactive actions, feedback, and alternate controls when real-time information is unavailable. Also important is to demonstrate representative hardware, software, and tools that can automatically retrieve reliable, predictive, real-time information from the Internet and make it available to a building management system. Demonstration of a building management system needs to include use of information in a traditional or evolutionary control strategy, with the goal of increasing space comfort while reducing operating costs.

Ultimately, formal pilot or demonstration projects will be required to address the full realm of cost and logistical issues for selected approaches that are deemed the most promising. Considerations include the choice of specific locale (e.g., to take advantage of ample local weather data) and building type (e.g., size, function, HVAC configuration, current automation). Project success will need to be assessed both in qualitative and quantitative terms. Qualitative aspects include the types of problems encountered and the extent to which they can be remedied. One major quantitative tool for the assessment would be a formal cost/benefit analysis that considers equipment, software, and training requirements along with the types of paybacks and the length of the payback period. 


\begin{tabular}{|c|c|}
\hline ASHRAE & American Society of Heating, Refrigerating and Air-Conditioning Engineers \\
\hline AVN & Model run out to five days, encompasses North America/Oceans \\
\hline AWS & Automated Weather Service \\
\hline B2B & Business-to-Business \\
\hline BAS & Building Automation System \\
\hline BLM & Bureau of Land Management \\
\hline CASIO & Energy pricing system \\
\hline $\mathrm{CO} 2$ & Carbon Monoxide \\
\hline COMIS & Conjunction of Multizone Infiltration Specialists \\
\hline CPU & Central Processing Unit \\
\hline DDC & Direct Digital Control (?) \\
\hline DNS & Domain Name System \\
\hline DOD & Department of Defense \\
\hline DOE & Department of Energy \\
\hline EMS & Emergency Management System \\
\hline EPA & Environmental Protection Agency \\
\hline ETA & A model run out to three days, encompasses North America \\
\hline FAA & Federal Aviation Administration \\
\hline FEMA & Federal Emergency Management Agency \\
\hline FOUS & FOrecast U.S. \\
\hline FTP & File Transfer Protocol \\
\hline GIC & Geomagnetic-Induced Current \\
\hline GMT & Greenwich Mean Time \\
\hline GPS & Global Positioning System \\
\hline GSA & General Services Administration \\
\hline Hazmat & Hazardous Materials \\
\hline HOTELGYR NT & Hotel Registration System \\
\hline HTTP & HyperText Transport Protocol \\
\hline HVAC & Heating, Ventilation and Air Conditioning \\
\hline $\mathrm{IAH}$ & Houston International Airport \\
\hline IAQ & Indoor Air Quality \\
\hline IDE & Integrated Development Environment \\
\hline IDEA & International District Energy Association Conference \\
\hline IEA & Industrial Ethernet Association \\
\hline IFMA & International Facility Management Association \\
\hline IP & Internet Protocol \\
\hline ISO & Independent System Operator \\
\hline IT & Information Technology \\
\hline $\mathrm{LCD}$ & Liquid Crystal Display \\
\hline Meso-ETA & Same as ETA, but run on a finer grid scale \\
\hline MIT & Massachusetts Insitute of Technology \\
\hline MM5 & model run out to 48 hours, encompasses smaller scale features \\
\hline MOS & Model Output Statistics \\
\hline MRF & model run out to 15 days, encompasses world \\
\hline NASA & National Aeronautics and Space Administration \\
\hline NCEP & National Center for Environmental Prediction \\
\hline NCEP & National Center for Environmental Prediction \\
\hline NGM & model run out to two days, encompasses North America \\
\hline
\end{tabular}




\begin{tabular}{ll} 
NLDN & National Lightning Detection Network \\
NOAA & National Oceanic and Atmospheric Administration \\
NOx & Nitrogen \\
NRC & Nuclear Regulatory Commission \\
NWS & National Weather Service \\
NWSTG & NWS Telecommunications Gateway \\
OA & Outside Air \\
OASIS & Open Access Same-Time Information Access System \\
OCC & Occupancy \\
ODVA & Open DeviceNet Vendor Association \\
OEM & Original Equipment Manufacturer \\
OS & Operating System \\
OS/2 & Operating System/2 \\
PDA & Personal Digital Assistant \\
PM & Particulate Matter \\
QA & Quality Assurance \\
QC & Quality Control \\
REIT & Real Estate Investment Trust \\
RFID & Radio Frequency Identification \\
RH & Relative Humidity \\
RUC & model run out to 12 hours, encompasses North America (U.S.) \\
SDS & Structured Data Services \\
SDS & Structured Data Services \\
SEC & Space Environment Center \\
SOx & Sulphur Dioxide \\
SSL & Secure Sockets Layer \\
TCO & Total Cost of Ownership \\
TCP & Transmission Control Protocol \\
TCP/IP & Transmission Control Protocol/Internet Protocol \\
UKMET & United Kingdom Meteorology \\
URAC & Stand-alone acronym for the Health Web Site Accreditation Program \\
URL & Uniformed Resource Locator \\
VFD & Variable (speed) Fan Device \\
WBD & Whole-Building Diagnostician \\
WUFI-ORNL/IBP & Hygrothermal Model Developed by Oak Ridge \\
XML & Extensible Markup Language \\
& \\
\hline & \\
Ond &
\end{tabular}

